Supporting Information

\title{
Chemical Modifications Reduce Auditory Cell Damage Induced by Aminoglycoside Antibiotics
}

Sivan Louzoun Zada, ${ }^{a}$ Bar Ben Baruch, ${ }^{a}$ Luba Simhaev, ${ }^{b}$ Hamutal Engel, ${ }^{b}$ and Micha Fridman ${ }^{a, *}$

${ }^{a}$ School of Chemistry, Raymond and Beverley Sackler Faculty of Exact Sciences, Tel Aviv University, Tel Aviv, Israel, 6997801.

${ }^{b}$ Blavatnik Center for Drug Discovery, Tel Aviv University, Tel Aviv, 6997801, Israel.

${ }^{*}$ Correspondence to: mfridman@tauex.tau.ac.il 
Content:

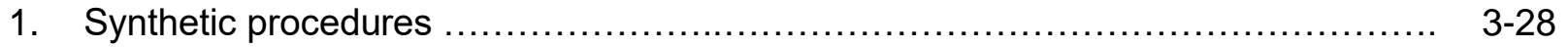

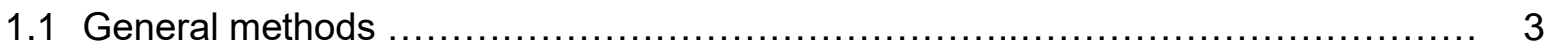

1.2 Synthetic procedures and characterizations of all molecules generated (Schemes S1-5)

2. Minimal inhibitory concentration (MIC) experiments (Table S1) 29-30

3. In vitro inhibition of protein translation in eukaryotic and prokaryotic systems 30-31

3.1 Cell-free prokaryotic in vitro translation inhibition assay 30-31

3.2 Cell-free eukaryotic in vitro translation inhibition assay 31

4. Docking and Molecular dynamic calculations (Tables S2-S5 and figures S1-S2) ... 31-38

4.1 System selection $31-32$

4.2 Docking of ligands to the A-site 32

4.3 System preparation 33

4.4 Molecular dynamics simulations 33-34

4.5 Data Analysis 34

5. HEI-OC1 cells viability assay 39

6. HEI-OC1 Cells permeabilization assay (Figure S3) $39-40$

7. Mitochondrial and cytosolic protein translation evaluation in $\mathrm{HEI}-\mathrm{OC} 1$ Cells assay (Figure S4) $40-41$

8. $\quad{ }^{1} \mathrm{H}$ NMR and ${ }^{13} \mathrm{C}$ NMR spectra (Figures S5-S22) ................................ $42-50$

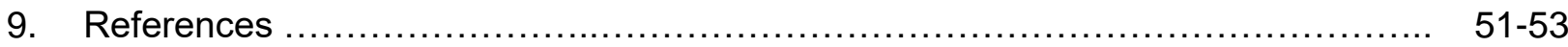




\section{Synthetic procedures}

1.1 General methods: ${ }^{1} \mathrm{H}$ NMR and 1D-TOCSY experiments were recorded on Bruker Avance 400 or 500 spectrometers, and chemical shifts (reported in ppm) were calibrated to $\mathrm{CDCl}_{3}, \mathrm{CD}_{3} \mathrm{OD}$, or $\mathrm{D}_{2} \mathrm{O}\left(\delta=7.26,3.31,4.79\right.$, respectively). ${ }^{13} \mathrm{C}$ NMR spectra were recorded on Bruker Avance 400 or 500 spectrometers at 100 or $125 \mathrm{MHz}$, respectively. Multiplicities are reported with the following abbreviations: br, broad; s, singlet; $d$, doublet; $t$, triplet; $d$, doublet of triplets; dd, doublet of doublets; ddd, doublet of doublet of doublets; qd, quartet of doublets; m, multiplet; eq, equatorial; ax, axial. Coupling constants $(\mathcal{C})$ are given in Hertz. For NMR samples, the free base form of compounds 1-9 was treated with 95\% TFA and freeze-dried to afford the corresponding TFA salts. Low-resolution electrospray ionization mass spectra (LRMS) were measured on a Waters 3100 mass detector. High-resolution electrospray ionization mass spectra (HRMS) were measured on a Waters Synapt instrument. Chemical reactions were monitored by TLC (Merck, Silica gel 60, $F_{254}$ ). Visualization was achieved using a cerium molybdate stain $\left[5 \mathrm{~g}\left(\mathrm{NH}_{4}\right)_{2} \mathrm{Ce}\left(\mathrm{NO}_{3}\right)_{6}, 120 \mathrm{~g}\right.$ $\left(\mathrm{NH}_{4}\right)_{6} \mathrm{Mo}_{7} \mathrm{O}_{24} \cdot 4 \mathrm{H}_{2} \mathrm{O}, 80 \mathrm{~mL} \mathrm{H} \mathrm{SO}_{4}$, and $720 \mathrm{~mL} \mathrm{H} \mathrm{H}_{2} \mathrm{O}$. All chemicals, unless otherwise stated, were obtained from commercial sources. Compounds were purified by flash chromatography (Merck, Silica gel 60). 


\subsection{Synthetic procedures and characterizations of all molecules generated:}

Scheme S1: Synthesis of compound $1^{\text {[a] }}$
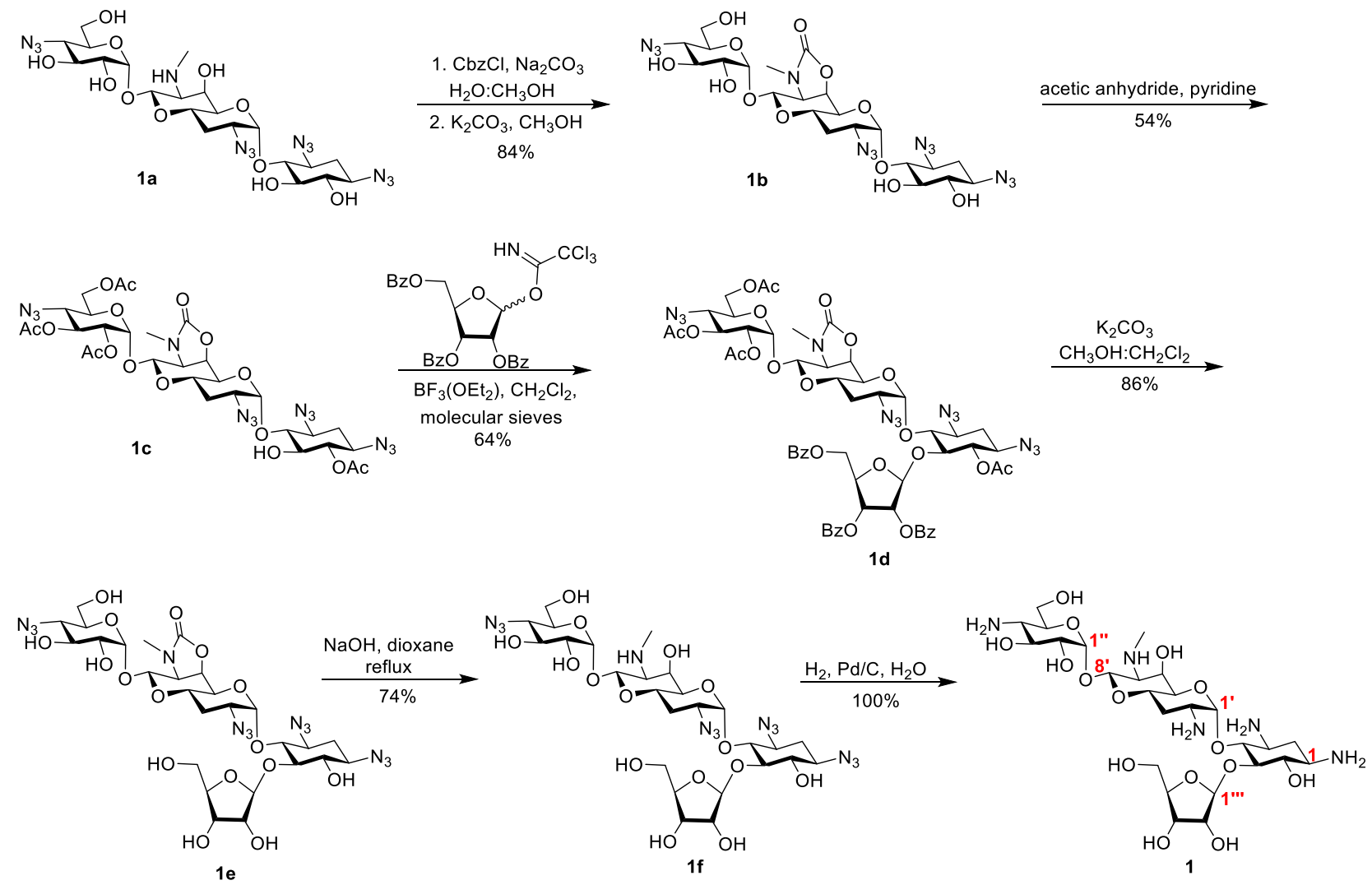

[a] Proton numbers are in red.

Compound $\mathbf{1 b}$ : The synthesis of compound $\mathbf{1 b}$ was carried out according to a previously reported procedure ${ }^{1}$ with minor modifications. $\mathrm{Na}_{2} \mathrm{CO}_{3}(2.0 \mathrm{~g}, 18.9 \mathrm{mmol})$ was added to a cold solution of $1 \mathbf{a}^{1}(2.45 \mathrm{~g}, 3.8 \mathrm{mmol})$ in $75 \%$ methanol in water $(40 \mathrm{~mL})$. Benzyl chloroformate $(\mathrm{CbzCl}, 1.6 \mathrm{~mL}$, $11.2 \mathrm{mmol}$ ) was added in three portions to the reaction mixture at $0^{\circ} \mathrm{C}$, and the mixture was stirred at room temperature. Reaction progress was monitored by TLC analysis (methanol/dichloromethane, 1:9), and after $3 \mathrm{~h}$ the solution was filtered with vacuum, and the filtrate was evaporated under reduced pressure. The crude was dissolved in $50 \mathrm{~mL}$ of methanol, and $\mathrm{K}_{2} \mathrm{CO}_{3}(0.6 \mathrm{~g}, 4.3 \mathrm{mmol})$ was added. The reaction mixture was stirred overnight at $40^{\circ} \mathrm{C}$. Upon completion (as shown by TLC analysis, methanol/dichloromethane, 1:9), the solvent was removed by evaporation, and the crude product was purified by flash column chromatography 
(methanol/dichloromethane) to yield $1 \mathrm{~b}(2.1 \mathrm{~g}, 84 \%)$ as a white solid. LRMS (ESI): $\mathrm{m} / \mathrm{z}$ calcd for $\mathrm{C}_{22} \mathrm{H}_{30} \mathrm{~N}_{13} \mathrm{O}_{12}$ : 668.21 [M-H]; found 668.05. ${ }^{1} \mathrm{H}$ NMR (400 MHz, $\left.\mathrm{CD}_{3} \mathrm{OD}\right) \delta 5.35(\mathrm{~d}, \mathrm{~J}=3.4 \mathrm{~Hz}, 1 \mathrm{H}$, $\left.\mathrm{H}^{-1} \mathbf{1}^{\prime}\right), 5.30\left(\mathrm{~d}, \mathrm{~J}=3.9 \mathrm{~Hz}, 1 \mathrm{H}, \mathrm{H}-1^{\prime \prime}\right), 5.13\left(\mathrm{~d}, \mathrm{~J}=2.5 \mathrm{~Hz}, 1 \mathrm{H}, \mathrm{H}-8^{\prime}\right), 4.96(\mathrm{dd}, \mathrm{J}=10.6,3.3 \mathrm{~Hz}, 1 \mathrm{H}$, $\left.\mathrm{H}^{-} 5^{\prime}\right), 4.92-4.88\left(\mathrm{~m}, 1 \mathrm{H}, \mathrm{H}-6^{\prime}\right), 4.04\left(\mathrm{dd}, \mathrm{J}=8.8,2.6 \mathrm{~Hz}, 1 \mathrm{H}, \mathrm{H}-7^{\prime}\right), 3.86-3.75\left(\mathrm{~m}, 3 \mathrm{H}, \mathrm{H}-3^{\prime \prime}, \mathrm{H}-4^{\prime}\right.$, H-6"), 3.66 (dd, J = 12.1, 5.2 Hz, 1H, H-6"), $3.63-3.58$ (m, 1H, H-3), 3.55 (dd, J = 9.6, 3.9 Hz, 1H, H-2"), 3.48 - 3.42 (m, 3H, H-5, H-5", H-4), $3.42-3.34$ (m, 2H, H-1, H-4"), $3.30-3.29$ (m, 1H, H6), 3.28 - $3.22(\mathrm{~m}, 1 \mathrm{H}, \mathrm{H}-2$ '), 2.89 (s, 3H, NCH 3 ), 2.32 (ddd, J = 12.7, $4.4 \mathrm{~Hz}, 1 \mathrm{H}, \mathrm{H}-2 \mathrm{eq}), 2.22$ (m, 2H, H-3'eq, H-3'ax), 1.51 (ddd, J = $12.4 \mathrm{~Hz}, 1 \mathrm{H}, \mathrm{H}-2 \mathrm{ax}) .{ }^{13} \mathrm{C}$ NMR $\left(100 \mathrm{MHz}, \mathrm{CD}_{3} \mathrm{OD}\right) \delta$ 158.6, 98.8 (anomeric), 94.8 (anomeric), 91.7 (anomeric), 81.3, 76.5, 76.3, 72.7, 72.0, 71.4, 70.8, 65.7, 65.3, $62.4,61.3,60.5,59.9,58.6,56.8,31.4,29.7,28.8$.

Compound 1c: The synthesis of compound 1c was carried out according to a previously reported procedure $^{2}$ with minor modifications. To a solution of $\mathbf{1 b}(2.1 \mathrm{~g}, 3.14 \mathrm{mmol})$ in dry pyridine $(40 \mathrm{~mL})$, acetic anhydride $(2.3 \mathrm{~mL}, 24.5 \mathrm{mmol})$ was added. The reaction mixture was stirred at room temperature overnight. Reaction progress was monitored by TLC analysis (ethyl acetate/petroleum ether, 6:4). Upon completion, the reaction mixture was diluted with ethyl acetate and washed with an aqueous $1 \mathrm{M} \mathrm{HCl}$ solution. The organic layer was washed with brine, dried over anhydrous $\mathrm{MgSO}_{4}$, filtered, and concentrated under reduced pressure. Purification by flash column chromatography $\left(\mathrm{SiO}_{2}\right.$; ethyl acetate/petroleum ether) gave $1 \mathrm{c}(1.4 \mathrm{~g}, 54 \%)$ as a white solid. LRMS (ESI): $\mathrm{m} / \mathrm{z}$ calcd for $\mathrm{C}_{30} \mathrm{H}_{40} \mathrm{~N}_{13} \mathrm{O}_{16}: 838.27[\mathrm{M}+\mathrm{H}]^{+}$; found 837.97. ${ }^{1} \mathrm{H}$ NMR $\left(400 \mathrm{MHz}, \mathrm{CD}_{3} \mathrm{OD}\right) \delta$ $5.46\left(\mathrm{dd}, \mathrm{J}=9.26 \mathrm{~Hz}, 1 \mathrm{H}, \mathrm{H}-3^{\prime \prime}\right), 5.41$ (d, J = 3.8 Hz, 1H, H-1"), 5.35 (d, J = 3.4 Hz, 1H, H-1'), 5.10 (d, J = 2.7 Hz, 1H, H-8'), 4.96 (dd, J = 10.3, 3.8 Hz, 1H, H-2"), $4.92-4.90$ (m, 1H, H-6'), 4.87 (dd, $\mathrm{J}=9.5 \mathrm{~Hz}, 1 \mathrm{H}, \mathrm{H}-6), 4.70-4.78\left(\mathrm{~m}, 1 \mathrm{H}, \mathrm{H}-5^{\prime}\right), 4.37\left(\mathrm{dd}, \mathrm{J}=12.3 \mathrm{~Hz}, 1 \mathrm{H}, \mathrm{H}-6{ }^{\prime \prime}\right), 4.27$ (dd, J = 12.2, $4.8 \mathrm{~Hz}, 1 \mathrm{H}, \mathrm{H}-6 "), 4.08$ (dd, J = 8.7, $\left.2.7 \mathrm{~Hz}, 1 \mathrm{H}, \mathrm{H}-7^{\prime}\right), 3.83$ - 3.76 (m, 4H, H-4", H-5", H-4', H-5), $3.76-3.68(m, 1 \mathrm{H}, \mathrm{H}-1), 3.67-3.54(\mathrm{~m}, 2 \mathrm{H}, \mathrm{H}-3, \mathrm{H}-4), 3.40$ (dt, J = 12.7, $\left.4.0 \mathrm{~Hz}, 1 \mathrm{H}, \mathrm{H}-2{ }^{\prime}\right), 2.94$ (s, 3H, NCH ), 2.45 (ddd, J = 13.0, 8.7, $4.3 \mathrm{~Hz}, 1 \mathrm{H}, \mathrm{H}-2 \mathrm{eq}$ ), 2.28 - 2.21 (m, 1H, H-3'eq), 2.15 (s, $\left.3 \mathrm{H}, \mathrm{COCH}_{3}\right), 2.14\left(\mathrm{~s}, 3 \mathrm{H}, \mathrm{COCH}_{3}\right), 2.13\left(\mathrm{~s}, 3 \mathrm{H}, \mathrm{COCH}_{3}\right), 2.09\left(\mathrm{~s}, \mathrm{~J}=3.6 \mathrm{~Hz}, 3 \mathrm{H}, \mathrm{COCH}_{3}\right), 1.92$ (ddd, J = 11.7 Hz, 1H, H-3'ax), 1.69 (ddd, J = $12.5 \mathrm{~Hz}, 1 \mathrm{H}, \mathrm{H}-2 \mathrm{ax}) .{ }^{13} \mathrm{C}$ NMR $\left(100 \mathrm{MHz}, \mathrm{CD}_{3} \mathrm{OD}\right) \delta$ 
171.0, 170.7, 170.4, 98.9 (anomeric), 94.6 (anomeric), 94.3 (anomeric), 81.6, 76.3, 74.1, 70.9, $70.7,70.4,68.9,65.6,65.4,63.1,60.3,60.1,58.5,58.0,57.0,31.1,30.6,28.9,20.0,19.6,19.5$, 19.3

Compound 1d: The synthesis of compound 1d was carried out according to a previously reported procedure $^{2}$ with minor modifications. To a mixture of acceptor $1 \mathrm{c}(710 \mathrm{mg}, 0.85 \mathrm{mmol})$ and 2,3,5tri-O-benzoyl-D-ribofuranosyl-trichloroacetimidate glycosyl donor ${ }^{3}(1.0 \mathrm{~g}, 1.65 \mathrm{mmol})$ in anhydrous dichloromethane $(15 \mathrm{~mL})$ was added powdered, flame-dried 4-Å molecular sieves (1.4 g). After stirring for $10 \mathrm{~min}$ at room temperature, the mixture was cooled to $-50{ }^{\circ} \mathrm{C}$, and $\mathrm{BF}_{3} \cdot \mathrm{OEt}_{2}(40 \mu \mathrm{L})$ was added. The reaction was allowed to warm to room temperature and was analyzed by TLC (ethyl acetate/petroleum ether, 1:1). Upon completion, the reaction was diluted with ethyl acetate and filtered through Celite. After thorough washing of the Celite with ethyl acetate, the washes were combined, and the organic layer was washed with brine, dried over $\mathrm{MgSO}_{4}$, and concentrated under reduced pressure. The crude product was purified by flash column chromatography $\left(\mathrm{SiO}_{2}\right.$; ethyl acetate/petroleum ether) to yield 1d (694 mg, 64\%) as a white solid. LRMS (ESI): m/z calcd for $\mathrm{C}_{57} \mathrm{H}_{60} \mathrm{~N}_{13} \mathrm{O}_{25}: 1326.38$ [M+CHOO]; found 1326.59. ${ }^{1} \mathrm{H}$ NMR (400 MHz, CD $\left.{ }_{3} \mathrm{OD}\right) \delta 8.15$ (dd, J $=7.0,1.6 \mathrm{~Hz}, 2 \mathrm{H}, \mathrm{Bz}), 7.94$ (dd, J = 7.3, 1.3 Hz, 2H, Bz), 7.90 (dd, J = 7.2, 1.3 Hz, 2H, Bz), $7.67-$ $7.59(\mathrm{~m}, 2 \mathrm{H}, \mathrm{Bz}), 7.59-7.48(\mathrm{~m}, 3 \mathrm{H}, \mathrm{Bz}), 7.45(\mathrm{t}, \mathrm{J}=7.8 \mathrm{~Hz}, 2 \mathrm{H}, \mathrm{Bz}), 7.37$ (t, J = 7.8 Hz, 2H, Bz), 5.78 (dd, J = 7.4, 4.3 Hz, 1H, H-3"'), $5.66-5.60$ (m, 2H, H-1'", H-2'"), $5.48-5.41\left(\mathrm{~m}, 1 \mathrm{H}, \mathrm{H}-3{ }^{\prime \prime}\right)$, $5.40\left(\mathrm{~d}, \mathrm{~J}=3.9 \mathrm{~Hz}, 1 \mathrm{H}, \mathrm{H}-1^{\prime}\right), 5.38(\mathrm{~d}, \mathrm{~J}=3.9 \mathrm{~Hz}, 1 \mathrm{H}, \mathrm{H}-1 "), 5.11-5.07$ (m, 2H, H-8', H-5'"), 4.96 (dd, J = 10.3, 3.8 Hz, 1H, H-2"), $4.93-4.89$ (m, 1H, H-6'), 4.82 (dd, J = 10.6, 3.1 Hz, 1H, H-5'), $4.76-4.65$ (m, 2H, H-6, H-4"'), $4.40-4.32$ (m, 2H, H-6", H-5'"), 4.26 (dd, J = 12.2, 5.0 Hz, $1 \mathrm{H}, \mathrm{H}-$ 6"), $4.08-4.04\left(m, 1 H, H-7^{\prime}\right), 3.86-3.81$ (m, 2H, H-4", H-5"), $3.81-3.72(m, 2 H, H-5, H-4 '), 3.62$ (ddd, J = 12.0, 9.9, 4.6 Hz, 1H, H-1), $3.56-3.48(m, 2 H, H-3, H-2 '), 3.13(d d, J=9.3 \mathrm{~Hz}, 1 \mathrm{H}, \mathrm{H}-4$ ), $2.94\left(\mathrm{~s}, 3 \mathrm{H}, \mathrm{NCH}_{3}\right), 2.41$ (ddd, J = 12.4, $\left.4.3 \mathrm{~Hz}, 1 \mathrm{H}, \mathrm{H}-2 \mathrm{eq}\right), 2.30$ (s, 3H, $\left.\mathrm{COCH}_{3}\right), 2.25-2.18(\mathrm{~m}$, 1H, H-3'eq), 2.10 (s, 3H, COCH $H_{3}$, 2.09 (s, 3H, COCH $\mathrm{CH}_{3}, 2.08\left(\mathrm{~s}, 3 \mathrm{H}, \mathrm{COCH}_{3}\right), 1.83-1.77(\mathrm{~m}, 1 \mathrm{H}$, H-3'ax), $1.43-1.31(\mathrm{~m}, 1 \mathrm{H}, \mathrm{H}-2 \mathrm{ax}) .{ }^{13} \mathrm{C}$ NMR (100 MHz, CD $\left.\mathrm{OD}\right) \delta 171.0,170.6,170.5,166.4$, $165.6,165.5,158.5,133.6,133.4,133.2,130.1,130.0,129.7,129.4,129.0,128.9,128.6,128.5$, 
128.3, 107.2 (anomeric), 97.1 (anomeric), 94.0 (anomeric), 93.8 (anomeric), 80.2, 79.7, 79.5, 75.0, $74.6,74.3,71.4,70.9,70.8,70.3,68.9,65.4,65.3,6.1,62.3,60.3,60.2,58.1,58.1,31.7,30.5$, $28.8,20.0,19.5,19.3$.

Compound 1e: The fully protected ribosylated compound 1d (490 mg, $0.38 \mathrm{mmol})$ was dissolved in methanol/dichloromethane $(9: 1,10 \mathrm{~mL})$, and $\mathrm{K}_{2} \mathrm{CO}_{3}(106 \mathrm{mg}, 0.77 \mathrm{mmol})$ was added. The mixture was stirred overnight at room temperature. Upon completion (as shown by TLC analysis methanol/dichloromethane, 1:9), the solvent was removed by evaporation, and the crude product was purified by flash column chromatography $\left(\mathrm{SiO}_{2} ;\right.$ methanol/dichloromethane) to yield $1 \mathrm{e}$ (262 mg, $86 \%$ ) as a white solid. LRMS (ESI): m/z calcd for $\mathrm{C}_{27} \mathrm{H}_{38} \mathrm{~N}_{13} \mathrm{O}_{16}: 800.26$ [M-H]; found 799.97. ${ }^{1} \mathrm{H}$ NMR $\left(500 \mathrm{MHz}, \mathrm{CD}_{3} \mathrm{OD}\right) \delta 5.34\left(\mathrm{~d}, \mathrm{~J}=3.4 \mathrm{~Hz}, 1 \mathrm{H}, \mathrm{H}-1\right.$ '), $5.32\left(\mathrm{br} \mathrm{s}, 1 \mathrm{H}, \mathrm{H}-1{ }^{\prime \prime}\right), 5.31$ (d, J = 3.9 $\mathrm{Hz}, 1 \mathrm{H}, \mathrm{H}-1 "), 5.13\left(\mathrm{~d}, \mathrm{~J}=2.6 \mathrm{~Hz}, 1 \mathrm{H}, \mathrm{H}-8^{\prime}\right), 4.95\left(\mathrm{dd}, \mathrm{J}=10.6,3.3 \mathrm{~Hz}, 1 \mathrm{H}, \mathrm{H}-5^{\prime}\right), 4.89$ (dd, J = 8.9, 3.3 Hz, 1H, H-6'), 4.20 (dd, J = 7.1, 4.7 Hz, 1H, H-3'"), 4.16 (dd, J = 4.7 Hz, 1H, H-2'"), 4.04 (dd, J $\left.=8.8,2.6 \mathrm{~Hz}, 1 \mathrm{H}, \mathrm{H}-7^{\prime}\right), 3.94$ (ddd, J = 7.6, 4.8, 3.2 Hz, 1H, H-4"'), $3.85-3.77$ (m, 3H, H-3", H-4', H-5"'), 3.75 (dd, J = 7.1, $5.3 \mathrm{~Hz}, 1 \mathrm{H}, \mathrm{H}-6 "), 3.71$ (dd, J = $9.3 \mathrm{~Hz}, 1 \mathrm{H}, \mathrm{H}-4), 3.69-3.60$ (m, 4H, H-3, H-5, H-6", H-5"'), 3.60 - 3.54 (m, 2H, H-6, H-2"), 3.48 - 3.38 (m, 2H, H-1, H-5"), 3.36 (dd, J = 9.6 $\mathrm{Hz}, 1 \mathrm{H}, \mathrm{H}-4 "), 3.14$ (ddd, J = 12.4, 8.0, $4.2 \mathrm{~Hz}, 1 \mathrm{H}, \mathrm{H}-2$ '), 2.90 (s, 3H, NCH3), $2.33-2.26$ (m, 2H, H-3'eq, H-3'ax), $2.26-2.19$ (m, 1H, H-2eq), 1.54 (ddd, J = $12.5 \mathrm{~Hz}, 1 \mathrm{H}, \mathrm{H}-2 \mathrm{ax}) .{ }^{13} \mathrm{C}$ NMR (125 $\mathrm{MHz}, \mathrm{CD}_{3} \mathrm{OD}$ ) $\delta$ 158.3, 106.1 (anomeric), 98.4 (anomeric), 94.5 (anomeric), 91.5 (anomeric), 83.1, $82.9,77.7,75.6,74.8,72.5,71.9,71.2,70.6,69.9,65.5,65.2,62.2,61.4,61.2,60.4,59.7,58.8$, $56.3,30.9,29.6,28.6$.

Compound 1f: To a stirred solution of $1 \mathrm{e}(105 \mathrm{mg}, 0.013 \mathrm{mmol})$ in 1,4-dioxane $(6 \mathrm{~mL})$ was added 3.0 $\mathrm{M}$ aqueous $\mathrm{NaOH}(1.5 \mathrm{~mL})$, and the mixture was heated at $90{ }^{\circ} \mathrm{C}$ overnight. Upon completion (as shown by TLC analysis; ammonia methanol/dichloromethane, 2:8), the solvent was removed by evaporation, and the crude product was purified by flash column chromatography $\left(\mathrm{SiO}_{2}\right.$; ammonia methanol/dichloromethane) to yield $1 \mathrm{f}(74 \mathrm{mg}, 74 \%)$ as a white solid. LRMS (ESI): $\mathrm{m} / \mathrm{z}$ calcd for $\mathrm{C}_{26} \mathrm{H}_{40} \mathrm{~N}_{13} \mathrm{O}_{15}: 774.28[\mathrm{M}-\mathrm{H}]$; found 773.97. ${ }^{1} \mathrm{H}$ NMR $\left(500 \mathrm{MHz}, \mathrm{CD}_{3} \mathrm{OD}\right) \delta 5.69(\mathrm{~d}, \mathrm{~J}=3.5$ $\left.\mathrm{Hz}, 1 \mathrm{H}, \mathrm{H}-1^{\prime}\right), 5.35\left(\mathrm{~d}, \mathrm{~J}=1.0 \mathrm{~Hz}, 1 \mathrm{H}, \mathrm{H}-1^{\prime \prime \prime}\right), 5.32\left(\mathrm{~d}, \mathrm{~J}=3.9 \mathrm{~Hz}, 1 \mathrm{H}, \mathrm{H}-1{ }^{\prime \prime}\right), 4.94(\mathrm{~d}, \mathrm{~J}=8.3 \mathrm{~Hz}, 1 \mathrm{H}$, 
H-8'), 4.28 (dd, J = 2.0 Hz, 1H, H-6'), 4.15 (dd, J = 7.1, 4.8 Hz, 1H, H-3"'), 4.09 (dd, J = 4.7, $1.1 \mathrm{~Hz}$, 1H, H-2'"), 3.97 - 3.89 (m, 1H, H-4"'), 3.85 - 3.66 (m, 9H, H-4, H-5, H-6, H-3", H-6", H-6", H-4', H5', H-5"'), 3.64 (dd, J = 11.9, 4.9 Hz, 1H, H-5'"), 3.60 (ddd, J = 10.4, 4.4, 2.0 Hz, 1H, H-5"), 3.53 3.48 (m, 2H, H-3, H-2"), 3.46 - 3.37 (m, 2H, H-1, H-4"), 3.20 (ddd, J = 13.0, 8.2, 4.2 Hz, 1H, H-2'), 2.72 (dd, J = 8.3, $\left.2.6 \mathrm{~Hz}, 1 \mathrm{H}, \mathrm{H}-7^{\prime}\right), 2.52$ (s, 3H, NCH ), 2.25 - 2.18 (m, 2H, H-3'eq, H-2eq), 2.12 2.03 (m, 1H, H-3'ax), 1.42 (ddd, J = $12.5 \mathrm{~Hz}, 1 \mathrm{H}, \mathrm{H}-2 \mathrm{ax}) .{ }^{13} \mathrm{C} \mathrm{NMR}\left(100 \mathrm{MHz}, \mathrm{CD}_{3} \mathrm{OD}\right.$ ) $\delta 108.5$ (anomeric), 97.8 (anomeric), 96.6 (anomeric), 96.0 (anomeric), 84.9, 84.5, 77.1, 76.9, 76.8, 73.7, $72.9,72.7,71.9,71.4,67.9,66.4,63.5,63.1,62.4,61.8,61.5,57.6,33.2,32.9,29.3$.

Compound 1: The azide-protected ribosylated compound $1 \mathbf{f}$ (32 $\mathrm{mg}, 0.04 \mathrm{mmol})$ was dissolved in water (6 mL), and palladium on charcoal (Pd/C; 10\% Pd, cat.) was added. Hydrogen was bubbled through the suspension for $10 \mathrm{~min}$, and the reaction mixture was stirred under hydrogen atmosphere at room temperature for $3 \mathrm{~h}$. Progress of the reaction was monitored by low-resolution ESI-MS. Upon completion, the mixture was filtered through a syringe filter (25-mm diameter; pore size $0.2 \mu \mathrm{m}$; PTEF membrane) and freeze-dried to yield $\mathbf{1}$ (28 $\mathrm{mg}$, quantitative yield) as a white solid. HRMS (ESI): $\mathrm{m} / \mathrm{z}$ calcd for $\mathrm{C}_{26} \mathrm{H}_{50} \mathrm{~N}_{5} \mathrm{O}_{15}: 672.3303[\mathrm{M}+\mathrm{H}]^{+}$; found $672.3307 .{ }^{1} \mathrm{H}$ NMR (500 $\left.M H z, D_{2} \mathrm{O}\right) \delta 5.92\left(\mathrm{~d}, \mathrm{~J}=3.9 \mathrm{~Hz}, 1 \mathrm{H}, \mathrm{H}-1^{\prime}\right), 5.55(\mathrm{~d}, \mathrm{~J}=4.0 \mathrm{~Hz}, 1 \mathrm{H}, \mathrm{H}-1 "), 5.39(\mathrm{~d}, \mathrm{~J}=1.8 \mathrm{~Hz}, 1 \mathrm{H}$, $\left.H^{-1}{ }^{\prime \prime}\right), 5.27$ (d, J = 8.5 Hz, 1H, H-8'), 4.64 (dd, J = 2.5 Hz, 1H, H-6'), 4.24 (dd, J = 4.7, $1.8 \mathrm{~Hz}, 1 \mathrm{H}$, H-2'"), 4.20 (dd, J = 7.0, 4.8 Hz, 1H, H-3"'), $4.10-4.06$ (m, 1H, H-4"'), $4.06-3.96$ (m, 3H, H-4, H5", H-4'), 3.96 - 3.88 (m, 4H, H-5, H-3", H-6", H-5"'), 3.84 (dd, J = 12.4, 4.7 Hz, 1H, H-6"), 3.78 (dd, $\mathrm{J}=9.8,4.0 \mathrm{~Hz}, 1 \mathrm{H}, \mathrm{H}-2 "), 3.75-3.67$ (m, 4H, H-6, H-2', H-5', H-5"'), 3.52 (ddd, J = $10.2 \mathrm{~Hz}, 1 \mathrm{H}$, H-3), 3.44 (dd, J = 8.5, $\left.2.8 \mathrm{~Hz}, 1 \mathrm{H}, \mathrm{H}-7^{\prime}\right), 3.41-3.30$ (m, 2H, H-1, H-4"), 2.84 (s, 3H, NCH3), 2.50 (ddd, J = 8.5, 4.1 Hz, 1H, H-2eq), 2.41 (ddd, J = 10.9, 4.3 Hz, 1H, H-3'eq), 2.09 (ddd, J = $11.7 \mathrm{~Hz}$, 1H, H-3'ax), 1.87 (ddd, J = $12.6 \mathrm{~Hz}, 1 \mathrm{H}, \mathrm{H}-2 \mathrm{ax}) .{ }^{13} \mathrm{C}$ NMR (125 MHz, $\mathrm{D}_{2} \mathrm{O}$ ) $\delta 116.5$ (q, $\mathrm{J}=290$, $\mathrm{CF}_{3} \mathrm{COOH}$ ), 110.4 (anomeric), 94.7 (anomeric), 94.6 (anomeric), 93.0 (anomeric), 85.1, 82.6, 75.3, $72.7,70.3,69.9,69.6,69.1,68.5,66.1,62.8,61.0,60.4,59.5,52.2,49.9,48.6,48.01,30.1,26.8$. 
Scheme S2: Synthesis of compounds 2 and $3^{[a]}$

A.

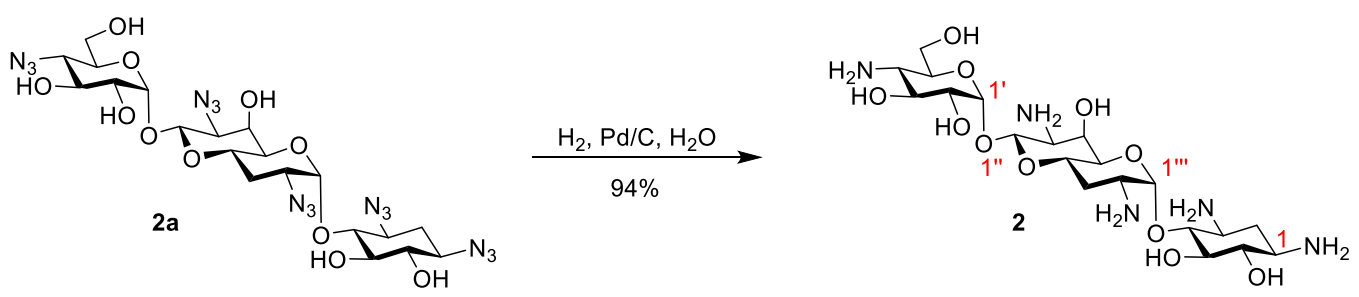

B.
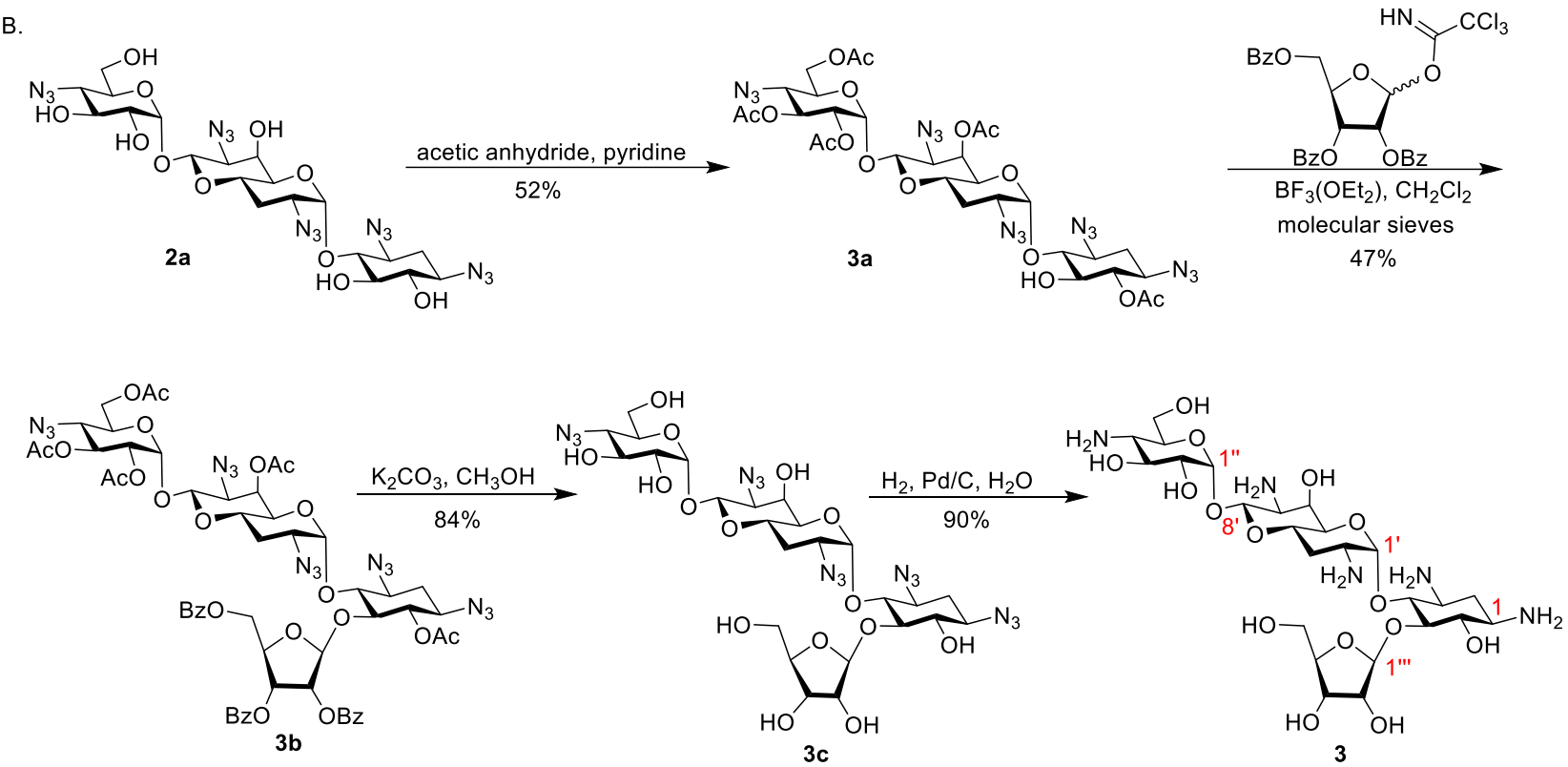

[a] Proton numbers are in red.

Compound 2: Compound 2 was prepared as described for compound 1 using $2 a^{1}$ (68 $\mathrm{mg}, 0.10$ $\mathrm{mmol})$, water $(6 \mathrm{~mL})$, and $10 \% \mathrm{Pd} / \mathrm{C}$ (cat.). The reaction mixture was filtered and freeze-dried to yield 2 (51 mg, 94\%) as a white solid. HRMS (ESI): $\mathrm{m} / \mathrm{z}$ calcd for $\mathrm{C}_{20} \mathrm{H}_{40} \mathrm{~N}_{5} \mathrm{O}_{11}: 526.2724[\mathrm{M}+\mathrm{H}]^{+}$; found 526.2722. ${ }^{1} \mathrm{H}$ NMR (500 MHz, $\left.\mathrm{D}_{2} \mathrm{O}\right) \delta 5.75(\mathrm{~d}, \mathrm{~J}=3.8 \mathrm{~Hz}, 1 \mathrm{H}, \mathrm{H}-1$ '), $5.52(\mathrm{~d}, \mathrm{~J}=3.9 \mathrm{~Hz}, 1 \mathrm{H}$, H-1"), 5.25 (d, J = 8.6 Hz, 1H, H-8'), 4.48 (dd, J = 2.6 Hz, 1H, H-6'), $4.06-3.99$ (m, 2H, H-5", H4'), 3.99 - 3.89 (m, 3H, H-4, H-3", H-6"), 3.88 - 3.81 (m, 2H, H-6", H-5'), $3.79-3.74$ (m, 1H, H-2"), $3.73-3.67(m, 2 H, H-5, H-2 '), 3.63-3.53(m, 2 H, H-3, H-6), 3.54-3.49(m, 1 H, H-7 '), 3.39-3.32$ (m, 2H, H-4", H-1), 2.54 (ddd, J = 12.5, 4.2 Hz, 1H, H-2eq), 2.42 (ddd, J = 10.8, 4.3 Hz, 1H, H3'eq), 2.08 (ddd, J = $11.35 \mathrm{~Hz}, 1 \mathrm{H}, \mathrm{H}-3$ 'ax), 1.90 (ddd, J = $12.6 \mathrm{~Hz}, 1 \mathrm{H}, \mathrm{H}-2 \mathrm{ax}$ ). ${ }^{13} \mathrm{C}$ NMR (125 MHz, 
$\mathrm{D}_{2} \mathrm{O}$ ) $\delta 95.7$ (anomeric), 94.6 (anomeric), 93.3 (anomeric), 78.5, 75.2, 72.6, 70.3, 69.7, 69.4, 68.4, $66.2,65.6,60.4,53.2,52.2,49.7,48.5,48.0,28.4,26.9$.

Compound 3a: Compound 3a was prepared as described for compound 1c using $2 \mathbf{a}^{1}$ (709 mg, $1.08 \mathrm{mmol})$, acetic anhydride $(1 \mathrm{~mL}, 10.6 \mathrm{mmol})$, and dry pyridine $(5 \mathrm{~mL})$. The reaction was monitored by TLC analysis (ethyl acetate/petroleum ether, 1:1). Purification by flash column chromatography $\left(\mathrm{SiO}_{2}\right.$; ethyl acetate/petroleum ether) gave $3 \mathbf{a}(490 \mathrm{mg}, 52 \%)$ as a white solid. LRMS (ESI): m/z calcd for $\mathrm{C}_{31} \mathrm{H}_{40} \mathrm{~N}_{15} \mathrm{O}_{18}: 910.27$ [M+CHOO]; found $910.58 .{ }^{1} \mathrm{H}$ NMR $(400 \mathrm{MHz}$, $\left.\mathrm{CD}_{3} \mathrm{OD}\right) \delta 5.65\left(\mathrm{dd}, \mathrm{J}=6.8,3.9 \mathrm{~Hz}, 1 \mathrm{H}, \mathrm{H}-6^{\prime}\right), 5.58\left(\mathrm{~d}, \mathrm{~J}=3.4 \mathrm{~Hz}, 1 \mathrm{H}, \mathrm{H}-1^{\prime}\right), 5.52-5.43(\mathrm{~m}, 2 \mathrm{H}$, H-1", H-3"), 4.91 (d, J = 8.5 Hz, 1H, H-8'), $4.89-4.81$ (m, 2H, H-2", H-6), 4.44 (dd, J = 12.2, 2.1 Hz, 1H, H-6"), 4.26 (dd, J = 12.2, 5.3 Hz, 1H, H-6"), 4.03 (dd, J = 10.0, 2.6 Hz, 1H, H-5'), 3.96 (ddd, $\left.\mathrm{J}=10.5,5.1,2.1 \mathrm{~Hz}, 1 \mathrm{H}, \mathrm{H}-5^{\prime \prime}\right), 3.85-3.74\left(\mathrm{~m}, 3 \mathrm{H}, \mathrm{H}-4^{\prime \prime}, \mathrm{H}-7^{\prime}, \mathrm{H}-4^{\prime}\right), 3.71-3.59(\mathrm{~m}, 3 \mathrm{H}, \mathrm{H}-1, \mathrm{H}-$ 4, H-5), $3.59-3.51$ (m, 1H, H-3), 3.22 (ddd, J = 12.7, $4.0 \mathrm{~Hz}, 1 \mathrm{H}, \mathrm{H}-2$ '), 2.33 (ddd, J = 12.7, 4.4 $\mathrm{Hz}, 1 \mathrm{H}, \mathrm{H}-2 \mathrm{eq}), 2.22-2.15$ (m, 1H, H-3'eq), 2.12 (s, 3H, COCH $\mathrm{C}_{3}, 2.11$ (s, 3H, $\left.\mathrm{COCH}_{3}\right), 2.10$ (s, $3 \mathrm{H}, \mathrm{COCH}_{3}$ ), 2.10 (s, 3H, $\mathrm{COCH}_{3}$ ), $2.04-1.98$ (m, 4H, H-3'ax, $\mathrm{COCH}_{3}$ ), 1.60 (ddd, J = $12.4 \mathrm{~Hz}$, $1 \mathrm{H}, \mathrm{H}-2 \mathrm{ax}) .{ }^{13} \mathrm{C} \mathrm{NMR}\left(100 \mathrm{MHz}, \mathrm{CD}_{3} \mathrm{OD}\right) \delta 172.24,172.0,171.7,171.4,171.3,159.6,98.8$ (anomeric), 97.6 (anomeric), 94.3 (anomeric), 80.2, 77.7, 75.8, 71.6, 71.5, 70.4, 69.9, 69.3, 68.8, $64.0,63.1,61.3,60.9,59.4,57.4,32.8,29.1,20.9,20.6$.

Compound 3b: Compound $\mathbf{3 b}$ was prepared as described for compound $\mathbf{1 d}$ using acceptor $\mathbf{3 a}$ (470 mg, $0.54 \mathrm{mmol}$ ), 2,3,5-tri-O-benzoyl-D-ribofuranosyl-trichloroacetimidate glycosyl donor ${ }^{3}(1 \mathrm{~g}$, $1.65 \mathrm{mmol})$, flame dried 4- $\AA$ molecular sieves $(1.5 \mathrm{~g})$, anhydrous dichloromethane $(10 \mathrm{~mL})$, and $\mathrm{BF}_{3} \cdot \mathrm{OEt}_{2}(40 \mu \mathrm{L})$. Progress of the reaction was monitored by TLC analysis (ethyl acetate/petroleum ether, 3:7). The crude was purified by flash chromatography $\left(\mathrm{SiO}_{2}\right.$; ethyl acetate/petroleum ether) to yield $\mathbf{3 b}$ (350 mg, 47\%) as a white solid. LRMS (ESI): $\mathrm{m} / \mathrm{z}$ calcd for $\mathrm{C}_{56} \mathrm{H}_{59} \mathrm{~N}_{15} \mathrm{O}_{23} \mathrm{Na}$ : 1332.38 $[\mathrm{M}+\mathrm{Na}]^{+}$; found 1332.27. ${ }^{1} \mathrm{H} \mathrm{NMR}\left(400 \mathrm{MHz}, \mathrm{CD}_{3} \mathrm{OD}\right) \delta 8.09$ (dd, J = 8.7, $\left.1.4 \mathrm{~Hz}, 2 \mathrm{H}, \mathrm{Bz}\right), 7.94$ (dd, $\mathrm{J}=8.7,1.4 \mathrm{~Hz}, 2 \mathrm{H}, \mathrm{Bz}), 7.88(\mathrm{dd}, \mathrm{J}=8.7,1.4 \mathrm{~Hz}, 2 \mathrm{H}, \mathrm{Bz}), 7.66-7.58(\mathrm{~m}, 2 \mathrm{H}, \mathrm{Bz}), 7.55$ (t, J = 7.4 $\mathrm{Hz}, 3 \mathrm{H}, \mathrm{Bz}), 7.45$ (t, J = 7.8 Hz, 2H, Bz), 7.37 (t, J = 7.9 Hz, 2H, Bz), 5.81 (dd, J = 7.2, 4.7 Hz, 1H, H-3'"), 5.70 (dd, J = 2.8 Hz, 1H, H-6'), 5.66 (dd, J = 5.0 Hz, 1H, H-2'"), 5.54 (br s, 1H, H-1'"), 5.52 
- $5.43\left(\mathrm{~m}, 3 \mathrm{H}, \mathrm{H}-1^{\prime \prime}, \mathrm{H}-3^{\prime \prime}, \mathrm{H}-1^{\prime}\right), 5.13$ (dd, J = 12.3, 3.1 Hz, 1H, H-5"'), 4.92 - 4.87 (m, 2H, H-2", H8'), 4.68 - 4.58 (m, 2H, H-6, H-4"'), 4.45 (dd, J = 12.2, 2.1 Hz, 1H, H-6"), $4.33-4.24$ (m, 2H, H-6", H-5'"), 4.05 - 3.93 (m, 2H, H-5", H-5'), 3.87 - 3.72 (m, 4H, H-5, H-4", H-7', H-4'), 3.52 - 3.33 (m, $\left.3 \mathrm{H}, \mathrm{H}-1, \mathrm{H}-3, \mathrm{H}-2^{\prime}\right), 3.02$ (dd, J = 9.7 Hz, 1H, H-4), $2.30-2.21$ (m, 4H, H-2eq, $\mathrm{COCH}_{3}$ ), $2.21-2.14$ (m, 4H, H-3'eq, $\mathrm{COCH}_{3}$ ), 2.11 (s, 3H, $\left.\mathrm{COCH}_{3}\right), 2.10$ (s, 3H, COCH 3 ), 1.99 (s, 3H, COCH$)_{3}, 1.89$ (ddd, J = 11.6 Hz, 1H, H-3'ax), 1.26 (ddd, J = $12.8 \mathrm{~Hz}, 1 \mathrm{H}, \mathrm{H}-2 \mathrm{ax}) .{ }^{13} \mathrm{C} \mathrm{NMR}\left(100 \mathrm{MHz}, \mathrm{CD}_{3} \mathrm{OD}\right.$ ) $\delta$ 172.2, 171.7, 171.6, 171.5, 171.4, 167.6, 166.8, 166.7, 134.9, 134.7, 134.3, 131.4, 131.2, 130.7, 130.6, 130.3, 130.2, 129.9, 129.7, 129.6, 108.4 (anomeric), 97.5 (anomeric), 97.2 (anomeric), 94.3 (anomeric), 81.4, 80.9, 78.5, 76.1, 75.7, 72.4, 71.6, 71.5, 70.4, 69.8, 69.3, 68.7, 64.0, 63.2, 61.4, $60.4,59.5,58.2,32.2,29.8,21.3,20.8,20.6,20.6,20.5$.

Compound 3c: compound $\mathbf{3 c}$ was prepared as described for compound 1e using $\mathbf{3 b}$ (314 mg, 0.24 $\mathrm{mmol}), \mathrm{K}_{2} \mathrm{CO}_{3}(66 \mathrm{mg}, 0.48 \mathrm{mmol})$ and methanol $(10 \mathrm{~mL})$. Progress of the reaction was monitored by TLC analysis (methanol/dichloromethane, 1:9). The crude was purified by flash chromatography $\left(\mathrm{SiO}_{2}\right.$; methanol/dichloromethane) to yield 3c (159 mg, 84\%) as a white solid. LRMS (ESI): m/z calcd for $\mathrm{C}_{25} \mathrm{H}_{36} \mathrm{~N}_{15} \mathrm{O}_{15}$ : 786.25 [M-H]; found 786.14. ${ }^{1} \mathrm{H}$ NMR $\left(500 \mathrm{MHz}, \mathrm{CD}_{3} \mathrm{OD}\right) \delta 5.69(\mathrm{~d}, \mathrm{~J}=3.5$ $\left.\mathrm{Hz}, 1 \mathrm{H}, \mathrm{H}-1^{\prime}\right), 5.34\left(\mathrm{~d}, \mathrm{~J}=1.1 \mathrm{~Hz}, 1 \mathrm{H}, \mathrm{H}-1^{\prime \prime \prime}\right), 5.31\left(\mathrm{~d}, \mathrm{~J}=3.7 \mathrm{~Hz}, 1 \mathrm{H}, \mathrm{H}-1{ }^{\prime \prime}\right), 5.06(\mathrm{~d}, \mathrm{~J}=8.4 \mathrm{~Hz}, 1 \mathrm{H}$, H-8'), 4.22 (dd, J = 2.3 Hz, 1H, H-6'), 4.15 (dd, J = 6.9, $\left.4.8 \mathrm{~Hz}, 1 \mathrm{H}, \mathrm{H}-3^{\prime \prime \prime}\right), 4.09$ (dd, J = 4.7, $1.0 \mathrm{~Hz}$, $\left.1 \mathrm{H}, \mathrm{H}-2^{\prime \prime \prime}\right), 3.96-3.89$ (m, 1H, H-4"'), $3.89-3.81$ (m, 3H, H-3", H-4', H-5'), $3.81-3.66$ (m, 5H, H4, H-5, H-6", H-6", H-5'"), 3.64 (dd, J = 11.9, 5.0 Hz, 1H, H-5"'), 3.60 (ddd, J = 10.5, 5.3, 3.1 Hz, 1H, H-5"), 3.55 - 3.39 (m, 6H, H-1, H-3, H-6, H-2", H-4" H-7'), 3.20 (ddd, J = 12.9, 4.1 Hz, 1H, H2'), 2.25 - 2.17 (m, 2H, H-2eq, H-3'eq), 2.09 (ddd, J = 11.3 Hz, 1H, H-3'ax), 1.43 (ddd, J = 12.5 Hz, $1 \mathrm{H}, \mathrm{H}-2 \mathrm{ax}) .{ }^{13} \mathrm{C} \mathrm{NMR}\left(125 \mathrm{MHz}, \mathrm{CD}_{3} \mathrm{OD}\right) \delta 108.5$ (anomeric), 97.8 (anomeric), 96.2 (anomeric), 95.5 (anomeric), 84.9, 84.5, 77.0, 76.9, 76.8, 73.7, 72.8, 71.4, 71.2, 69.3, 67.9, 64.8, 63.1, 62.1, $61.8,61.4,57.5,32.9,29.2$. 
Compound 3: Compound 3 was prepared as described for compound 1 using 3 c (30 mg, 0.04 $\mathrm{mmol})$, water $(6 \mathrm{~mL})$, and $10 \% \mathrm{Pd} / \mathrm{C}$ (cat.). The reaction mixture was filtered and freeze-dried to yield 3 (23 mg, 90\%) as a white solid. HRMS (ESI): m/z calcd for $\mathrm{C}_{25} \mathrm{H}_{48} \mathrm{~N}_{5} \mathrm{O}_{15}: 658.3147[\mathrm{M}+\mathrm{H}]^{+}$; found 658.3142. ${ }^{1} \mathrm{H}$ NMR $\left(400 \mathrm{MHz}, \mathrm{D}_{2} \mathrm{O}\right) \delta 5.88$ (ddd, J = 3.9 Hz, $1 \mathrm{H}, \mathrm{H}-1$ '), 5.48 (d, J = $3.9 \mathrm{~Hz}$, $1 \mathrm{H}, \mathrm{H}-1 "), 5.35$ (d, J = $\left.1.1 \mathrm{~Hz}, 1 \mathrm{H}, \mathrm{H}-1^{\prime \prime \prime}\right), 5.21$ (d, J = $8.6 \mathrm{~Hz}, 1 \mathrm{H}, \mathrm{H}-8$ '), 4.47 (dd, J = $2.5 \mathrm{~Hz}, 1 \mathrm{H}$, H-6'), 4.20 (dd, J = 4.7, 1.5 Hz, 1H, H-2'"), 4.16 (dd, J = 6.9, 4.9 Hz, 1H, H-3'"), $4.09-3.84$ (m, 8H, H-4, H-5, H-4', H-3", H-5", H-6", H-4'", H-5"'), 3.79 (dd, J = 12.4, 4.6 Hz, 1H, H-6"), 3.72 (dd, J = 9.6, $3.8 \mathrm{~Hz}, 1 \mathrm{H}, \mathrm{H}-2 "), 3.70-3.62\left(\mathrm{~m}, 4 \mathrm{H}, \mathrm{H}-6, \mathrm{H}-2^{\prime}, \mathrm{H}-5^{\prime}, \mathrm{H}-5^{\prime \prime \prime}\right), 3.59-3.46\left(\mathrm{~m}, 2 \mathrm{H}, \mathrm{H}-3, \mathrm{H}-\mathrm{7}^{\prime}\right)$, 3.39 - 3.26 (m, 2H, H-1, H-4"), 2.49 (ddd, J = 12.3, 4.1 Hz, 1H, H-2eq), $2.39-2.31$ (m, 1H, H3'eq), 2.05 (ddd, J = 11.8 Hz, 1H, H-3'ax), 1.87 (ddd, J = $12.6 \mathrm{~Hz}, 1 \mathrm{H}, \mathrm{H}-2 a x) .{ }^{13} \mathrm{C}$ NMR (125 MHz, $\left.\mathrm{D}_{2} \mathrm{O}\right) \delta 116.34$ (q, $\mathrm{J}=293, \mathrm{CF}_{3} \mathrm{COOH}$ ), 110.4 (anomeric), 94.7 (anomeric), 94.6 (anomeric), 93.3 (anomeric), 85.0, 82.6, 75.6, 75.3, 72.6, 70.3, 69.8, 69.4, 69.1, 68.4, 66.2, 65.6, 61.0, 60.4, 53.1, $52.2,49.8,48.5,48.0,28.3,26.8$. 
Scheme S3: Synthesis of compounds 4 and $5^{[a]}$
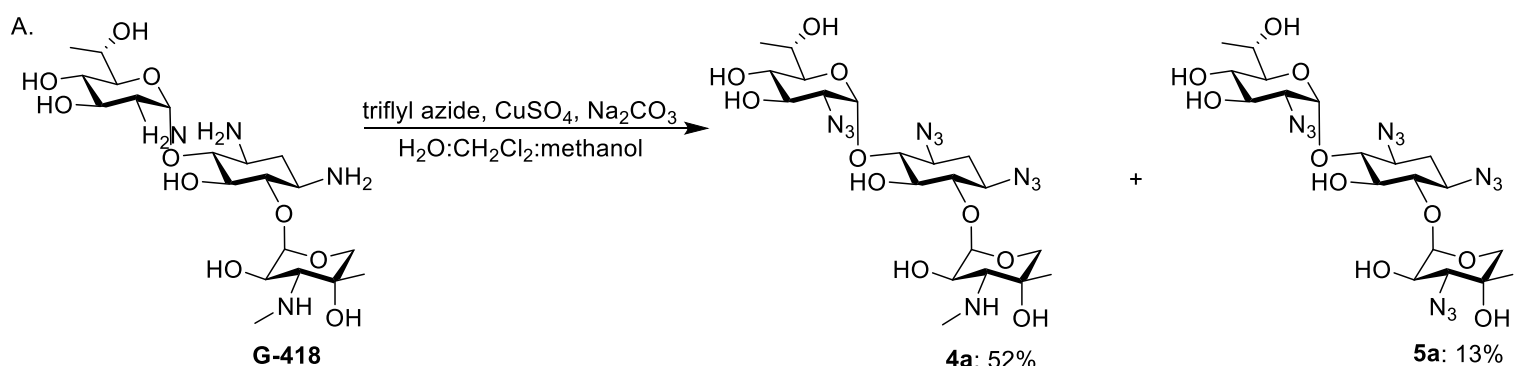
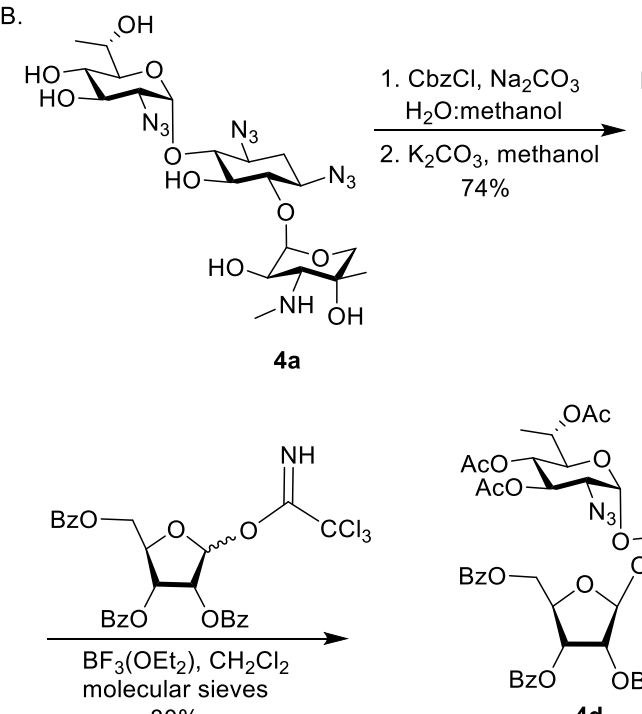

$80 \%$
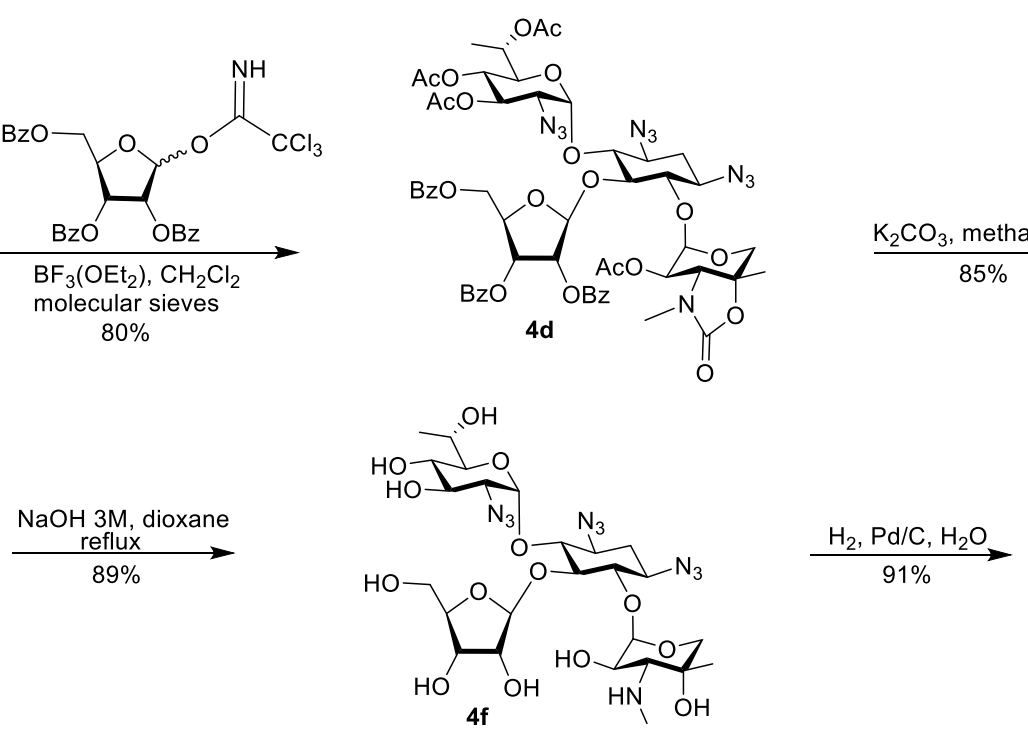
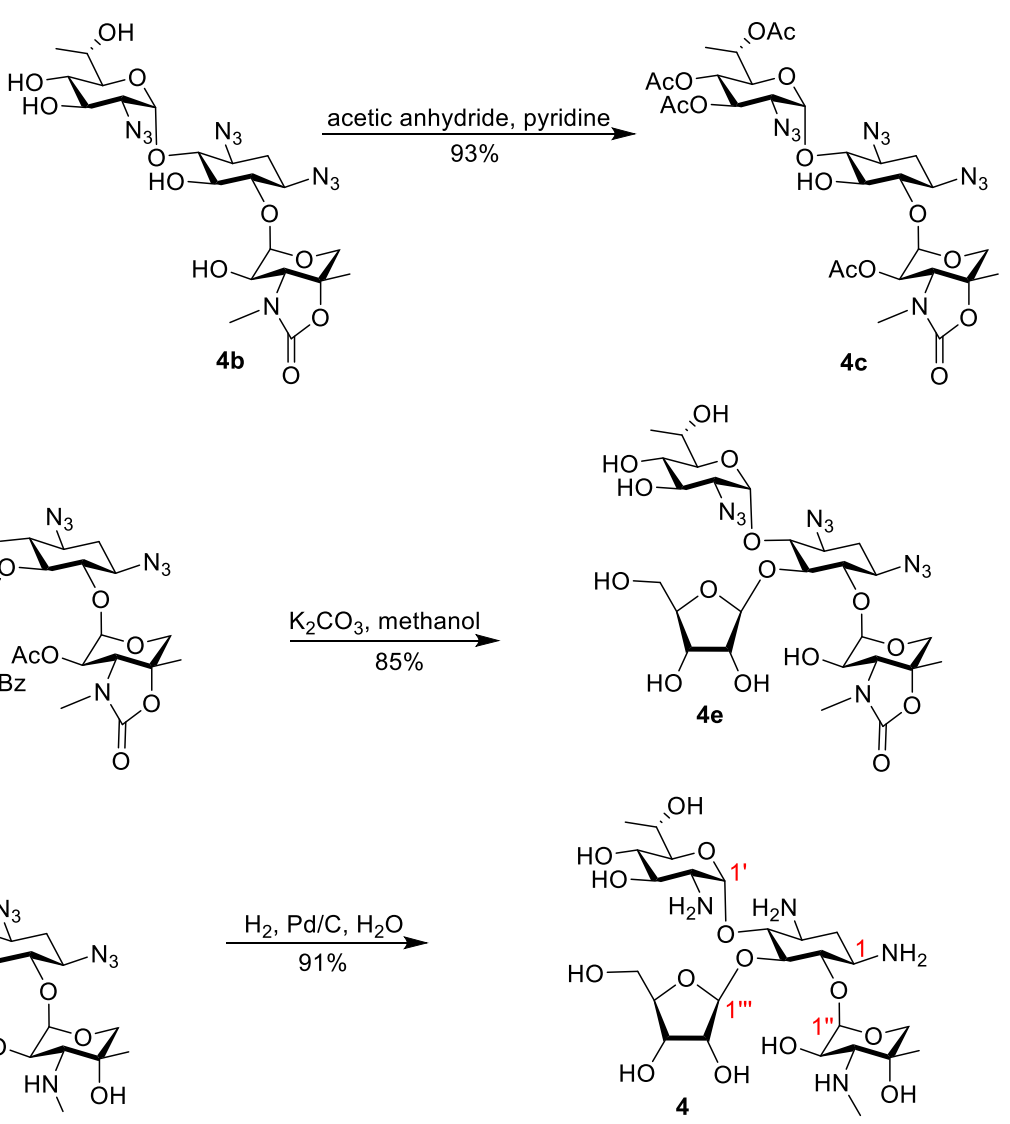

C.
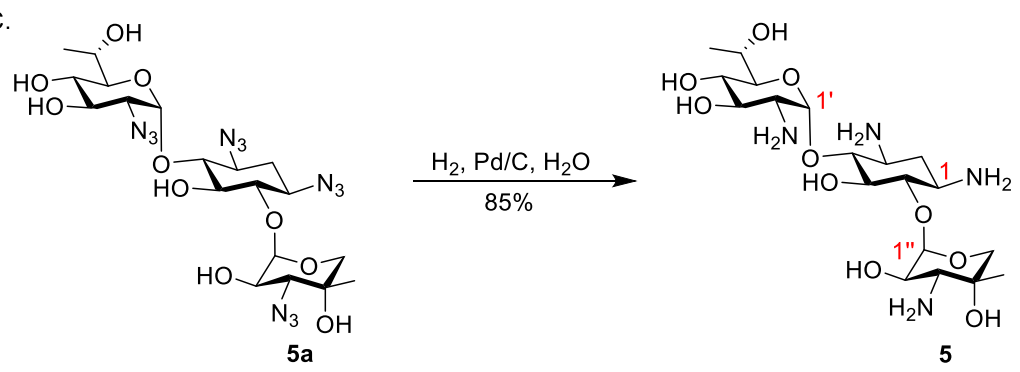

[a] Proton numbers are in red. 
Compounds 4a and 5a: Sodium azide $(3.94 \mathrm{~g}, 0.06 \mathrm{~mol})$ was dissolved in water (12 mL) and an equal volume of dichloromethane $(12 \mathrm{~mL})$ was added while stirring at room temperature. The resulting suspension was cooled to $0{ }^{\circ} \mathrm{C}$, and $\mathrm{Tf}_{2} \mathrm{O}(4.4 \mathrm{~mL}, 26.2 \mathrm{mmol})$ was added in 8 portions under vigorous stirring. The mixture was stirred at $0{ }^{\circ} \mathrm{C}$ for $3 \mathrm{~h}$ before sat. $\mathrm{NaHCO}_{3}(13 \mathrm{~mL})$ was added to quench the reaction. The organic layer was removed, and the aqueous layer was extracted with dichloromethane $(3 \mathrm{~mL})$. The organic layers were combined (triflyl azide solution) and kept at $0^{\circ} \mathrm{C}$ until needed. In a separate flask, G-418 sulfate $(2.0 \mathrm{~g}, 2.9 \mathrm{mmol}), \mathrm{NaHCO}_{3}(3.3 \mathrm{~g}$, $0.04 \mathrm{~mol})$, and $\mathrm{CuSO}_{4} \cdot 5 \mathrm{H}_{2} \mathrm{O}(86.5 \mathrm{mg}, 0.35 \mathrm{mmol})$ were dissolved in $\mathrm{H}_{2} \mathrm{O}(15 \mathrm{~mL})$ and cooled to 0 ${ }^{\circ} \mathrm{C}$. The triflyl azide solution was added dropwise to the reaction mixture at $0{ }^{\circ} \mathrm{C}$, followed by dropwise addition of methanol $(24 \mathrm{~mL})$. The reaction mixture was allowed to come to room temperature and was stirred overnight. Upon completion as shown by TLC (ammonia methanol/dichloromethane, $15: 85)$, butylamine $(0.4 \mathrm{~mL}, 4.35 \mathrm{mmol})$ was added to quench the excess $\mathrm{TfN}_{3}$. The solvent was removed by evaporation, and the crude product was purified by flash column chromatography $\left(\mathrm{SiO}_{2}\right.$; ammonia methanol/dichloromethane) to yield $4 \mathrm{a}$ (863 $\mathrm{mg}, 52 \%$ yield) and 5a (214 mg, 13\% yield) as white solids.

(4a): LRMS (ESI): $\mathrm{m} / \mathrm{z}$ calcd for $\mathrm{C}_{20} \mathrm{H}_{33} \mathrm{~N}_{10} \mathrm{O}_{10}: 573.24$ [M-H]; found 573.10. ${ }^{1} \mathrm{H}$ NMR $(400 \mathrm{MHz}$, $\left.\mathrm{CD}_{3} \mathrm{OD}\right) \delta 5.74\left(\mathrm{~d}, \mathrm{~J}=3.7 \mathrm{~Hz}, 1 \mathrm{H}, \mathrm{H}-1^{\prime}\right), 5.27\left(\mathrm{~d}, \mathrm{~J}=3.7 \mathrm{~Hz}, 1 \mathrm{H}, \mathrm{H}-1{ }^{\prime \prime}\right), 4.15(\mathrm{~d}, \mathrm{~J}=12.3 \mathrm{~Hz}, 1 \mathrm{H}$, H-5"), $4.08-4.00$ (m, 1H, H-6'), $3.99-3.88$ (m, 2H, H-3', H-5'), $3.85-3.77$ (m, 1H, H-2"), $3.71-$ $3.60(m, 2 H, H-3, H-5), 3.59-3.47(m, 2 H, H-1, H-4), 3.40-3.32(m, 2 H, H-6, H-4), 3.25(d, J=$ 12.3 Hz, 1H, H-5"), 3.07 (dd, J = 10.5, 3.8 Hz, 1H, H-2'), $2.80-2.70$ (m, 1H, H-3"), 2.67 (s, 3H, $\mathrm{NCH}_{3}$ ), $2.40-2.30$ (m, 1H, H-2eq), 1.52 (ddd, J = $\left.12.4 \mathrm{~Hz}, 1 \mathrm{H}, \mathrm{H}-2 \mathrm{ax}\right), 1.24$ (d, J = $6.5 \mathrm{~Hz}, 3 \mathrm{H}, 6$ '$\mathrm{CH}_{3}$ ), 1.21 (s, 3H, 4"-CH3). ${ }^{13} \mathrm{C}$ NMR (125 MHz, CD ${ }_{3} \mathrm{OD}$ ) $\delta 99.8$ (anomeric), 98.6 (anomeric), 81.9, $79.9,76.3,75.2,74.1,72.3,69.7,69.1,68.8,65.6,64.6,61.8,60.7,37.7,33.4,23.1,17.8$.

(5a): LRMS (ESI): $\mathrm{m} / \mathrm{z}$ calcd for $\mathrm{C}_{19} \mathrm{H}_{29} \mathrm{~N}_{12} \mathrm{O}_{10}$ : 585.21 [M-H]; found 585.13. ${ }^{1} \mathrm{H}$ NMR (400 MHz, $\left.\mathrm{CD}_{3} \mathrm{OD}\right) \delta 5.74\left(\mathrm{~d}, \mathrm{~J}=3.8 \mathrm{~Hz}, 1 \mathrm{H}, \mathrm{H}-1^{\prime}\right), 5.33(\mathrm{~d}, \mathrm{~J}=3.8 \mathrm{~Hz}, 1 \mathrm{H}, \mathrm{H}-1 "), 4.15(\mathrm{~d}, \mathrm{~J}=12.3 \mathrm{~Hz}, 1 \mathrm{H}$, H-5"), 4.07 - 3.89 (m, 4H, H-3', H-5', H-6' H-2"), 3.71 - 3.62 (m, 2H, H-3, H-5), $3.56-3.48$ (m, 3H, H-1, H-4, H-3"), 3.39 - 3.33 (m, 2H, H-6, H-4'), 3.25 (d, J = $\left.12.3 \mathrm{~Hz}, 1 \mathrm{H}, \mathrm{H}-5^{\prime \prime}\right), 3.07$ (dd, J = 10.5, 
$3.8 \mathrm{~Hz}, 1 \mathrm{H}, \mathrm{H}-2$ '), 2.35 (ddd, J = 12.1, 3.9 Hz, 1H, H-2eq), 1.52 (ddd, J = 12.4 Hz, 1H, H-2ax), 1.24 (d, J = $6.5 \mathrm{~Hz}, 3 \mathrm{H}, 6$ 6'- $\left.^{-} \mathrm{CH}_{3}\right), 1.19\left(\mathrm{~s}, 3 \mathrm{H}, 4 "-\mathrm{CH}_{3}\right) .{ }^{13} \mathrm{C} \mathrm{NMR}\left(100 \mathrm{MHz}, \mathrm{CD}_{3} \mathrm{OD}\right) \delta 99.8$ (anomeric), 98.6 (anomeric), 81.3, 79.9, 76.2, 75.2, 74.1, 72.8, 72.3, 69.8, 69.2, 68.6, 67.6, 64.6, 61.9, 60.7, $33.5,22.6,17.9$.

Compound 4b: Compound 4b was prepared as described for compound 1b using 4a (360 mg, $0.63 \mathrm{mmol}), \mathrm{Na}_{2} \mathrm{CO}_{3}(332 \mathrm{mg}, 3.13 \mathrm{mmol})$, and benzyl chloroformate $(0.3 \mathrm{~mL}, 1.9 \mathrm{mmol})$ in $75 \%$ methanol in water $(8 \mathrm{~mL})$. Reaction progress was monitored by TLC analysis (methanol/dichloromethane, 1:9), and after $12 \mathrm{~h}$ the solution was filtered with vacuum, and the filtrate was evaporated under reduced pressure. The crude was dissolved in $20 \mathrm{~mL}$ of methanol, and $\mathrm{K}_{2} \mathrm{CO}_{3}(522 \mathrm{mg}, 3.8 \mathrm{mmol})$ was added. The reaction mixture was stirred overnight at $40{ }^{\circ} \mathrm{C}$. Progress of the reaction was monitored by LRMS. The solvent was removed by evaporation, and the crude product was purified by flash column chromatography $\left(\mathrm{SiO}_{2}\right.$, methanol/dichloromethane) to yield $\mathbf{4 b}$ (278 $\mathrm{mg}, 74 \%$ yield over two steps) as a white solid. LRMS (ESI): m/z calcd for $\mathrm{C}_{21} \mathrm{H}_{31} \mathrm{~N}_{10} \mathrm{O}_{11}: 599.22[\mathrm{M}-\mathrm{H}]$; found 599.26. ${ }^{1} \mathrm{H}$ NMR (400 MHz, CD $\left.{ }_{3} \mathrm{OD}\right) \delta 5.76(\mathrm{~d}, \mathrm{~J}=3.8 \mathrm{~Hz}, 1 \mathrm{H}$, H-1'), 5.07 (d, J = 3.7 Hz, 1H, H-1"), 4.25 (d, J = 12.8 Hz, 1H, H-5"), 4.15 (dd, J = 3.9 Hz, 1H, H2"), $4.07-3.98\left(m, 1 \mathrm{H}, \mathrm{H}-6^{\prime}\right), 3.97-3.87\left(m, 2 \mathrm{H}, \mathrm{H}-3^{\prime}, \mathrm{H}-5^{\prime}\right), 3.71-3.45(m, 7 \mathrm{H}, \mathrm{H}-1, \mathrm{H}-3, \mathrm{H}-4$, H-5, H-6, H-3", H-5"), 3.36 (dd, J = 9.9, 8.8 Hz, 1H, H-4'), 3.06 (dd, J = 10.5, 3.8 Hz, 1H, H-2'), 2.92 (s, 3H, NCH$)_{3}$ ), 2.30 (ddd, J = 12.6, 4.3 Hz, 1H, H-2eq), 1.49 (ddd, J = $12.4 \mathrm{~Hz}, 1 \mathrm{H}, \mathrm{H}-2 \mathrm{ax}$ ), 1.40 (s, $3 \mathrm{H}, 4^{\prime \prime}-\mathrm{CH}_{3}$ ), 1.24 (d, J = 6.5 Hz, 3H, 6'-CH ). ${ }^{13} \mathrm{C}$ NMR (125 MHz, CD ${ }_{3} \mathrm{OD}$ ) $\delta$ 159.9, 98.6 (anomeric), 97.5 (anomeric), 83.3, 79.6, 79.6, 76.3, 75.2, 74.2, 72.2, 69.2, 67.2, 66.6, 64.8, 64.6, 61.5, 60.8, $33.2,30.4,23.4,17.9$.

Compound 4c: Compound 4c was prepared as described for compound 1c using 4b (280 mg, $0.47 \mathrm{mmol})$, acetic anhydride $(0.5 \mathrm{~mL}, 5.3 \mathrm{mmol})$, and dry pyridine $(5 \mathrm{~mL})$. Progress of the reaction was monitored by TLC analysis (ethyl acetate/petroleum ether, 1:1). Purification by flash column chromatography $\left(\mathrm{SiO}_{2}\right.$; ethyl acetate/petroleum ether,) gave $4 \mathbf{c}(335.4 \mathrm{mg}, 93 \%)$ as a white solid. LRMS (ESI): $\mathrm{m} / \mathrm{z}$ calcd for $\mathrm{C}_{29} \mathrm{H}_{40} \mathrm{~N}_{10} \mathrm{O}_{15} \mathrm{Cl}: 803.24[\mathrm{M}+\mathrm{Cl}]$; found 803.07. ${ }^{1} \mathrm{H}$ NMR $(400 \mathrm{MHz}$, $\left.\mathrm{CD}_{3} \mathrm{OD}\right) \delta 5.89\left(\mathrm{~d}, \mathrm{~J}=3.7 \mathrm{~Hz}, 1 \mathrm{H}, \mathrm{H}^{-1} \mathbf{1}^{\prime}\right), 5.45\left(\mathrm{dd}, \mathrm{J}=10.8,9.2 \mathrm{~Hz}, 1 \mathrm{H}, \mathrm{H}-3^{\prime}\right), 5.32-5.26(\mathrm{~m}, 2 \mathrm{H}$, 
H-1", H-2"), 5.02 - 4.92 (m, 2H, H-4', H-6'), 4.40 (dd, J = 10.5, 2.0 Hz, 1H, H-5'), 4.22 (d, J = 13.2 Hz, 1H, H-5"), 3.81 - 3.73 (m, 2H, H-3", H-5"), 3.67 - $3.56(m, 3 H, H-1, H-3, H-5), 3.52$ (dd, J = 17.4, 8.1 Hz, 1H, H-4), 3.48 - 3.39 (m, 2H, H-6, H-2'), 2.91 (s, 3H, NCH $H_{3}$, 2.35 (ddd, J = 12.7, 4.3 $\mathrm{Hz}, 1 \mathrm{H}, \mathrm{H}-2 \mathrm{eq}), 2.15$ (s, 3H, COCH$\left.H_{3}\right), 2.07$ (s, 3H, COCH$\left.H_{3}\right), 2.06\left(\mathrm{~s}, 3 \mathrm{H}, \mathrm{COCH}_{3}\right), 2.05(\mathrm{~s}, 3 \mathrm{H}$,

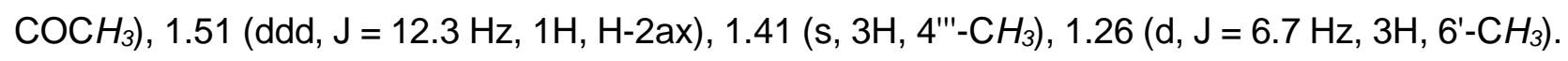
${ }^{13} \mathrm{C} \mathrm{NMR}\left(100 \mathrm{MHz}, \mathrm{CD}_{3} \mathrm{OD}\right) \delta 172.0,171.6,171.5,171.2,159.5,98.8$ (anomeric), 96.0 (anomeric), 83.7, 80.4, 79.4, 76.4, 71.4, 70.7, 70.0, 68.7, 66.0, 62.6, 61.9, 61.4, 60.5, 33.0, 30.7, 30.3, 22.9, $21.2,20.7,20.6,13.8$.

Compound 4d: Compound $\mathbf{4 d}$ was prepared as described for compound $\mathbf{1 d}$ using acceptor $\mathbf{4 c}$ (160 mg, $0.21 \mathrm{mmol}$ ), 2,3,5-tri-O-benzoyl-D-ribofuranosyl-trichloroacetimidate glycosyl donor ${ }^{3}$ (500 $\mathrm{mg}, 0.83 \mathrm{mmol})$, flame dried 4-Å molecular sieves $(1.5 \mathrm{~g})$, anhydrous dichloromethane (10 mL), and $\mathrm{BF}_{3} \cdot \mathrm{OEt}_{2}(40 \mu \mathrm{L})$. Progress of the reaction was monitored by TLC analysis (ethyl acetate/petroleum ether, 4:6). The crude was purified by flash chromatography $\left(\mathrm{SiO}_{2}\right.$; ethyl acetate/petroleum ether) to yield $\mathbf{4 d}(203 \mathrm{mg}, 80 \%)$ as a white solid. LRMS (ESI): $\mathrm{m} / \mathrm{z}$ calcd for $\mathrm{C}_{55} \mathrm{H}_{60} \mathrm{~N}_{10} \mathrm{O}_{22} \mathrm{Cl}: 1247.36$ [M+Cl]; found 1247.44. ${ }^{1} \mathrm{H}$ NMR $\left(500 \mathrm{MHz}, \mathrm{CD}_{3} \mathrm{OD}\right) \delta 8.21$ (dd, $\mathrm{J}=8.1$, $1.0 \mathrm{~Hz}, 2 \mathrm{H}, \mathrm{Bz}$ ), 8.07 (dd, J = 8.2, 1.1 Hz, 2H, Bz), 7.91 (dd, J = 8.2, $1.1 \mathrm{~Hz}, 2 \mathrm{H}, \mathrm{Bz}$ ), $7.68-7.63$ (m, 2H, Bz), $7.61-7.56(\mathrm{~m}, 1 \mathrm{H}, \mathrm{Bz}), 7.54-7.48$ (m, 4H, Bz), 7.39 (t, J = 7.9 Hz, 2H, Bz), 6.17 (dd, $\left.\mathrm{J}=7.1,4.8 \mathrm{~Hz}, 1 \mathrm{H}, \mathrm{H}-3^{\prime \prime \prime}\right), 5.94$ (d, J = 4.8 Hz, 1H, H-2"'), 5.85 (d, J = 4.0 Hz, 1H, H-1'), 5.62 (br s, $\left.1 \mathrm{H}, \mathrm{H}-1^{\prime \prime \prime}\right), 5.57$ (dd, J = 2.8 Hz, 1H, H-2"), 5.31 (dd, J = 10.6, 9.3 Hz, 1H, H-3'), 5.14 (dd, J = 12.1, $\left.2.8 \mathrm{~Hz}, 1 \mathrm{H}, \mathrm{H}-5^{\prime \prime \prime}\right), 5.04$ (d, J = 3.0 Hz, 1H, H-1"), 4.97 (qd, J = 6.7, 2.0 Hz, 1H, H-6' ), $4.91-4.87$ (m, 1H, H-4'), $4.66-4.60$ (m, 1H, H-4"'), 4.50 (dd, J = 12.1, 3.5 Hz, 1H, H-5'"), 4.38 (dd, J = 10.5, $\left.1.9 \mathrm{~Hz}, 1 \mathrm{H}, \mathrm{H}-5^{\prime}\right), 4.21$ (d, J = $\left.12.3 \mathrm{~Hz}, 1 \mathrm{H}, \mathrm{H}-5 "\right), 3.70$ (d, J = $\left.12.3 \mathrm{~Hz}, 1 \mathrm{H}, \mathrm{H}-5 "\right), 3.67$ - 3.62 (m, 2H, H-5, H-3"), 3.58 - 3.45 (m, 3H, H-1, H-3, H-2'), 3.16 (dd, J = $9.8 \mathrm{~Hz}, 1 \mathrm{H}, \mathrm{H}-4), 2.92(\mathrm{~s}, 3 \mathrm{H}$, $\mathrm{NCH}_{3}$ ), 2.83 (dd, J = 9.5 Hz, 1H, H-6), 2.30 (ddd, J = 8.2, $4.5 \mathrm{~Hz}, 1 \mathrm{H}, \mathrm{H}-2 \mathrm{eq}$ ), 2.09 (s, 3H, COCH$)_{3}$, $2.05\left(\mathrm{~s}, 3 \mathrm{H}, \mathrm{COCH}_{3}\right), 2.04$ (s, 3H, $\left.\mathrm{COCH}_{3}\right), 2.04$ (s, 3H, $\left.\mathrm{COCH}_{3}\right), 1.29$ (d, J = 6.6 Hz, 3H, 6'-CH $\mathrm{CH}_{3}$, 1.22 (s, 3H, 4"-CH3), 1.16 (ddd, J = $13.3 \mathrm{~Hz}, 1 \mathrm{H}, \mathrm{H}-2 \mathrm{ax}) .{ }^{13} \mathrm{C} \mathrm{NMR}\left(100 \mathrm{MHz}, \mathrm{CD}_{3} \mathrm{OD}\right.$ ) $\delta 172.1$, $171.5,171.2,167.6,167.0,134.9,134.8,134.4,131.4,130.7,130.4,129.9,129.7,129.6,108.6$ 
(anomeric), 98.0 (anomeric), 97.2 (anomeric), 83.2, 82.0, 81.0, 78.6, 77.6, 77.1, 72.8, 72.1, 71.2, 70.6, 70.0, 69.6, 65.9, 64.4, 64.0, 63.0, 61.8, 60.1, 32.8, 29.9, 23.3, 21.4, 20.7, 20.6, 13.7.

Compound 4e: compound $\mathbf{4 e}$ was prepared as described for compound 1e using $\mathbf{4 d}$ (184 mg, 0.15 $\mathrm{mmol}), \mathrm{K}_{2} \mathrm{CO}_{3}(42 \mathrm{mg}, 0.30 \mathrm{mmol})$, and methanol $(10 \mathrm{~mL})$. Progress of the reaction was monitored by TLC analysis (methanol/dichloromethane, 15:85). The crude was purified by flash chromatography $\left(\mathrm{SiO}_{2}\right.$; methanol/dichloromethane) to yield 4 e $(95 \mathrm{mg}, 85 \%)$ as a white solid. LRMS (ESI): m/z calcd for $\mathrm{C}_{26} \mathrm{H}_{39} \mathrm{~N}_{10} \mathrm{O}_{15}: 731.26$ [M-H]'; found 730.99. ${ }^{1} \mathrm{H} \mathrm{NMR}\left(500 \mathrm{MHz}, \mathrm{CD}_{3} \mathrm{OD}\right)$ $\delta 5.90\left(\mathrm{~d}, \mathrm{~J}=3.8 \mathrm{~Hz}, 1 \mathrm{H}, \mathrm{H}-1^{\prime}\right), 5.45$ (d, J = $\left.0.9 \mathrm{~Hz}, 1 \mathrm{H}, \mathrm{H}-1{ }^{\prime \prime}\right), 5.07$ (d, J = 3.0 Hz, 1H, H-1"), 4.26 (dd, J = 3.1 Hz, 1H, H-2"), 4.19 (d, J = $12.5 \mathrm{~Hz}, 1 \mathrm{H}, \mathrm{H}-5 "), 4.12$ (dd, J = 4.9, 1.1 Hz, 1H, H-2"'), $4.06-3.99$ (m, 2H, H-6', H-3"'), $3.96-3.90$ (m, 3H, H-3', H-5' H-4"'), 3.88 (dd, J = 8.2 Hz, 1H, H5), $3.84(\mathrm{dd}, \mathrm{J}=9.0 \mathrm{~Hz}, 1 \mathrm{H}, \mathrm{H}-4), 3.80$ (dd, J = 11.6, $\left.2.9 \mathrm{~Hz}, 1 \mathrm{H}, \mathrm{H}-5{ }^{\prime \prime}\right), 3.73-3.64(\mathrm{~m}, 4 \mathrm{H}, \mathrm{H}-3$, H-3", H-5", H-5"'), 3.64 - 3.57 (m, 2H, H-1, H-6), $3.38-3.33(\mathrm{~m}, 1 \mathrm{H}, \mathrm{H}-4$ '), 3.10 (dd, J = 10.5, 3.9 $\mathrm{Hz}, 1 \mathrm{H}, \mathrm{H}-2$ '), 2.89 (s, 3H, NCH$H_{3}$, 2.31 (ddd, J = 12.9, 8.7, $\left.4.4 \mathrm{~Hz}, 1 \mathrm{H}, \mathrm{H}-2 \mathrm{eq}\right), 1.50-1.43$ (m, 4H, H-2ax, 4"- $\left.\mathrm{CH}_{3}\right), 1.24\left(\mathrm{~d}, \mathrm{~J}=6.5 \mathrm{~Hz}, 3 \mathrm{H}, 66^{\prime}-\mathrm{CH}_{3}\right) .{ }^{13} \mathrm{C} \mathrm{NMR}\left(100 \mathrm{MHz}, \mathrm{CD}_{3} \mathrm{OD}\right) \delta$ 159.8, 110.4 (anomeric), 97.8 (anomeric), 97.4 (anomeric), 84.5, 82.3, 81.5, 78.8, 76.4, 75.4, 74.0, 72.4, 71.8, $68.9,68.8,65.9,65.5,64.5,64.1,61.9,61.1,32.7,30.1,23.8,17.6$.

Compound 4f: Compound $\mathbf{4 f}$ was prepared as described for compound 1f using $4 \mathrm{e}$ (80 mg, 0.12 $\mathrm{mmol})$ and $3.0 \mathrm{M}$ aqueous $\mathrm{NaOH}(1.5 \mathrm{~mL})$ in 1,4-dioxane $(6 \mathrm{~mL})$ at $90{ }^{\circ} \mathrm{C}$ overnight. Upon completion as shown by TLC analysis (ammonia methanol/dichloromethane, 2:8), the solvent was removed by evaporation, and the crude product was purified by flash column chromatography $\left(\mathrm{SiO}_{2}\right.$; ammonia methanol/dichloromethane) to yield $\mathbf{4 f}(69 \mathrm{mg}, 89 \%)$ as a white solid. LRMS (ESI): $\mathrm{m} / \mathrm{z}$ calcd for $\mathrm{C}_{25} \mathrm{H}_{41} \mathrm{~N}_{10} \mathrm{O}_{14}: 705.28[\mathrm{M}-\mathrm{H}]$; found 704.98. ${ }^{1} \mathrm{H}$ NMR $\left(500 \mathrm{MHz}, \mathrm{CD}_{3} \mathrm{OD}\right) \delta 5.63(\mathrm{~d}, \mathrm{~J}$ $\left.=3.7 \mathrm{~Hz}, 1 \mathrm{H}, \mathrm{H}-1^{\prime}\right), 5.33(\mathrm{~d}, \mathrm{~J}=3.6 \mathrm{~Hz}, 1 \mathrm{H}, \mathrm{H}-1 "), 5.29$ (d, J = 1.0 Hz, 1H, H-1"'), 4.13 (dd, J = 7.1, $5.2 \mathrm{~Hz}, 1 \mathrm{H}, \mathrm{H}-4), 4.11$ - 4.04 (m, 2H, H-6', H-5"), 4.01 - 3.96 (m, 3H, H-5, H-2", H-2"'), 3.96 - 3.92 (m, 1H, H-4'"), 3.92 - 3.86 (m, 2H, H-3', H-3"'), 3.86 - 3.74 (m, 5H, H-1, H-3, H-6, H-5', H-5"'), 3.70 (dd, J = 12.0, 5.7 Hz, 1H, H-5'"), 3.40 (d, J = 12.4 Hz, 1H, H-5"), $3.36-3.32$ (m, 1H, H-4'), 3.17 (dd, J = 10.4, 3.7 Hz, 1H, H-2'), 3.01 (d, J = 10.0 Hz, 1H, H-3"), 2.78 (s, 3H, NCH $H_{3}$, 2.39 (ddd, J = 
17.0, $5.6 \mathrm{~Hz}, 1 \mathrm{H}, \mathrm{H}-2 \mathrm{eq}), 1.63$ - 1.53 (m, 1H, H-2ax), 1.32 (s, 3H, 4"-CH $), 1.24$ (d, J = 6.5 Hz, 3H, 6'-CH3). ${ }^{13} \mathrm{C}$ NMR (125 MHz, CD ${ }_{3} \mathrm{OD}$ ) $\delta 109.7$ (anomeric), 99.5 (anomeric), 97.4 (anomeric), 84.7, 81.3, 79.8, 77.3, 76.4, 75.8, 73.8, 72.6, 71.6, 71.1, 69.0, 68.7, 68.3, 66.3, 64.6, 63.5, 60.3, 59.9, $36.5,31.9,22.9,17.1$.

Compound 4: Compound 4 was prepared as described for compound $\mathbf{1}$ using $\mathbf{4 f}$ (33 $\mathrm{mg}, 0.05$ $\mathrm{mmol})$, water $(6 \mathrm{~mL})$, and $10 \% \mathrm{Pd} / \mathrm{C}$ (cat.). The reaction mixture was filtered and freeze-dried to yield 4 (27 mg, 91\%) as a white solid. HRMS (ESI): m/z calcd for $\mathrm{C}_{25} \mathrm{H}_{49} \mathrm{~N}_{4} \mathrm{O}_{14}: 629.3245[\mathrm{M}+\mathrm{H}]^{+}$; found 629.3243. ${ }^{1} \mathrm{H}$ NMR $\left(500 \mathrm{MHz}, \mathrm{D}_{2} \mathrm{O}\right) \delta 5.55(\mathrm{~d}, \mathrm{~J}=3.7 \mathrm{~Hz}, 1 \mathrm{H}, \mathrm{H}-1$ '), $5.32(\mathrm{~d}, \mathrm{~J}=2.4 \mathrm{~Hz}, 1 \mathrm{H}$, H-1'"), 5.23 (d, J = 3.6 Hz, 1H, H-1"), 4.29 (qd, J = 6.5, 2.4 Hz, 1H, H-6'), 4.23 (dd, J = 10.9, 3.6 $\mathrm{Hz}, 1 \mathrm{H}, \mathrm{H}-2 "), 4.19$ (dd, J = 6.2, $\left.4.9 \mathrm{~Hz}, 1 \mathrm{H}, \mathrm{H}-3{ }^{\prime \prime \prime}\right), 4.16$ (dd, J = 4.8, $\left.2.5 \mathrm{~Hz}, 1 \mathrm{H}, \mathrm{H}-2^{\prime \prime \prime}\right), 4.10-4.04$ (m, 3H, H-4, H-5, H-4"'), 4.03 - 3.97 (m, 2H, H-6, H-5"), 3.98 - 3.89 (m, 2H, H-5', H-5"'), 3.89 3.85 (m, 1H, H-3'), 3.70 (dd, J = 12.4, 6.7 Hz, 1H, H-5"'), 3.63 - 3.54 (m, 4H, H-1, H-3, H-3", H-5"), $3.54-3.47$ (m, 2H, H-2', H-4'), 2.93 (s, 3H, NCH N , 2.50 (ddd, J = 12.7, 4.2 Hz, 1H, H-2eq), 1.89 (ddd, J = 12.7 Hz, 1H, H-2ax), 1.38 (s, 3H, 4"- $\left.\mathrm{CH}_{3}\right), 1.24$ (d, J = 6.6 Hz, 3H, 6'-CH $\mathrm{CH}_{3}{ }^{13} \mathrm{C}$ NMR (125 $\left.\mathrm{MHz}, \mathrm{D}_{2} \mathrm{O}\right) \delta 163.9$ (d, $J=35 \mathrm{~Hz}, \mathrm{CF}_{3} \mathrm{COOH}$ ), 116.2 (q, $J=292, \mathrm{CF}_{3} \mathrm{COOH}$ ), 108.3 (anomeric), 100.7 (anomeric), 96.8 (anomeric), 82.9, 82.5, 82.3, 81.7, 75.8, 74.3, 69.9, 69.7, 69.4, 69.4, 68.0, $66.5,65.0,63.1,62.0,53.7,49.3,48.9,34.3,28.6,20.8,14.3$.

Compound 5: Compound 5 was prepared as described for compound 1 using 5 a (39 mg, 0.07 $\mathrm{mmol})$, water $(6 \mathrm{~mL})$, and $10 \% \mathrm{Pd} / \mathrm{C}$ (cat.). The reaction mixture was filtered and freeze-dried to yield 5 (27 mg, 85\%) as a white solid. HRMS (ESI): m/z calcd for $\mathrm{C}_{19} \mathrm{H}_{39} \mathrm{~N}_{4} \mathrm{O}_{10}: 438.2656[\mathrm{M}+\mathrm{H}]^{+}$; found 438.2660. ${ }^{1} \mathrm{H}$ NMR $\left(500 \mathrm{MHz}, \mathrm{D}_{2} \mathrm{O}\right) \delta 5.59(\mathrm{~d}, \mathrm{~J}=4.0 \mathrm{~Hz}, 1 \mathrm{H}, \mathrm{H}-1$ '), $5.12(\mathrm{~d}, \mathrm{~J}=3.7 \mathrm{~Hz}, 1 \mathrm{H}$, H-1"), 4.26 (qd, J = 6.5, 2.3 Hz, 1H, H-6'), 4.11 (dd, J = 10.8, 3.7 Hz, 1H, H-2"), 4.02 (d, J = 12.8 $\left.\mathrm{Hz}, 1 \mathrm{H}, \mathrm{H}-5^{\prime \prime}\right), 3.93-3.75$ (m, 5H, H-4, H-5, H-6, H-3', H-5'), $3.62-3.44$ (m, 6H, H-1, H-3, H-2', H4', H-3", H-5"), 2.53 (ddd, J = 12.7, 4.2 Hz, 1H, H-2eq), 1.90 (ddd, J = 12.7 Hz, 1H, H-2ax), 1.29 (s, 3H, 4"- $\left.\mathrm{CH}_{3}\right), 1.23\left(\mathrm{~d}, \mathrm{~J}=6.6 \mathrm{~Hz}, 3 \mathrm{H}, 66^{\prime}-\mathrm{CH}_{3}\right) .{ }^{13} \mathrm{C} \mathrm{NMR}\left(125 \mathrm{MHz}, \mathrm{D}_{2} \mathrm{O}\right) \delta 101.1$ (anomeric), 97.9 (anomeric), 83.5, 82.1, 75.4, 73.5, 70.1, 69.5, 69.1, 67.7, 66.2, 65.3, 55.8, 54.1, 49.5, 48.9, 28.1, 20.5, 14.5 . 
Scheme S4: Synthesis of compounds 6 and $7^{[a]}$

A.
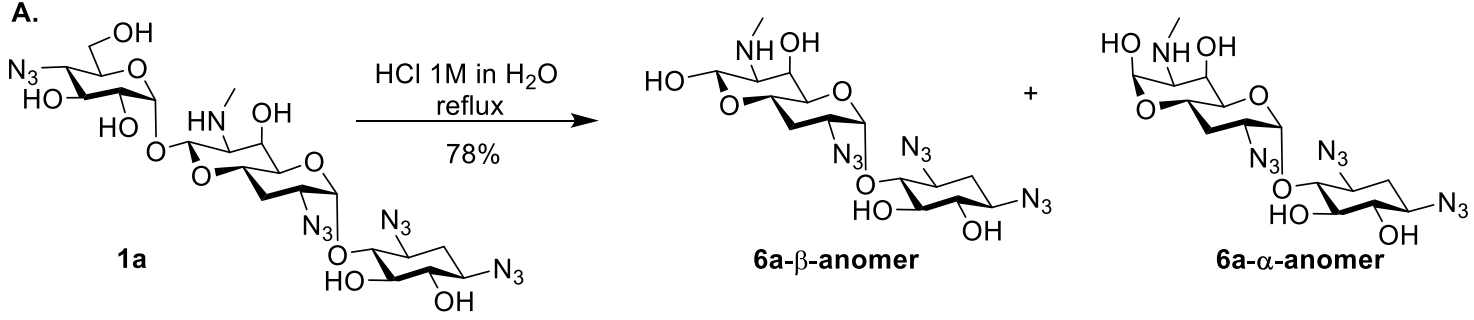

6a- $\beta$-anomer

6a- $\alpha$-anomer
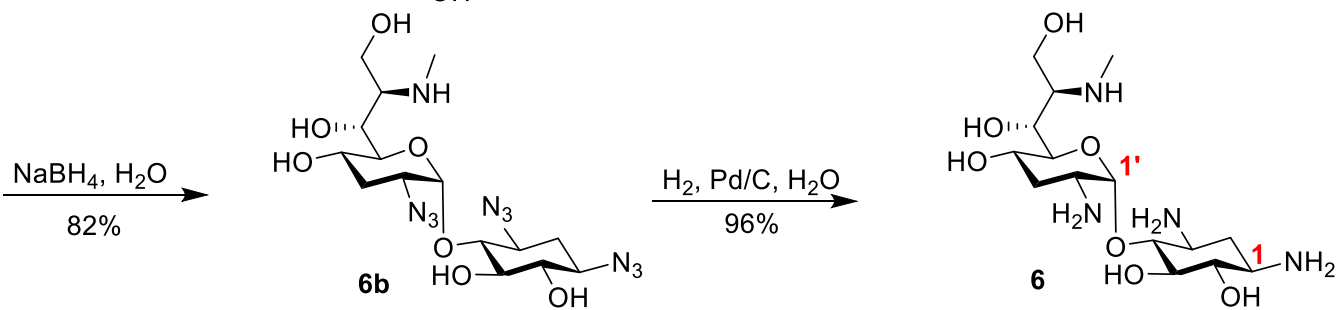

B.
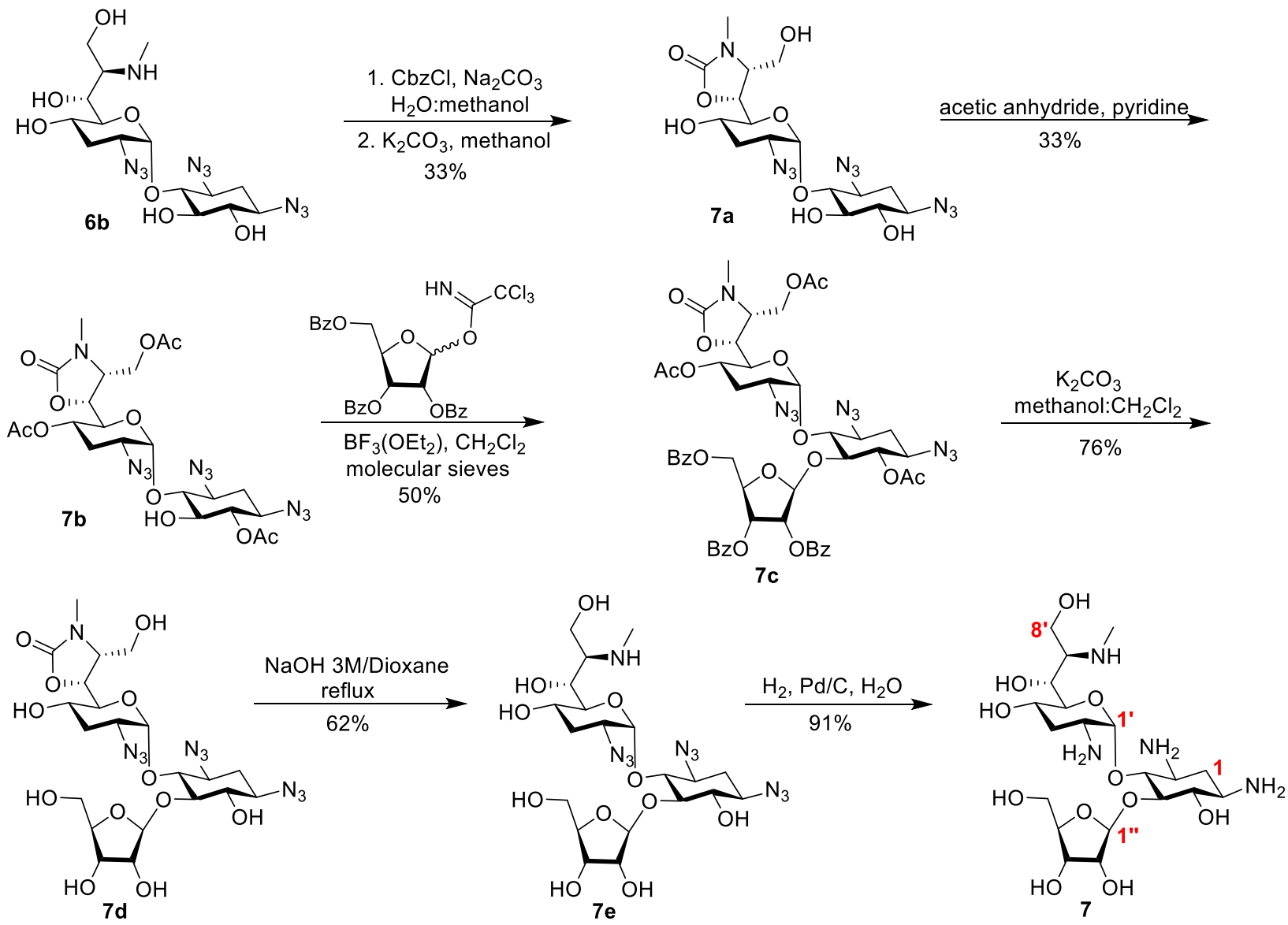

[a] Proton numbers are in red.

Compound 6a: Compound $1 \mathrm{a}^{1}(2.0 \mathrm{~g}, 3.11 \mathrm{mmol})$ was added to $50 \mathrm{~mL}$ of aqueous $1 \mathrm{M} \mathrm{HCl}$ and the mixture was heated to $90^{\circ} \mathrm{C}$ and stirred for $12 \mathrm{~h}$. Reaction progress was monitored by TLC analysis (ammonia methanol/dichloromethane, 2:8), and the crude was purified by flash 
chromatography $\left(\mathrm{SiO}_{2}\right.$; ammonia methanol/dichloromethane) to yield $6 \mathbf{a}(1.1 \mathrm{~g}, 78 \%)$ as a yellowish solid. LRMS (ESI): $\mathrm{m} / \mathrm{z}$ calcd for $\mathrm{C}_{15} \mathrm{H}_{25} \mathrm{~N}_{10} \mathrm{O}_{7}: 457.19[\mathrm{M}+\mathrm{H}]^{+}$; found 457.35. ${ }^{1} \mathrm{H} \mathrm{NMR}(400 \mathrm{MHz}$, $\left.\mathrm{CD}_{3} \mathrm{OD}\right) \delta 5.63(\mathrm{~d}, \mathrm{~J}=3.5 \mathrm{~Hz}, 1 \mathrm{H}, \mathrm{H}-1$ ' $\beta$ anomer), 5.61 (d, J = $3.5 \mathrm{~Hz}, 1 \mathrm{H}, \mathrm{H}-1$ ' $\alpha$ anomer), 5.13 (d, J = 3.6 Hz, 1H, H-8' $\beta$ anomer), 4.80 (d, J = 8.2 Hz, 1H, H-8' a anomer), $4.25-4.21(\mathrm{~m}, 1 \mathrm{H}, \mathrm{H}-$ 6' $\beta$ anomer), $4.22-4.18$ (m, 1H, H-6' $\alpha$ anomer), 4.10 (ddd, J = 11.0, 4.6 Hz, 1H, H-4' $\beta$ anomer), 3.88 - 3.81 (m, 2H, H-5' $\alpha$ anomer, $\mathrm{H}^{-4}$ ' $^{\mathrm{m}}$ anomer), 3.79 (dd, J = 10.1, 2.6 Hz, 1H, H-5' $\beta$ anomer), $3.56-3.46(\mathrm{~m}, 6 \mathrm{H}, \mathrm{H}-3, \mathrm{H}-4, \mathrm{H}-5$, both anomers), $3.46-3.36(\mathrm{~m}, 2 \mathrm{H}, \mathrm{H}-1$ both anomers $), 3.29-$ $3.18(\mathrm{~m}, 4 \mathrm{H}, \mathrm{H}-6, \mathrm{H}-2$ ', both anomers), 2.59 (dd, J = 6.5, 3.3 Hz, 1H, H-7' $\beta$ anomer), $2.43(\mathrm{~m}, 6 \mathrm{H}$, $\mathrm{NCH}_{3}$ both anomers), 2.35 (dd, J = 8.2, $2.8 \mathrm{~Hz}, 1 \mathrm{H}, \mathrm{H}-7^{\prime}$ a anomer), $2.29-2.20$ (m, 2H, H-2eq both anomers), $2.20-1.97$ (m, 4H, H-3'eq, H-3'ax, both anomers), $1.48-1.35$ (m, 2H, H-2ax both anomers). ${ }^{13} \mathrm{C}$ NMR (125 MHz, $\mathrm{CD}_{3} \mathrm{OD}$ ) $\delta 99.1$ (anomeric), 99.1 (anomeric), 95.8 (anomeric), 93.7 (anomeric), 80.7, 80.6, 77.9, 77.93, 72.1, 71.7, 67.5, 67.5, 66.4, 65.6, 61.7, 61.6, 61.2, 61.2, 60.7, $58.1,57.8,33.4,33.3,32.3,29.5,29.4$.

Compound 6b: Compound $6 \mathrm{~b}$ was prepared as previously reported ${ }^{4}$ with some modifications. A solution of $6 \mathrm{a}(424 \mathrm{mg}, 0.93 \mathrm{mmol})$ in water $(8 \mathrm{~mL})$ was adjusted to $\mathrm{pH} 9.0(1 \mathrm{M} \mathrm{NaOH})$ and cooled to $5^{\circ} \mathrm{C} . \mathrm{NaBH}_{4}(60 \mathrm{mg}, 1.59 \mathrm{mmol})$ was added, and the mixture was stirred overnight at $5^{\circ} \mathrm{C}$. Upon completion (as shown by TLC analysis, ammonia methanol/dichloromethane, $2: 8$ ), the mixture was adjusted to $\mathrm{pH} 1(1 \mathrm{M} \mathrm{HCl})$, and the solvent was removed by evaporation. The crude product was purified by flash column chromatography $\left(\mathrm{SiO}_{2}\right.$ : ammonia methanol/dichloromethane,) to yield $\mathbf{6 b}$ (350 mg, 82\%) as a yellowish solid. LRMS (ESI): $\mathrm{m} / \mathrm{z}$ calcd for $\mathrm{C}_{15} \mathrm{H}_{27} \mathrm{~N}_{10} \mathrm{O}_{7}: 459.21[\mathrm{M}+\mathrm{H}]^{+}$; found 459.34. ${ }^{1} \mathrm{H}$ NMR (400 MHz, $\left.\mathrm{CD}_{3} \mathrm{OD}\right) \delta 5.78(\mathrm{~d}, \mathrm{~J}=3.4 \mathrm{~Hz}, 1 \mathrm{H}, \mathrm{H}-1$ '), $4.22(\mathrm{dd}, \mathrm{J}=6.2,3.1 \mathrm{~Hz}, 1 \mathrm{H}$, H-6'), 4.14 (dd, J = 12.4, 3.5 Hz, 1H, H-8'), $3.96-3.84$ (m, 2H, H-5', H-8'), 3.79 (ddd, J = 10.1, 4.8 $\left.\mathrm{Hz}, 1 \mathrm{H}, \mathrm{H}-4^{\prime}\right), 3.62-3.50$ (m, 3H, H-3, H-4, H-5), 3.51 - 3.40 (m, 2H, H-1, H-7'), 3.37 - 3.31 (m, 1H, H-6), 3.24 (ddd, J = 12.6, 4.1 Hz, 1H, H-2'), 2.81 (s, 3H, NCH $), 2.24$ (ddd, J = 8.1, 3.7 Hz, 1H, H-2eq), 2.19 - 2.01 (m, 2H, H-3'ax, H-3'eq), 1.53 - 1.36 (m, 1H, H-2ax). ${ }^{13} \mathrm{C}$ NMR (125 MHz, $\mathrm{CD}_{3} \mathrm{OD}$ ) $\delta 97.4$ (anomeric), 79.5, 78.2, 78.1, 73.3, 73.0, 67.4, 63.7, 61.8, 61.5, 60.1, 57.4, 33.4, 33.3, 31.6. 
Compound 6: Compound 6 was prepared as described for compound 1 using $6 \mathrm{~b}$ (30 mg, 0.06 $\mathrm{mmol})$, water $(6 \mathrm{~mL})$, and $10 \% \mathrm{Pd} / \mathrm{C}$ (cat.). The reaction mixture was filtered and freeze-dried to yield 6 (24 mg, 96\%) as a white solid. HRMS (ESI): m/z calcd for $\mathrm{C}_{15} \mathrm{H}_{33} \mathrm{~N}_{4} \mathrm{O}_{7}: 381.2349[\mathrm{M}+\mathrm{H}]^{+}$; found 381.2344. ${ }^{1} \mathrm{H}$ NMR (400 MHz, $\left.\mathrm{D}_{2} \mathrm{O}\right) \delta 5.51\left(\mathrm{~d}, \mathrm{~J}=3.2 \mathrm{~Hz}, 1 \mathrm{H}, \mathrm{H}-1^{\prime}\right), 4.50$ (dd, J = 6.4, 3.2 $\left.\mathrm{Hz}, 1 \mathrm{H}, \mathrm{H}-6^{\prime}\right), 4.15-4.04$ (m, 2H, H-5', H-8'), 3.96 - 3.81 (m, 3H, H-4, H-4', H-8'), 3.77 - 3.64 (m, $\left.2 \mathrm{H}, \mathrm{H}-5, \mathrm{H}-2^{\prime}\right), 3.63-3.49\left(\mathrm{~m}, 3 \mathrm{H}, \mathrm{H}-3, \mathrm{H}-6, \mathrm{H}-7^{\prime}\right), 3.41-3.29(\mathrm{~m}, 1 \mathrm{H}, \mathrm{H}-1), 2.83(\mathrm{~s}, 3 \mathrm{H}, \mathrm{NCH})_{3}$, 2.52 (ddd, J = 12.3, 8.5, 4.1 Hz, 1H, H-2eq), 2.37 (ddd, J = 11.8, 8.0, 4.3 Hz, 1H, H-3'eq), 1.99 (ddd, J = 11.6 Hz, 1H, H-3'ax), 1.87 (ddd, J = 12.6 Hz, 1H, H-2ax). $\left.{ }^{13} \mathrm{C} \mathrm{NMR} \mathrm{(125} \mathrm{MHz,} \mathrm{D}{ }_{2} \mathrm{O}\right) \delta$ 95.6 (anomeric), 80.9, 76.1, 74.5, 72.4, 65.0, 63.3, 61.0, 57.0, 49.6, 48.8, 47.9, 30.9, 30.2, 28.3.

Compound 7a: Compound 7a was prepared as described for compound $\mathbf{1 b}$ with minor modifications. 6b (600 mg, $1.3 \mathrm{mmol}), \mathrm{Na}_{2} \mathrm{CO}_{3}(700 \mathrm{mg}, 6.6 \mathrm{mmol})$, and benzyl chloroformate $(0.7$ $\mathrm{mL}, 3.9 \mathrm{mmol}$ ) were stirred in $17 \mathrm{~mL}$ mixture of $75 \%$ methanol in water. Progress of the reaction was monitored by TLC analysis (methanol/dichloromethane, 1:9). After $12 \mathrm{~h}$ the solvent was evaporated under reduced pressure, and the crude was transferred through silica with $4 \%$ of methanol in dichloromethane. The solvent was evaporated, and the crude was dissolved in $15 \mathrm{~mL}$ of methanol, and $\mathrm{K}_{2} \mathrm{CO}_{3}(610 \mathrm{mg}, 4.4 \mathrm{mmol})$ was added. The reaction mixture was stirred overnight at $40^{\circ} \mathrm{C}$. Upon completion as shown by TLC analysis (methanol/dichloromethane, 1:9), the solvent was removed by evaporation, and the crude product was purified by flash column chromatography $\left(\mathrm{SiO}_{2}\right.$; methanol/dichloromethane) to yield $7 \mathrm{a}(200 \mathrm{mg}, 33 \%$ yield over two steps) as a white solid. LRMS (ESI): m/z calcd for $\mathrm{C}_{16} \mathrm{H}_{23} \mathrm{~N}_{10} \mathrm{O}_{8}: 483.17$ [M-H]'; found 482.99. ${ }^{1} \mathrm{H}$ NMR (400 MHz, $\left.\mathrm{CD}_{3} \mathrm{OD}\right)$ $\delta 5.69\left(\mathrm{~d}, \mathrm{~J}=3.4 \mathrm{~Hz}, 1 \mathrm{H}, \mathrm{H}-1^{\prime}\right), 4.52\left(\mathrm{dd}, \mathrm{J}=8.8,6.1 \mathrm{~Hz}, 1 \mathrm{H}, \mathrm{H}-8^{\prime}\right), 4.33$ (dd, J = 9.1 Hz, 1H, H-8'), 4.15 (dd, J = 5.3, 1.2 Hz, 1H, H-6'), 4.06 (ddd, J = 9.2, 6.1, 1.2 Hz, 1H, H-7'), 3.89 (dd, J = 9.7, 5.3 $\left.\mathrm{Hz}, 1 \mathrm{H}, \mathrm{H}-5^{\prime}\right), 3.66$ (ddd, J = 10.0, 4.7 Hz, 1H, H-4'), $3.56-3.46(\mathrm{~m}, 3 \mathrm{H}, \mathrm{H}-3, \mathrm{H}-4, \mathrm{H}-5), 3.45-3.36$ (m, $1 \mathrm{H}, \mathrm{H}-1), 3.30-3.22(\mathrm{~m}, 1 \mathrm{H}, \mathrm{H}-6), 3.17$ (ddd, J = 8.0, $4.3 \mathrm{~Hz}, 1 \mathrm{H}, \mathrm{H}-2$ '), $2.86(\mathrm{~s}, 3 \mathrm{H}, \mathrm{NCH})_{3}$, 2.24 (ddd, J = 13.0, 4.4 Hz, 1H, H-2eq), 2.17 - 1.99 (m, 2H, H-3'eq, H-3'ax), 1.42 (ddd, J = 12.3 $\mathrm{Hz}, 1 \mathrm{H}, \mathrm{H}-2 \mathrm{ax}) .{ }^{13} \mathrm{C}$ NMR (100 MHz, $\left.\mathrm{CD}_{3} \mathrm{OD}\right) \delta$ 161.4, 97.1 (anomeric), 79.5, 78.1, 78.0, 73.8, 69.5, $68.4,64.4,61.8,61.4,60.0,57.4,33.4,31.9,29.0$. 
Compound 7b: Compound 7b was prepared as described for compound 1c using 7a (410 mg, $0.71 \mathrm{mmol})$, acetic anhydride $(0.85 \mathrm{~mL}, 9.0 \mathrm{mmol})$, and dry pyridine $(7 \mathrm{~mL})$. Progress of the reaction was monitored by TLC analysis (ethyl acetate/petroleum ether, 1:1). Purification by flash column chromatography $\left(\mathrm{SiO}_{2}\right.$ : ethyl acetate/petroleum ether) gave $7 \mathbf{b}(166 \mathrm{mg}, 33 \%)$ as a white solid. LRMS (ESI): $\mathrm{m} / \mathrm{z}$ calcd for $\mathrm{C}_{22} \mathrm{H}_{30} \mathrm{~N}_{10} \mathrm{O}_{11} \mathrm{Cl}: 645.18[\mathrm{M}+\mathrm{Cl}]$; found $645.15 .{ }^{1} \mathrm{H}$ NMR $(400 \mathrm{MHz}$, $\left.\mathrm{CD}_{3} \mathrm{OD}\right) \delta 5.73\left(\mathrm{~d}, \mathrm{~J}=3.4 \mathrm{~Hz}, 1 \mathrm{H}, \mathrm{H}^{-1} \mathbf{1}^{\prime}\right), 5.28-5.24\left(\mathrm{~m}, 1 \mathrm{H}, \mathrm{H}-6^{\prime}\right), 4.99-4.93\left(\mathrm{~m}, 1 \mathrm{H}, \mathrm{H}-4^{\prime}\right), 4.58$ (dd, J = 9.1, $\left.5.7 \mathrm{~Hz}, 1 \mathrm{H}, \mathrm{H}-8^{\prime}\right), 4.39-4.33\left(\mathrm{~m}, 1 \mathrm{H}, \mathrm{H}-8^{\prime}\right), 4.30-4.24\left(\mathrm{~m}, 2 \mathrm{H}, \mathrm{H}-5^{\prime}, \mathrm{H}-7^{\prime}\right), 3.58-$ 3.40 (m, 4H, H-1, H-3, H-5, H-6), 3.29 - 3.24 (m, 2H, H-4, H-2'), 2.75 (s, 3H, NCH $H_{3}, 2.29-2.15$ (m, 3H, H-2eq, H-3'ax, H-3'eq), 2.12 (s, 3H, $\left.\mathrm{COCH}_{3}\right), 2.09$ (s, 3H, $\left.\mathrm{COCH}_{3}\right), 2.02\left(\mathrm{~s}, 3 \mathrm{H}, \mathrm{COCH}_{3}\right)$, $1.44-1.35$ (m, 1H, H-2ax). ${ }^{13} \mathrm{C}$ NMR (100 MHz, $\left.\mathrm{CD}_{3} \mathrm{OD}\right) \delta 172.0,171.7,171.6,97.7$ (anomeric), 80.0, 77.8, 75.9, 72.4, 68.8, 67.8, 65.2, 61.1, 59.3, 58.1, 56.8, 33.1, 29.2, 20.9, 20.8, 20.7.

Compound 7c: Compound 7c was prepared as described for compound 1d using acceptor $\mathbf{7 b}$ (166 mg, $0.27 \mathrm{mmol}$ ), 2,3,5-tri-O-benzoyl-D-ribofuranosyl-trichloroacetimidate glycosyl donor ${ }^{3}$ (540 $\mathrm{mg}, 0.89 \mathrm{mmol})$, flame dried 4-Å molecular sieves $(1.7 \mathrm{~g})$, anhydrous dichloromethane (10 mL), and $\mathrm{BF}_{3} \cdot \mathrm{OEt}_{2}(40 \mu \mathrm{L})$. Progress of the reaction was monitored by TLC analysis (ethyl acetate/petroleum ether, 6:4). The crude was purified by flash chromatography $\left(\mathrm{SiO}_{2}\right.$ : ethyl acetate/petroleum ether) to yield $7 \mathrm{c}(141 \mathrm{mg}, 50 \%)$ as a white solid. LRMS (ESI): $\mathrm{m} / \mathrm{z}$ calcd for $\mathrm{C}_{48} \mathrm{H}_{50} \mathrm{~N}_{10} \mathrm{O}_{18} \mathrm{Cl}: 1089.30$ [M+Cl]; found 1089.29. ${ }^{1} \mathrm{H} \mathrm{NMR}\left(400 \mathrm{MHz}, \mathrm{CD}_{3} \mathrm{OD}\right) \delta 8.18$ (dd, J = 8.5, $1.6 \mathrm{~Hz}, 2 \mathrm{H}, \mathrm{Bz}$ ), 7.95 (dd, J = 8.3, 1.2 Hz, 2H, Bz), 7.90 (dd, J = 8.5, 1.4 Hz, 2H, Bz), $7.71-7.55$ (m, 5H, Bz), 7.46 (t, J = 7.8 Hz, 2H, Bz), 7.39 (t, J = 7.9 Hz, 2H, Bz), 5.85 (dd, J = 6.4, 4.8 Hz, 1H, H-3"), $5.75-5.69$ (m, 2H, H-1', H-2"), 5.64 (d, J = 1.7 Hz, 1H, H-1"), 5.16 (d, J = 1.5 Hz, 1H, H-6'), 5.00 (dd, J = 12.3, $\left.2.9 \mathrm{~Hz}, 1 \mathrm{H}, \mathrm{H}-5{ }^{\prime}\right), 4.82\left(\mathrm{dd}, \mathrm{J}=10.7,4.9 \mathrm{~Hz}, 1 \mathrm{H}, \mathrm{H}-4{ }^{\prime}\right), 4.76-4.70(\mathrm{~m}, 1 \mathrm{H}, \mathrm{H}-$ 4"), 4.42 - 4.34 (m, 2H, H-8', H-5"), 4.24 (dd, J = 10.4, $2.3 \mathrm{~Hz}, 1 \mathrm{H}, \mathrm{H}-5$ '), $4.15-3.93$ (m, 4H, H-5, H-6, H-7', H-8'), 3.67 - 3.54 (m, 2H, H-1, H-3), 3.41 - 3.32 (m, 2H, H-4, H-2'), 2.73 (s, 3H, NCH , $^{2}$ 2.31 (ddd, J = 12.4, 8.5, 4.1 Hz, 1H, H-2eq), 2.25 (s, 3H, COCH , $_{3}, 2.23-2.15$ (m, 2H, H-3'eq, H3'ax), 2.10 (s, 3H, $\left.\mathrm{COCH}_{3}\right), 2.06\left(\mathrm{~s}, 3 \mathrm{H}, \mathrm{COCH}_{3}\right), 1.28-1.24(\mathrm{~m}, 1 \mathrm{H}, \mathrm{H}-2 \mathrm{ax}) .{ }^{13} \mathrm{C}$ NMR $(100 \mathrm{MHz}$, $\left.\mathrm{CD}_{3} \mathrm{OD}\right) \delta 171.9,171.7,171.6,167.6,166.9,166.7,160.9,134.9,134.7,134.6,131.1,130.7$, 
130.7, 129.8, 129.7, 129.6, 108.6 (anomeric), 96.1 (anomeric), 82.1, 80.7, 78.5, 76.2, 76.0, 72.5, $72.1,68.6,67.7,65.0,64.3,61.0,59.6,58.0,57.5,32.9,30.7,29.6,29.2,21.3,20.8,20.8$.

Compound 7d: compound 7d was prepared as described for compound 1e using 7c (141 mg, $0.13 \mathrm{mmol}), \mathrm{K}_{2} \mathrm{CO}_{3}(37 \mathrm{mg}, 0.27 \mathrm{mmol})$, and methanol/dichloromethane (8:1, $\left.9 \mathrm{~mL}\right)$. Progress of the reaction was monitored by TLC analysis (methanol/dichloromethane, 1:9). The crude was purified by flash chromatography $\left(\mathrm{SiO}_{2}\right.$ : methanol/dichloromethane) to yield $\mathbf{7 d}(60.7 \mathrm{mg}, 76 \%)$ as a white solid. (ESI): $\mathrm{m} / \mathrm{z}$ calcd for $\mathrm{C}_{21} \mathrm{H}_{31} \mathrm{~N}_{10} \mathrm{O}_{12}: 615.21$ [M-H]; found 615.13. ${ }^{1} \mathrm{H} \mathrm{NMR}(500 \mathrm{MHz}$, $\left.\mathrm{CD}_{3} \mathrm{OD}\right) \delta 5.77\left(\mathrm{~d}, \mathrm{~J}=3.4 \mathrm{~Hz}, 1 \mathrm{H}, \mathrm{H}-1^{\prime}\right), 5.34(\mathrm{~d}, \mathrm{~J}=1.2 \mathrm{~Hz}, 1 \mathrm{H}, \mathrm{H}-1 "), 4.51$ (dd, J = 8.8, $6.2 \mathrm{~Hz}$, $\left.1 \mathrm{H}, \mathrm{H}-8^{\prime}\right), 4.33\left(\mathrm{dd}, \mathrm{J}=9.1 \mathrm{~Hz}, 1 \mathrm{H}, \mathrm{H}-8^{\prime}\right), 4.15\left(\mathrm{~d}, \mathrm{~J}=5.2 \mathrm{~Hz}, 1 \mathrm{H}, \mathrm{H}-6^{\prime}\right), 4.11$ (dd, J = 6.6, $4.8 \mathrm{~Hz}$, 1H, H-3"), $4.09-4.03$ (m, 2H, H-7', H-2"), $3.95-3.88$ (m, 2H, H-5', H-4"), 3.76 (dd, J = 11.8, 3.3 Hz, 1H, H-5"), $3.71-3.65$ (m, 3H, H-4, H-5, H-4'), 3.62 (dd, J = 11.8, 5.4 Hz, 1H, H-5"), $3.60-3.53$ (m, 1H, H-3), $3.52-3.46(\mathrm{~m}, 1 \mathrm{H}, \mathrm{H}-6), 3.42$ (ddd, J = 10.2, $4.9 \mathrm{~Hz}, 1 \mathrm{H}, \mathrm{H}-1), 3.17$ (ddd, J = 8.1, $4.4 \mathrm{~Hz}, 1 \mathrm{H}, \mathrm{H}-2$ ) , 2.87 (s, 3H, NCH ), 2.21 (ddd, J = 12.8, $4.4 \mathrm{~Hz}, 1 \mathrm{H}, \mathrm{H}-2 \mathrm{eq}$ ), $2.15-2.04$ (m, 2H, H-3'eq, H-3'ax), 1.42 (ddd, J = $12.4 \mathrm{~Hz}, 1 \mathrm{H}, \mathrm{H}-2 \mathrm{ax}) .{ }^{13} \mathrm{C}$ NMR (125 MHz, CD ${ }_{3} \mathrm{OD}$ ) $\delta$ 161.4, 109.3 (anomeric), 96.3 (anomeric), 85.2, 84.5, 77.2, 76.9, 76.3, 73.9, 71.6, 69.4, 68.3, 64.5, 63.6, 62.0, $61.9,60.1,57.3,33.1,32.0,29.0$.

Compound 7e: Compound 7e was prepared as described for compound 1f using 7d (130 mg, $0.21 \mathrm{mmol})$ and $3.0 \mathrm{M}$ aqueous $\mathrm{NaOH}(2 \mathrm{~mL})$ in 1,4-dioxane $(4 \mathrm{~mL})$ at $90{ }^{\circ} \mathrm{C}$ overnight. Upon completion as shown by TLC analysis (ammonia methanol/dichloromethane, 2:8), the solvent was removed by evaporation, and the crude product was purified by flash column chromatography $\left(\mathrm{SiO}_{2}\right.$; ammonia methanol/dichloromethane) to yield $7 \mathrm{e}(77 \mathrm{mg}, 62 \%)$ as a white solid. $(\mathrm{ESI}): \mathrm{m} / \mathrm{z}$ calcd for $\mathrm{C}_{20} \mathrm{H}_{33} \mathrm{~N}_{10} \mathrm{O}_{11}: 589.23[\mathrm{M}-\mathrm{H}]$; found 589.17. ${ }^{1} \mathrm{H}$ NMR $\left(500 \mathrm{MHz}, \mathrm{CD}_{3} \mathrm{OD}\right) \delta 5.84(\mathrm{~d}, \mathrm{~J}=3.4$ $\left.\mathrm{Hz}, 1 \mathrm{H}, \mathrm{H}-1^{\prime}\right), 5.36$ (d, J = $\left.1.2 \mathrm{~Hz}, 1 \mathrm{H}, \mathrm{H}-1^{\prime \prime}\right), 4.19$ (dd, J = 6.2, $\left.2.9 \mathrm{~Hz}, 1 \mathrm{H}, \mathrm{H}-6^{\prime}\right), 4.15-4.10$ (m, 2H, H-8', H-3"), 4.07 (dd, J = 4.6, 1.2 Hz, 1H, H-2"), 3.95 - 3.85 (m, 3H, H-5', H-8', H-4"), 3.78 3.74 (m, 2H, H-4', H-5"), $3.73-3.68$ (m, 1H, H-5), 3.65 - 3.59 (m, 3H, H-4, H-6, H-5"), 3.51 - 3.41 (m, 3H, H-1, H-3, H-7'), 3.23 (ddd, J = 8.3, 3.7 Hz, 1H, H-2'), 2.80 (s, 3H, NCH3), 2.25 - 2.08 (m, 3H, H-2eq, H-3'eq, H-3'ax), 1.41 (ddd, J = $12.4 \mathrm{~Hz}, 1 \mathrm{H}, \mathrm{H}-2 \mathrm{ax}) .{ }^{13} \mathrm{C}$ NMR (100 MHz, $\left.\mathrm{CD}_{3} \mathrm{OD}\right) \delta$ 
109.1 (anomeric), 96.3 (anomeric), 85.2, 84.6, 77.2, 76.9, 76.3, 72.5, 72.1, 71.6, 69.0, 63.5, 63.4, $62.0,61.9,58.8,57.2,33.2,32.3,31.9$.

Compound 7: Compound 7 was prepared as described for compound 1 using $7 e$ (24 mg, 0.04 $\mathrm{mmol})$, water $(6 \mathrm{~mL})$, and $10 \% \mathrm{Pd} / \mathrm{C}$ (cat.). The reaction mixture was filtered and freeze-dried to yield 7 (19 mg, 91\%) as a white solid. HRMS (ESI): m/z calcd for $\mathrm{C}_{20} \mathrm{H}_{41} \mathrm{~N}_{4} \mathrm{O}_{11}: 513.2772[\mathrm{M}+\mathrm{H}]^{+}$; found 513.2771. ${ }^{1} \mathrm{H}$ NMR (400 MHz, $\left.\mathrm{D}_{2} \mathrm{O}\right) \delta 5.49(\mathrm{~d}, \mathrm{~J}=3.6 \mathrm{~Hz}, 1 \mathrm{H}, \mathrm{H}-1$ '), $5.21(\mathrm{~d}, \mathrm{~J}=1.4 \mathrm{~Hz}, 1 \mathrm{H}$, H-1"), 4.38 (dd, J = 4.1, 3.0 Hz, 1H, H-6'), $4.11-4.04$ (m, 2H, H-2", H-3"), $4.02-3.88$ (m, 4H, H4, H-5', H-8', H-4"), 3.86 - 3.74 (m, 4H, H-5, H-4', H-8', H-5"), 3.66 - 3.55 (m, 3H, H-6, H-2', H-5"), 3.50 (ddd, J = 10.4, 4.5 Hz, 1H, H-3), $3.43-3.36$ (m, 1H, H-7'), 3.27 (ddd, J = 12.4, $4.1 \mathrm{~Hz}, 1 \mathrm{H}, \mathrm{H}-$ 1), $2.72\left(\mathrm{~s}, 3 \mathrm{H}, \mathrm{NCH}_{3}\right.$ ), 2.41 (ddd, J = 12.5, $4.2 \mathrm{~Hz}, 1 \mathrm{H}, \mathrm{H}-2 \mathrm{eq}$ ), 2.24 (ddd, J = 12.2, $4.2 \mathrm{~Hz}, 1 \mathrm{H}, \mathrm{H}-$ 3'eq), 1.95 - 1.73 (m, 2H, H-2ax, H-3'ax). ${ }^{13} \mathrm{C}$ NMR (100 MHz, D $\left.2 \mathrm{O}\right) \delta 163.1$ (d, J = $35 \mathrm{~Hz}$, $\mathrm{CF}_{3} \mathrm{COOH}$ ), 116.5 (q, $\mathrm{J}=293, \mathrm{CF}_{3} \mathrm{COOH}$ ), 110.3 (anomeric), 94.9 (anomeric), 84.1, 82.9, 78.4, $76.5,75.2,72.3,69.2,65.3,63.3,61.2,61.1,57.1,49.8,49.0,47.7,31.2,30.0,28.1$. 


\section{Scheme S5: Synthesis of compounds 8 and $9^{[a]}$}
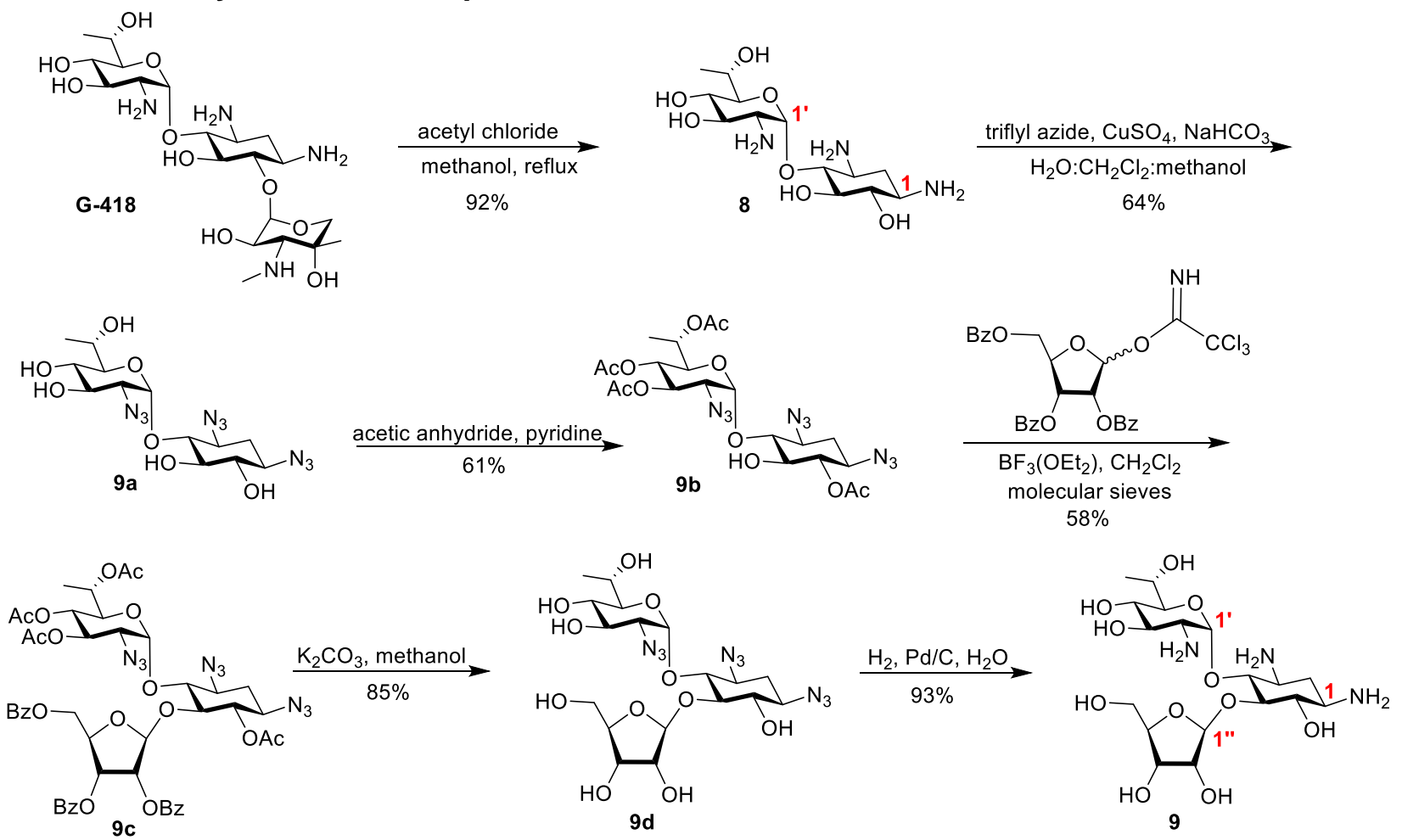

[a] Proton numbers are in red.

Compound 8: Compound 8 was prepared as previously reported. ${ }^{5}$ Briefly, acetyl chloride $(12 \mathrm{~mL}$, $0.17 \mathrm{~mol})$ was added dropwise to anhydrous methanol $(25 \mathrm{~mL})$ at $0{ }^{\circ} \mathrm{C}$. After $15 \mathrm{~min}$ of stirring, $\mathrm{G}$ 418 sulfate $(2.0 \mathrm{~g}, 2.8 \mathrm{mmol})$ was added, and the reaction was heated to reflux and stirred overnight. Upon completion as shown by TLC analysis (100\% ammonia methanol), the solvent was removed by evaporation, and the crude product was purified by flash column chromatography $\left(\mathrm{SiO}_{2}\right)$. The column was washed with dichloromethane, a mixture of methanol/dichloromethane (1:1), and $5 \%$ ammonium hydroxide solution (25\% in water) in methanol to yield 8 (899 $\mathrm{mg}, 92 \%)$ as a yellowish solid. HRMS (ESI): $\mathrm{m} / \mathrm{z}$ calcd for $\mathrm{C}_{13} \mathrm{H}_{28} \mathrm{~N}_{3} \mathrm{O}_{7}: 338.1927[\mathrm{M}+\mathrm{H}]^{+}$; found 338.1923. ${ }^{1} \mathrm{H}$ $\operatorname{NMR}\left(500 \mathrm{MHz}, \mathrm{D}_{2} \mathrm{O}\right) \delta 5.56$ (d, J = 3.9 Hz, 1H, H-1'), 4.25 (qd, J = 6.6, $\left.2.4 \mathrm{~Hz}, 1 \mathrm{H}, \mathrm{H}-6^{\prime}\right), 3.93$ (dd, $\left.\mathrm{J}=10.2,2.3 \mathrm{~Hz}, 1 \mathrm{H}, \mathrm{H}-5^{\prime}\right), 3.91-3.85\left(\mathrm{~m}, 1 \mathrm{H}, \mathrm{H}-3^{\prime}\right), 3.73-3.64(\mathrm{~m}, 2 \mathrm{H}, \mathrm{H}-4, \mathrm{H}-5), 3.57(\mathrm{dd}, \mathrm{J}=$ $9.2 \mathrm{~Hz}, 1 \mathrm{H}, \mathrm{H}-6), 3.46$ (dd, J = 10.1, $\left.9.1 \mathrm{~Hz}, 1 \mathrm{H}, \mathrm{H}-4^{\prime}\right), 3.42-3.34\left(\mathrm{~m}, 2 \mathrm{H}, \mathrm{H}-3, \mathrm{H}-2^{\prime}\right), 3.32-3.26$ (m, 1H, H-1), 2.41 (ddd, J = 12.7, 4.3 Hz, 1H, H-2eq), 1.74 (ddd, J = 12.6 Hz, 1H, H-2ax), 1.25 (d, 
$\left.\mathrm{J}=6.6 \mathrm{~Hz}, 3 \mathrm{H}, 6{ }^{\prime}-\mathrm{CH}_{3}\right) .{ }^{13} \mathrm{C}$ NMR $\left(125 \mathrm{MHz}, \mathrm{D}_{2} \mathrm{O}\right) \delta 97.9$ (anomeric), 83.3, 75.1, 74.9, 72.9, 70.4, $70.1,65.5,54.4,50.0,49.1,29.9,14.6$.

Compound 9a: Compound 9a was prepared as previously reported, with minor modifications. ${ }^{5}$ Sodium azide $(2.6 \mathrm{~g}, 0.04 \mathrm{~mol})$ was dissolved in water $(7 \mathrm{~mL})$, and an equal volume of dichloromethane $(7 \mathrm{~mL})$ was added while stirring at room temperature. The resulting suspension was cooled to $0^{\circ} \mathrm{C}$ and triflic anhydride $(3.33 \mathrm{~mL}, 19.8 \mathrm{mmol})$ was added dropwise under vigorous stirring. The mixture was stirred at $0{ }^{\circ} \mathrm{C}$ for $3 \mathrm{~h}$ before cold sat. $\mathrm{NaHCO}_{3}(7 \mathrm{~mL})$ was added to quench the reaction. The organic layer was removed, and the aqueous layer was extracted with dichloromethane $(2 \mathrm{~mL})$. The organic layers were combined (triflyl azide solution) and kept at $0{ }^{\circ} \mathrm{C}$ until needed. In a separate flask, compound 8 (556 mg, $1.7 \mathrm{mmol}), \mathrm{NaHCO}_{3}(1.7 \mathrm{~g}, 0.02 \mathrm{~mol})$, and $\mathrm{CuSO}_{4} \cdot 5 \mathrm{H}_{2} \mathrm{O}(31.6 \mathrm{mg}, 0.20 \mathrm{mmol})$ were dissolved in $\mathrm{H}_{2} \mathrm{O}(10 \mathrm{~mL})$, and triflyl azide solution was added dropwise to the reaction mixture followed by dropwise addition of methanol (33 $\mathrm{mL})$. The reaction mixture was stirred at room temperature overnight. Upon completion as showed by TLC (ethyl acetate/petroleum ether, 9:1), butylamine $(0.3 \mathrm{~mL}, 3.1 \mathrm{mmol})$ was added to quench the excess $\mathrm{TfN}_{3}$. The solvent was removed by evaporation, and the crude product was purified by flash column chromatography $\left(\mathrm{SiO}_{2}\right.$ : ethyl acetate/petroleum ether) to yield $9 \mathrm{a}$ ( $440 \mathrm{mg}, 64 \%$ yield) as a white solid. LRMS (ESI): m/z calcd for $\mathrm{C}_{13} \mathrm{H}_{20} \mathrm{~N}_{9} \mathrm{O}_{7}: 414.15[\mathrm{M}-\mathrm{H}]$; found 414.25. ${ }^{1} \mathrm{H}$ NMR (500 $\left.\mathrm{MHz}, \mathrm{CD}_{3} \mathrm{OD}\right) \delta 5.72\left(\mathrm{~d}, \mathrm{~J}=3.7 \mathrm{~Hz}, 1 \mathrm{H}, \mathrm{H}-1^{\prime}\right), 4.02\left(\mathrm{qd}, \mathrm{J}=10.5,5.2 \mathrm{~Hz}, 1 \mathrm{H}, \mathrm{H}-6^{\prime}\right), 3.96-3.88(\mathrm{~m}$, $\left.2 \mathrm{H}, \mathrm{H}-3^{\prime}, \mathrm{H}^{-5}\right), 3.56-3.45$ (m, 3H, H-1, H-3, H-5), $3.44-3.33\left(\mathrm{~m}, 2 \mathrm{H}, \mathrm{H}-4, \mathrm{H}-4^{\prime}\right), 3.25$ (dd, J = 9.2 $\mathrm{Hz}, 1 \mathrm{H}, \mathrm{H}-6), 3.07$ (dd, J = 10.5, 3.7 Hz, 1H, H-2'), 2.21 (ddd, J = 13.2, 3.8 Hz, 1H, H-2eq), $1.43-$ $1.35(\mathrm{~m}, 1 \mathrm{H}, \mathrm{H}-2 \mathrm{ax}), 1.24\left(\mathrm{~d}, \mathrm{~J}=6.7 \mathrm{~Hz}, 3 \mathrm{H}, 6 \mathrm{6}^{\prime}-\mathrm{CH}_{3}\right) .{ }^{13} \mathrm{C} \mathrm{NMR}\left(125 \mathrm{MHz}, \mathrm{CD}_{3} \mathrm{OD}\right) \delta 98.6$ (anomeric), 80.0, 77.9, 77.9, 75.2, 74.2, 72.3, 69.2, 64.6, 61.7, 61.1, 33.3, 30.7, 18.0

Compound 9b: Compound 9b was prepared as described for compound 1c using 9a (100 mg, $0.24 \mathrm{mmol})$, acetic anhydride $(0.2 \mathrm{~mL}, 2.1 \mathrm{mmol})$, and dry pyridine $(2 \mathrm{~mL})$. Reaction progress was monitored by TLC analysis (ethyl acetate/petroleum ether, 4:6). Purification by flash column chromatography $\left(\mathrm{SiO}_{2}\right.$ : ethyl acetate/petroleum ether) gave $9 \mathrm{~b}(85.4 \mathrm{mg}, 61 \%)$ as a white solid. LRMS (ESI): m/z calcd for $\mathrm{C}_{22} \mathrm{H}_{30} \mathrm{~N}_{9} \mathrm{O}_{13}$ : 628.20 [M+CHOO]-; found 628.35. ${ }^{1} \mathrm{H}$ NMR (500 MHz, 
$\left.\mathrm{CD}_{3} \mathrm{OD}\right) \delta 5.85$ (d, J = 3.7 Hz, 1H, H-1'), 5.44 (dd, J = 10.8, 9.2 Hz, 1H, H-3'), $5.02-4.92(\mathrm{~m}, 2 \mathrm{H}$, H-4', H-6'), $4.84-4.77$ (m, 1H, H-6), 4.40 (dd, J = 10.5, 2.1 Hz, 1H, H-5'), 3.74 (dd, J = 9.4 Hz, 1H, H-5), 3.69 - 3.59 (m, 2H, H-1, H-3), 3.55 (dd, J = 9.7 Hz, 1H, H-4), 3.39 (dd, J = 10.9, 3.7 Hz, 1H, H-2'), 2.34 (ddd, J = 12.8, 4.5 Hz, 1H, H-2eq), 2.13 (s, 3H, COCH $H_{3}, 2.06$ (s, 3H, COCH $\mathrm{COC}_{3}, 2.06$ (s, 3H, $\mathrm{COCH}_{3}$ ), 2.05 (s, 3H, $\mathrm{COCH}_{3}$ ), 1.51 (ddd, J = $\left.12.5 \mathrm{~Hz}, 1 \mathrm{H}, \mathrm{H}-2 \mathrm{ax}\right), 1.26$ (d, J = 6.7 Hz, 3H, 6'$\left.\mathrm{CH}_{3}\right) .{ }^{13} \mathrm{C} \mathrm{NMR}\left(100 \mathrm{MHz}, \mathrm{CDCl}_{3}\right) \delta 170.6,170.2,170.1,170.0,98.5$ (anomeric), 82.6, 75.2, 74.6, $71.2,70.9,69.2,68.8,61.6,58.4,57.9,32.0,21.0,20.8,20.7,20.7,13.9$.

Compound 9c: Compound 9c was prepared as described for compound 1d using acceptor 9b (200 mg, $0.34 \mathrm{mmol}$ ), 2,3,5-tri-O-benzoyl-D-ribofuranosyl-trichloroacetimidate glycosyl donor ${ }^{3}$ (700 $\mathrm{mg}, 1.15 \mathrm{mmol})$, flame dried 4-Å molecular sieves $(1.7 \mathrm{~g})$, anhydrous dichloromethane (10 mL), and $\mathrm{BF}_{3} \cdot \mathrm{OEt}_{2}(40 \mu \mathrm{L})$. Progress of the reaction was monitored by TLC analysis (ethyl acetate/petroleum ether, 3:7). The crude was purified by flash chromatography $\left(\mathrm{SiO}_{2}\right.$; ethyl acetate/petroleum ether) to yield $9 \mathrm{c}(204 \mathrm{mg}, 58 \%)$ as a white solid. LRMS (ESI): $\mathrm{m} / \mathrm{z}$ calcd for $\mathrm{C}_{47} \mathrm{H}_{49} \mathrm{~N}_{9} \mathrm{O}_{18} \mathrm{Cl}: 1062.29[\mathrm{M}+\mathrm{Cl}] ;$ found 1062.66. ${ }^{1} \mathrm{H} \mathrm{NMR}\left(500 \mathrm{MHz}, \mathrm{CD}_{3} \mathrm{OD}\right) \delta 8.19$ (dd, J = 8.9, 1.6 Hz, 2H, Bz), 7.95 (dd, J = 8.2, 1.1 Hz, 2H, Bz), 7.89 (dd, J = 8.2, 1.1 Hz, 2H, Bz), $7.69-7.55$ (m, 5H, Bz), 7.45 (t, J = 7.8 Hz, 2H, Bz), 7.38 (t, J = 7.9 Hz, 2H, Bz), 5.84 (dd, J = 6.9, 4.7 Hz, 1H, H-3"), 5.81 (d, J = 3.9 Hz, 1H, H-1'), 5.70 (dd, J = 4.6, $1.1 \mathrm{~Hz}, 1 \mathrm{H}, \mathrm{H}-2 "), 5.61(\mathrm{~d}, \mathrm{~J}=1.0 \mathrm{~Hz}, 1 \mathrm{H}$, H-1"), 5.31 (dd, J = 10.6, 9.4 Hz, 1H, H-3'), 5.11 (dd, J = 12.4, 2.9 Hz, 1H, H-5"), 4.93 (qd, J = 6.6, $\left.1.8 \mathrm{~Hz}, 1 \mathrm{H}, \mathrm{H}-6^{\prime}\right), 4.84-4.80$ (m, 1H, H-4'), $4.72-4.63\left(\mathrm{~m}, 2 \mathrm{H}, \mathrm{H}-6, \mathrm{H}-4{ }^{\prime \prime}\right), 4.39-4.27$ (m, 2H, H5', H-5"), 3.90 (dd, J = 9.3 Hz, 1H, H-5), 3.60 - 3.48 (m, 2H, H-1, H-3), 3.45 (dd, J = 10.7, 3.9 Hz,

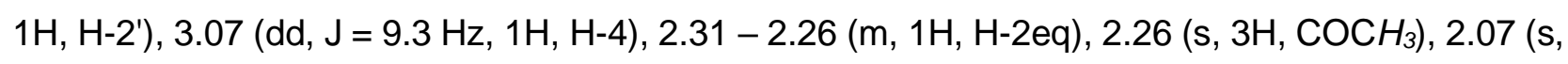
$\left.3 \mathrm{H}, \mathrm{COCH}_{3}\right), 2.05\left(\mathrm{~s}, 3 \mathrm{H}, \mathrm{COCH}_{3}\right), 2.04\left(\mathrm{~s}, 3 \mathrm{H}, \mathrm{COCH}_{3}\right), 1.23\left(\mathrm{~d}, \mathrm{~J}=6.7 \mathrm{~Hz}, 3 \mathrm{H}, 6^{\prime}-\mathrm{CH}_{3}\right), 1.20-$ $1.11(\mathrm{~m}, 1 \mathrm{H}, \mathrm{H}-2 \mathrm{ax}) .{ }^{13} \mathrm{C} \mathrm{NMR}\left(125 \mathrm{MHz}, \mathrm{CD}_{3} \mathrm{OD}\right) \delta 172.1,171.7,171.5,167.7,166.8,166.7$, $134.9,134.7,134.4,131.4,131.2,130.7,130.7,130.3,130.2,129.8,129.7,129.6,108.8$ (anomeric), 97.2 (anomeric), 81.7, 80.9, 78.5, 76.1, 75.8, 72.4, 72.0, 71.2, 70.5, 70.0, 63.5, 62.9, $60.3,59.5,32.7,21.4,21.3,20.6,13.7$. 
Compound 9d: Compound 9d was prepared as described for compound 1e using 9c (251 mg, $0.24 \mathrm{mmol}), \mathrm{K}_{2} \mathrm{CO}_{3}(67 \mathrm{mg}, 0.48 \mathrm{mmol})$, and methanol $(6 \mathrm{~mL})$. Progress of the reaction was monitored by TLC analysis (methanol/dichloromethane, 15:85). The crude was purified by flash chromatography $\left(\mathrm{SiO}_{2}\right.$ : methanol/dichloromethane) to yield $9 \mathbf{d}(119 \mathrm{mg}, 85 \%)$ as a white solid. LRMS (ESI): m/z calcd for $\mathrm{C}_{18} \mathrm{H}_{28} \mathrm{~N}_{9} \mathrm{O}_{11}: 546.19$ [M-H]'; found 546.32. ${ }^{1} \mathrm{H} \mathrm{NMR}\left(400 \mathrm{MHz}, \mathrm{CD}_{3} \mathrm{OD}\right)$ $\delta 5.83\left(\mathrm{~d}, \mathrm{~J}=3.7 \mathrm{~Hz}, 1 \mathrm{H}, \mathrm{H}-1^{\prime}\right), 5.36$ (d, J = $\left.1.0 \mathrm{~Hz}, 1 \mathrm{H}, \mathrm{H}-1{ }^{\prime}\right), 4.15$ (dd, J = 7.0, $\left.4.7 \mathrm{~Hz}, 1 \mathrm{H}, \mathrm{H}-3^{\prime \prime}\right)$, 4.09 (dd, J = 4.7, 1.2 Hz, 1H, H-2"), $4.07-4.01$ (m, 1H, H-6'), $3.97-3.89$ (m, 3H, H-3', H-5' H-4"), $3.81-3.69$ (m, 2H, H-4, H-5"), $3.69-3.61$ (m, 2H, H-6, H-5"), $3.59-3.38$ (m, 3H, H-1, H-3, H-5), $3.38-3.33\left(\mathrm{~m}, 1 \mathrm{H}, \mathrm{H}-4^{\prime}\right), 3.06\left(\mathrm{dd}, \mathrm{J}=10.5,3.8 \mathrm{~Hz}, 1 \mathrm{H}, \mathrm{H}-2^{\prime}\right), 2.18$ (ddd, J = 12.7, 4.3 Hz, $1 \mathrm{H}, \mathrm{H}-$ 2eq), 1.35 (ddd, J = $12.5 \mathrm{~Hz}, 1 \mathrm{H}, \mathrm{H}-2 \mathrm{ax}), 1.25$ (d, J = $\left.6.5 \mathrm{~Hz}, 3 \mathrm{H}, 6{ }^{\prime}-\mathrm{CH}_{3}\right) .{ }^{13} \mathrm{C} \mathrm{NMR}(125 \mathrm{MHz}$, $\mathrm{CD}_{3} \mathrm{OD}$ ) $\delta 108.6$ (anomeric), 97.5 (anomeric), 84.9, 84.4, 76.9, 76.9, 75.9, 75.3, 74.0, 72.1, 71.4, $69.0,64.5,63.2,61.8,61.6,33.1,17.6$.

Compound 9: Compound 9 was prepared as described for compound $\mathbf{1}$ using $\mathbf{9 d}$ (45 $\mathrm{mg}, 0.08$ $\mathrm{mmol})$, water $(6 \mathrm{~mL})$, and $10 \% \mathrm{Pd} / \mathrm{C}$ (cat.). The reaction mixture was filtered and freeze-dried to yield 9 (36 mg, 93\%) as a white solid. HRMS (ESI): $\mathrm{m} / \mathrm{z}$ calcd for $\mathrm{C}_{18} \mathrm{H}_{36} \mathrm{~N}_{3} \mathrm{O}_{11}: 470.2350[\mathrm{M}+\mathrm{H}]^{+}$; found 470.2349. ${ }^{1} \mathrm{H}$ NMR $\left(500 \mathrm{MHz}, \mathrm{D}_{2} \mathrm{O}\right) \delta 5.60(\mathrm{~d}, \mathrm{~J}=4.0 \mathrm{~Hz}, 1 \mathrm{H}, \mathrm{H}-1$ '), $5.23(\mathrm{~d}, \mathrm{~J}=1.7 \mathrm{~Hz}, 1 \mathrm{H}$, H-1"), 4.15 (qd, J = 6.5, 2.2 Hz, 1H, H-6'), $4.11-4.02$ (m, 2H, H-2", H-3"), $3.96-3.83$ (m, 2H, H4, H-4"), 3.82 - 3.69 (m, 4H, H-5, H-3', H-5', H-5"), 3.66 - 3.55 (m, 2H, H-6, H-5"), 3.48 (ddd, J = 12.6, 10.1, 4.3 Hz, 1H, H-3), $3.39-3.30$ (m, 2H, H-2', H-4'), 3.25 (ddd, J = 12.5, 10.7, 4.1 Hz, $1 \mathrm{H}$, $\mathrm{H}-1$ ), 2.39 (ddd, J = 12.6, 4.2 Hz, 1H, H-2eq), 1.76 (ddd, J = 12.6 Hz, 1H, H-2ax), 1.12 (d, J = 6.6 $\left.\mathrm{Hz}, 3 \mathrm{H}, 6{ }^{\prime}-\mathrm{CH}_{3}\right) \cdot{ }^{13} \mathrm{C} \mathrm{NMR}\left(125 \mathrm{MHz}, \mathrm{D}_{2} \mathrm{O}\right) \delta 162.9$ (q, $\left.J=35 \mathrm{~Hz}, \mathrm{CF}_{3} \mathrm{COOH}\right), 116.3(\mathrm{q}, J=291 \mathrm{~Hz}$, $\mathrm{CF}_{3} \mathrm{COOH}$ ), 109.9 (anomeric), 96.7 (anomeric), 83.8, 82.6, 78.7, 75.4, 75.0, 72.1, 69.9, 69.2, 68.8, $65.3,60.5,53.8,49.5,48.9,28.1,14.5$. 


\section{Minimal inhibitory concentration (MIC) experiments}

All bacterial strains utilized in this study were purchased from the American Type Culture Collection (ATCC). Starter cultures were grown overnight $\left(37^{\circ} \mathrm{C}, 5 \% \mathrm{CO}_{2}\right.$, aerobic conditions) in cationadjusted Mueller-Hinton broth (Sigma). After overnight culture, cells had reached stationary phase $\left(\mathrm{OD}_{600}>1\right)$ and were diluted 1:100 with fresh medium and further incubated for $2 \mathrm{~h}$ to an OD600 of 0.1-0.9 (logarithmic phase). The logarithmic phase bacterial suspension was diluted in fresh medium to obtain an $\mathrm{OD}_{600}$ of 0.008 . All strains were tested using a double-dilution method in 96 well plates (Costar, Corning). All compounds were dissolved in $\mathrm{H}_{2} \mathrm{O}$ (to stock solutions of $5 \mathrm{mg} / \mathrm{mL}$ ). Aliquots of compound were added to the growth medium to form the mother liquor (32 $\mu \mathrm{L}$ in 1218 $\mu \mathrm{L}$ of medium) at a concentration of $128 \mu \mathrm{g} / \mathrm{mL}$. Next, $100 \mu \mathrm{L}$ of serial double dilutions of compounds in growth medium $(128,64,32,16,8,4$, and $2 \mu \mathrm{g} / \mathrm{mL})$ were prepared in flat-bottomed 96-well microplates. Wells containing untreated bacteria and wells containing only growth medium (blank) were used as controls. An equal volume $(100 \mu \mathrm{L})$ of bacterial suspensions in growth medium was added to each well for a final volume of $200 \mu \mathrm{L}$ and final concentrations ranging from $64 \mu \mathrm{g} / \mathrm{mL}$ to $1 \mu \mathrm{g} / \mathrm{mL}$. After $18 \mathrm{~h}$ of incubation, MTT $\left(25 \mu \mathrm{L}\right.$ of a $1 \mathrm{mg} / \mathrm{mL}$ solution in $\left.\mathrm{H}_{2} \mathrm{O}\right)$ was added to each well followed by additional incubation at $37^{\circ} \mathrm{C}$ for $1 \mathrm{~h}$. Each concentration of compound was tested in triplicate, and the results were confirmed in two independent experiments. MIC values $(\mu \mathrm{g} / \mathrm{mL})$ were defined as the lowest concentration at which no bacterial growth was observed. 
Table S1. Minimal inhibitory concentration (MIC) values $[\mu \mathrm{g} / \mathrm{mL}]^{[a]}$

\begin{tabular}{|c|c|c|c|c|c|c|c|c|c|c|c|}
\hline & APR & 1 & 2 & 3 & G-418 & 4 & 5 & 6 & 7 & 8 & 9 \\
\hline \multicolumn{12}{|c|}{ Gram-negative bacteria } \\
\hline $\begin{array}{l}P . \text { aeruginosa } \\
\text { ATCC } 47085\end{array}$ & 4 & 16 & 16 & 16 & 64 & $>64$ & $>64$ & $>64$ & $>64$ & $>64$ & $>64$ \\
\hline $\begin{array}{l}P . \text { aeruginosa } \\
\text { ATCC } 27853\end{array}$ & 2 & 4 & 16 & 8 & $>64$ & $>64$ & $>64$ & $>64$ & 64 & $>64$ & $>64$ \\
\hline $\begin{array}{l}\text { K. pneumoniae } \\
\text { ATCC } 13883\end{array}$ & 4 & 4 & 16 & 8 & 1 & 16 & 2 & $>64$ & 64 & $>64$ & 64 \\
\hline $\begin{array}{l}\text { K. pneumoniae } \\
\text { ATCC } 10031\end{array}$ & 2 & 2 & 8 & 8 & 1 & 16 & 2 & $>64$ & 64 & $>64$ & 64 \\
\hline $\begin{array}{l}\text { K. pneumoniae } \\
\text { ATCC BAA-2470 }\end{array}$ & 4 & 2 & 8 & 8 & $>64$ & $>64$ & $>64$ & $>64$ & $>64$ & $>64$ & $>64$ \\
\hline $\begin{array}{l}\text { E. coli } \\
\text { ATCC } 25922\end{array}$ & 16 & 16 & 64 & 64 & 4 & 8 & 4 & $>64$ & $>64$ & $>64$ & $>64$ \\
\hline
\end{tabular}

\begin{tabular}{|c|c|c|c|c|c|c|c|c|c|c|c|}
\hline \multicolumn{12}{|c|}{ Gram-positive bacteria } \\
\hline $\begin{array}{l}\text { S. aureus } \\
\text { ATCC } 29213\end{array}$ & 4 & 8 & 32 & 16 & 2 & 32 & 4 & $>64$ & 64 & $>64$ & $>64$ \\
\hline $\begin{array}{l}\text { S. aureus } \\
\text { ATCC } 35556\end{array}$ & 1 & 2 & 4 & 4 & 1 & 4 & 1 & $>64$ & 16 & 32 & 32 \\
\hline $\begin{array}{l}\text { B. cereus } \\
\text { ATCC } 14579\end{array}$ & 8 & 8 & 16 & 16 & 4 & $>64$ & 8 & $>64$ & $>64$ & $>64$ & $>64$ \\
\hline $\begin{array}{l}\text { S. epidermidis } \\
\text { ATCC } 12228\end{array}$ & 2 & 4 & 16 & 8 & 2 & 16 & 2 & $>64$ & 32 & $>64$ & 64 \\
\hline
\end{tabular}

[a] MICs were determined using the double-dilution method. Each concentration of each compound was analyzed in triplicate in two independent sets of experiments.

\section{In vitro inhibition of protein translation in eukaryotic and prokaryotic Systems}

\subsection{Cell-free prokaryotic in vitro translation inhibition assay}

Protein translation inhibition was quantified in a coupled transcription/translation assay using $E$. coli S30 extracts for circular DNA with the pBEST/uc ${ }^{\mathrm{TM}}$ plasmid (Promega) according to the manufacturer's protocol. Briefly, reactions were carried out in a total volume of $10 \mu \mathrm{L}$. Each reaction contained $3 \mu \mathrm{L}$ of $\mathrm{S} 30$ Extract Circular, $1 \mu \mathrm{L}$ of pBEST/uc ${ }^{\mathrm{TM}}$ plasmid $(1 \mu \mathrm{g} / \mu \mathrm{L}), 4 \mu \mathrm{L}$ of $\mathrm{S} 30$ premix, $1 \mu \mathrm{L}$ of amino acid mixture, and $1 \mu \mathrm{L}$ of the tested compound in various concentrations. All translation mixtures were incubated at $37^{\circ} \mathrm{C}$ for $90 \mathrm{~min}$, cooled on ice for at least $5 \mathrm{~min}$, and diluted with $45 \mu \mathrm{L}$ of a dilution reagent (25 mM Tris-phosphate buffer, $\mathrm{pH} 7.8,2 \mathrm{mM}$ DTT, $2 \mathrm{mM}$ 1,2diaminocyclohexanetetraacetate, $10 \%$ glycerol, $1 \%$ Triton $\mathrm{X}-100$, and $1 \mathrm{mg} / \mathrm{mL}$ BSA) into white 
polystyrene 96-well flat-bottom plates (Corning). The luminescence was measured immediately after the addition of the luciferase assay reagent $(25 \mu \mathrm{L}$, Promega) using a TECAN microplate reader (Infinite F200 Pro). The concentrations of half-maximal inhibition $\left(\mathrm{IC}_{50}\right)$ were obtained from concentration-response curves fitted to the data of at least two independent experiments using Grafit 7 software.

\subsection{Cell-free eukaryotic in vitro translation inhibition assay}

Protein translation inhibition was quantified in a coupled transcription/translation assay using cell extract derived from rabbit reticulocytes supplemented with TNT® coupled reticulocyte lysate systems (Promega) according to the manufacturer's protocol. Briefly, reactions were carried out in a total volume of $10 \mu \mathrm{L}$. Each reaction contained $8 \mu \mathrm{L}$ of TnT® Quick Master Mix, $0.8 \mu \mathrm{L}$ of Luciferase T7 Control DNA plasmid $(1 \mu \mathrm{g} / \mu \mathrm{L}), 0.2 \mu \mathrm{L}$ of methionine, and $1 \mu \mathrm{L}$ of the tested compound in various concentrations. All translation mixtures were incubated at $30{ }^{\circ} \mathrm{C}$ for $60 \mathrm{~min}$, cooled on ice for at least $5 \mathrm{~min}$, and diluted with $45 \mu \mathrm{L}$ of a dilution reagent $(25 \mathrm{mM}$ Tris-phosphate buffer, pH 7.8, 2 mM DTT, 2 mM 1,2-diaminocyclohexanetetraacetate, 10\% glycerol, 1\% Triton X100 , and $1 \mathrm{mg} / \mathrm{mL} \mathrm{BSA}$ ) into white polystyrene 96-well flat-bottom plates (Corning). The luminescence was measured immediately after the addition of the luciferase assay reagent $(25 \mu \mathrm{L}$, Promega) using a TECAN microplate reader (Infinite F200 Pro). The $\mathrm{IC}_{50}$ values were obtained from concentration-response curves fitted to the data of at least two independent experiments using Grafit 7 software.

\section{Docking and molecular dynamics calculations}

\subsection{System selection}

The starting structures consisted of two rRNA strands each with 12 ribonucleotides surrounding A1492 and A1493 in each site. For the bacterial A-site structure, we extracted 24 ribonucleotides from the complex of the bacterial 30 S ribosome with APR (PDB code: 4AQY). ${ }^{6}$ For simulations of the cytosolic A-site two structures were used: The first was from the X-ray structure of a complex between APR and rRNA fragments representing the cytosolic A-site (PDB code: $2 \mathrm{G} 5 \mathrm{~K}) .{ }^{7}$ To 
facilitate crystallization, the rRNA sequence contained several ribonucleotides that differ from those in the conserved $H$. sapiens A-site sequence. These ribonucleotides were replaced with the conserved nucleotides using the rna_thread tool, as implemented in Resetta 2013 (Figure S1). The second structure was of the yeast $80 \mathrm{~S}$ ribosome in complex with G-418 (PDB code: $4 U 4 O)^{8}$ The A-site sequence of this rRNA is identical to that of the cytosolic $H$. sapiens A-site. Since there are currently no available X-ray structures of complexes of the mitochondrial A-site with APR or G-418, the 24-nucleotide region of a mitochondrial apo A-site rRNA was taken from the cryo-EM structure of the mammalian mitochondrial ribosome (PDB code: $5 \mathrm{AJ} 3) .{ }^{9}$ In this structure, the two adenines, A1492 and A1493, are bulged out in the on state.

All the structures were prepared using the Protein Preparation Wizard ${ }^{10}$ as implemented in Schrodinger's Maestro 11.2. ${ }^{11}$ This protocol adds missing hydrogen atoms considering a pH value of $7.0 \pm 1.0$, optimizes the hydrogen bond network, and performs restrained minimization. Crystallographic water molecules in the binding sites, which interact with the ligand (APR, G-418, and compounds 1, 3 and 5) and/or with the RNA, were retained during the preparation process, and were included in further calculations.

\subsection{Docking of ligands to the A-site}

The prepared structures were used for docking of APR, G-418, and compounds 1, 3, and $\mathbf{5}$. Docking calculations were performed using rDock 2013.1. ${ }^{12}$ Prior to docking the ligands were prepared using LigPrep in Schrodinger's Maestro 11.2. ${ }^{13}$ This protocol generates energy minimized three-dimensional structures of the ligands assuming protonation states at a pH value of $7.0 \pm 1.0$. Cavities within the binding sites were identified in crystal structures (PDB codes: 4AQY, 2G5K, $4 \cup 4 \mathrm{O}$, and $5 \mathrm{AJ} 3$ ), each with a radius of $4 \AA$ to define the docking volume. Docking was performed using the default parameters in rDock, except for the sampling mode for solvent translational degrees of freedom, which was set to 'FIXED'. For each ligand the best pose was selected based on the score. 


\subsection{System preparation}

Molecular dynamics (MD) simulations were performed for the bacterial and human A-sites in apostates and in the presence of ligands. Force field parameters for the ligands were obtained by using the ANTECHAMBER module in AMBER. ${ }^{14,15}$ The partial atomic charges for the ligands were derived using geometry optimization of the structures of the ligands by quantum-mechanical minimization. These calculations were performed with Jaguar, ${ }^{16}$ as implemented in Schrodinger's Maestro 11.2, using the 6-31G* basis set and the DFT-B3LYP level of theory. Each construct was submerged in SPC/E water model in truncated octahedron box with an additional $20-\AA$ extension along each axis of the RNA. Potassium and chloride ions were added to the water phase in order to neutralize the system and to obtain a salt concentration of $0.2 \mathrm{M}$.

\subsection{Molecular dynamics simulations}

All MD simulations were performed with the GROMACS 5.0.6 package ${ }^{17}$ using the Amber14 force field with the $\operatorname{bsc}_{\chi \circ}$ L3 $3_{\text {modification }}{ }^{18,19}$ for RNA with Smith \& Dang parameters for ions. ${ }^{20,21}$ The simulations were conducted in periodic boundary conditions with particle-mesh Ewald (PME) electrostatics with $10-\AA$ cutoff for long-range interactions. ${ }^{22}$ Prior to the production phase, the systems were equilibrated according to a protocol described by Auffinger et al. ${ }^{23}$ First, the simulated systems were energy minimized with the steepest descent minimization algorithm in order to remove van der Waals clashes. Following minimization, the systems were equilibrated in several rounds as follows: (1) 5 ns of simulation in NVT ensemble where the heavy atoms of the solute and the ions were frozen; (2) 500 ps of simulation in NPT ensemble where the heavy atoms of the solute and the ions were frozen; (3) 500 ps of simulation in NPT ensemble where the constraints on the ions were released; (4) several rounds of 500 ps of simulation during which positional restraints of $10,5,2,1,0.5,0.1,0.01$, and $0.001 \mathrm{kcal} / \mathrm{mol} / \AA^{2}$ were applied to the solute heavy atoms. During all the equilibration stages an integration time step of $1 \mathrm{fs}$ was used. Finally, the production simulations were carried out for $20 \mathrm{~ns}$ with a constant temperature of $310 \mathrm{~K}$ (under Vrescale coupling algorithm) and constant pressure of 1 atm (under Parrinello-Rahman coupling algorithm). The LINCS algorithm was applied to bond lengths involving hydrogens, allowing an 
integration time step of $2 \mathrm{fs} .{ }^{24}$ During this stage, weak positional restraints of $0.35 \mathrm{kcal} / \mathrm{mol} / \AA^{2}$ were applied to the heavy atoms of the terminal base pairs at each end of the RNA. Each of the systems considered in this work was simulated three times, each time starting from a different random seed.

\subsection{Data Analysis}

The resulting trajectories were visually inspected using VMD 1.9.3 software. ${ }^{25}$ The stability of the resulting trajectories and the average mobility of all the nucleotides were tested based on the root mean square deviation (RMSD) of the backbone atoms of the RNA from the equilibrated structures and on the root mean square fluctuations (RMSF), respectively. RMSD and RMSF were calculated using the rms and rmsf utilities of the GROMACS package, respectively.

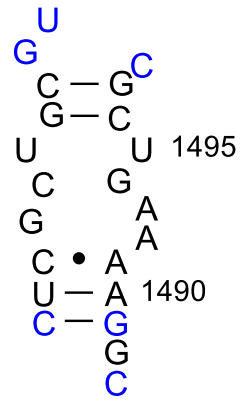

Secondary structure of cytosolic A-site used in PDB 2G5K

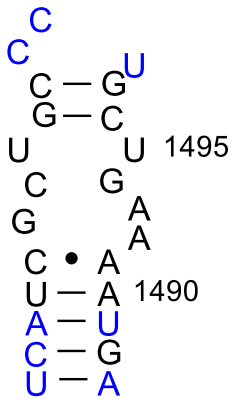

Secondary structure of conserved cytosolic A-site

Figure S1. Crystallized cytosolic A-site sequence and sequence used for MD simulations. Left: Secondary structure of cytosolic A-site in the crystal structure (PDB 2G5K). Right: The conserved structure used for the molecular dynamics simulation. In blue are the nucleotides that differ between the two structures. 
A. Bacterial A-site - APR derivatives

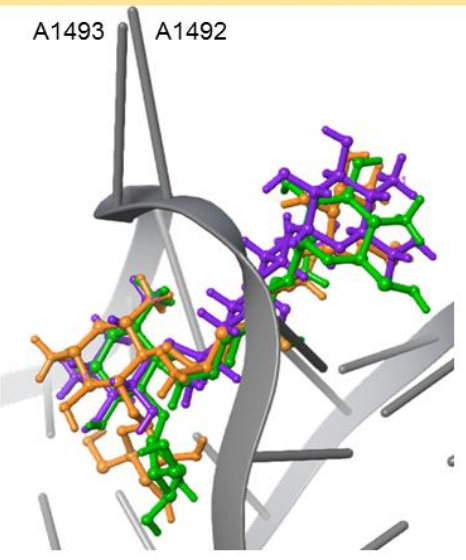

D. Bacterial A-site - G-418 derivatives

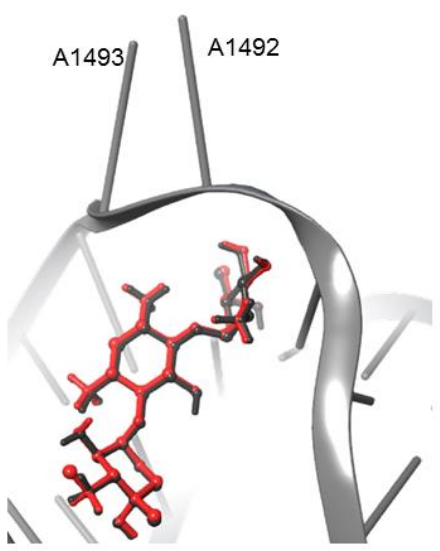

B. Cytosolic A-site - APR derivatives

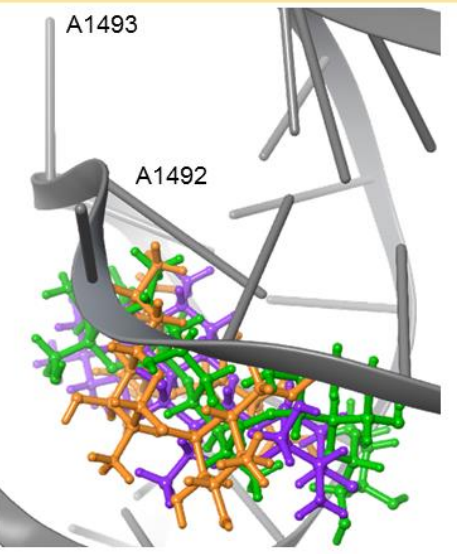

E. Cytosolic A-site - G-418 derivatives

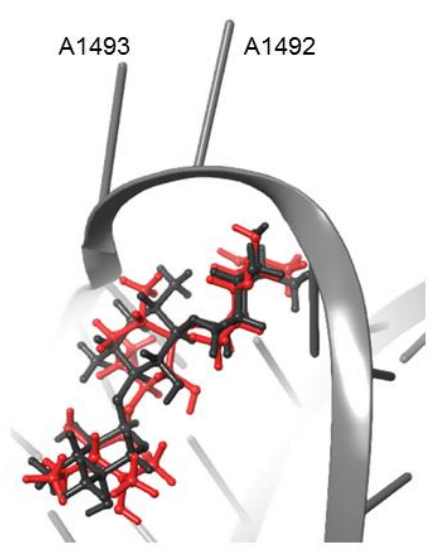

C. Mitochondrial A-site - APR derivatives

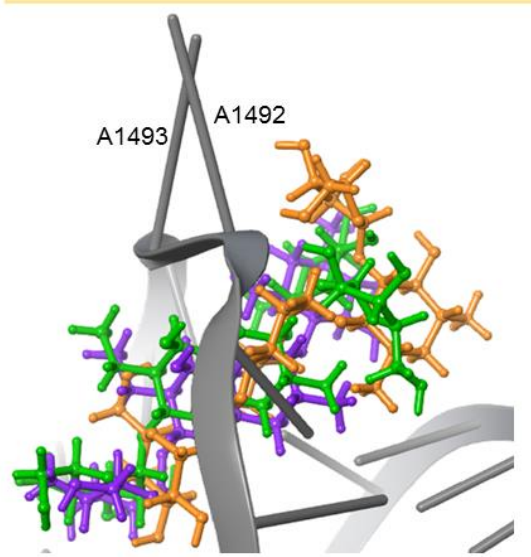

F. Mitochondrial A-site $-\mathrm{G}-418$ derivatives

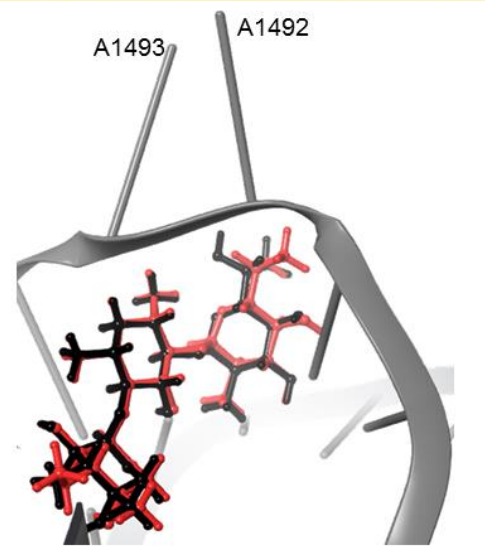

Figure S2. Docking structure of APR, G-418, and compounds 1,3 and 5 in the different Asites. (A-C) Docking structures in the presence of APR (purple) and its derivatives 1 (green) and 3 (orange). (D-F) Docking structures in the presence of G-418 (red) and its derivative 5 (black). 
Table S2: RMSD values of the equilibrated apo- bacterial, cytosolic and mitochondrial A-sites backbone atoms and RMSD values of all A-sites in the presence of APR, G-418, and compounds 1, 3, and 5. [a]

\begin{tabular}{lccc}
\hline & Bacterial A-site & Cytosolic A-site & Mitochondrial A-site \\
\hline apo A-site & $2.26 \pm 0.71$ & $2.39 \pm 0.65$ (PDB: 2 G5K) & $2.20 \pm 0.25$ \\
\hline Complex with APR & $2.83 \pm 0.32$ & $2.78 \pm 0.54$ (PDB: 4 U4O) & $1.49 \pm 0.17$ \\
\hline Complex with 1 & $2.59 \pm 0.84$ & $2.03 \pm 0.17$ & $1.62 \pm 0.40$ \\
\hline Complex with 3 & $2.00 \pm 0.68$ & $1.16 \pm 0.29$ & $1.55 \pm 0.25$ \\
\hline Complex with G-418 & $2.37 \pm 0.36$ & $1.41 \pm 0.17$ & $1.81 \pm 0.41$ \\
\hline Complex with 5 & $2.25 \pm 0.38$ & $1.64 \pm 0.31$ & $2.15 \pm 0.17$ \\
\hline
\end{tabular}

[a] RMSD values are in $\AA$.

Table S3: RMSF values of all 24 ribonucleotides in the apo bacterial A-site and RMSF values in the presence of APR, G-418, and compounds 1, 3, and 5. ${ }^{[a]}$

\begin{tabular}{|c|c|c|c|c|c|c|}
\hline Ribonucleotide & apo & APR & 1 & 3 & G-418 & 5 \\
\hline C1402 & $1.49 \pm 0.23$ & $1.37 \pm 0.14$ & $1.62 \pm 0.07$ & $1.35 \pm 0.25$ & $1.31 \pm 0.16$ & $1.18 \pm 0.05$ \\
\hline C1403 & $1.42 \pm 0.15$ & $1.2 \pm 0.11$ & $1.43 \pm 0.29$ & $1.17 \pm 0.14$ & $1.29 \pm 0.19$ & $1.01 \pm 0.04$ \\
\hline C1404 & $1.68 \pm 0.18$ & $1.23 \pm 0.05$ & $1.4 \pm 0.22$ & $1.23 \pm 0.12$ & $1.25 \pm 0.08$ & $1.06 \pm 0.06$ \\
\hline G1405 & $1.34 \pm 0.18$ & $1.32 \pm 0.2$ & $1.43 \pm 0.13$ & $1.27 \pm 0.1$ & $1.21 \pm 0.12$ & $1.04 \pm 0.06$ \\
\hline U1406 & $1.48 \pm 0.16$ & $1.47 \pm 0.12$ & $1.49 \pm 0.1$ & $1.47 \pm 0.13$ & $1.26 \pm 0.09$ & $1.19 \pm 0.04$ \\
\hline C1407 & $1.77 \pm 0.08$ & $1.32 \pm 0.1$ & $1.4 \pm 0.07$ & $1.2 \pm 0.07$ & $1.24 \pm 0.08$ & $1.21 \pm 0.04$ \\
\hline A1408 & $1.7 \pm 0.04$ & $1.32 \pm 0.12$ & $1.39 \pm 0.15$ & $1.19 \pm 0.09$ & $1.26 \pm 0.11$ & $1.19 \pm 0.05$ \\
\hline C1409 & $1.61 \pm 0.09$ & $1.28 \pm 0.09$ & $1.43 \pm 0.14$ & $1.23 \pm 0.1$ & $1.13 \pm 0.06$ & $1.13 \pm 0.05$ \\
\hline G1410 & $1.61 \pm 0.14$ & $1.29 \pm 0.05$ & $1.4 \pm 0.14$ & $1.24 \pm 0.11$ & $1.11 \pm 0.05$ & $1.11 \pm 0.05$ \\
\hline U1411 & $1.54 \pm 0.09$ & $1.25 \pm 0.02$ & $1.36 \pm 0.14$ & $1.23 \pm 0.08$ & $1.09 \pm 0.05$ & $1.11 \pm 0.07$ \\
\hline C1412 & $1.48 \pm 0.09$ & $1.22 \pm 0.03$ & $1.28 \pm 0.13$ & $1.18 \pm 0.04$ & $1.06 \pm 0.05$ & $1.1 \pm 0.06$ \\
\hline A1413 & $1.42 \pm 0.1$ & $1.2 \pm 0$ & $1.39 \pm 0.37$ & $1.11 \pm 0.03$ & $1.07 \pm 0.03$ & $1.27 \pm 0.39$ \\
\hline G1487 & $1.41 \pm 0.1$ & $1.15 \pm 0.05$ & $1.13 \pm 0.09$ & $1.07 \pm 0.03$ & $1.08 \pm 0.03$ & $1.12 \pm 0.02$ \\
\hline G1488 & $1.59 \pm 0.14$ & $1.23 \pm 0.05$ & $1.2 \pm 0.11$ & $1.14 \pm 0.02$ & $1.12 \pm 0.04$ & $1.14 \pm 0.04$ \\
\hline A1489 & $1.74 \pm 0.18$ & $1.27 \pm 0.05$ & $1.25 \pm 0.14$ & $1.17 \pm 0.01$ & $1.1 \pm 0.04$ & $1.12 \pm 0.04$ \\
\hline C1490 & $1.93 \pm 0.27$ & $1.32 \pm 0.07$ & $1.32 \pm 0.19$ & $1.19 \pm 0.05$ & $1.06 \pm 0.07$ & $1.05 \pm 0.01$ \\
\hline G1491 & $1.93 \pm 0.26$ & $1.32 \pm 0.11$ & $1.39 \pm 0.2$ & $1.2 \pm 0.08$ & $0.98 \pm 0.09$ & $0.96 \pm 0.02$ \\
\hline A1492 & $3.86 \pm 0.44$ & $2.35 \pm 0.28$ & $2.35 \pm 0.14$ & $2.29 \pm 0.22$ & $1.41 \pm 0.1$ & $1.71 \pm 0.19$ \\
\hline A1493 & $3.57 \pm 0.25$ & $2.35 \pm 0.34$ & $2.34 \pm 0.28$ & $2.25 \pm 0.18$ & $1.35 \pm 0.03$ & $2.02 \pm 0.49$ \\
\hline G1494 & $1.91 \pm 0.16$ & $1.54 \pm 0.31$ & $1.73 \pm 0.26$ & $1.43 \pm 0.08$ & $1.18 \pm 0.05$ & $1.16 \pm 0.11$ \\
\hline U1495 & $1.72 \pm 0.04$ & $1.6 \pm 0.26$ & $1.65 \pm 0.29$ & $1.36 \pm 0.09$ & $1.22 \pm 0.1$ & $1.13 \pm 0.04$ \\
\hline C1496 & $1.6 \pm 0.2$ & $1.5 \pm 0.27$ & $1.75 \pm 0.24$ & $1.36 \pm 0.2$ & $1.37 \pm 0.16$ & $1.14 \pm 0.02$ \\
\hline G1497 & $1.48 \pm 0.24$ & $1.61 \pm 0.32$ & $1.55 \pm 0.11$ & $1.26 \pm 0.12$ & $1.28 \pm 0.05$ & $1.24 \pm 0.08$ \\
\hline U1498 & $1.82 \pm 0.43$ & $2.2 \pm 1.04$ & $1.92 \pm 0.17$ & $1.35 \pm 0.49$ & $1.64 \pm 0.21$ & $1.33 \pm 0.15$ \\
\hline
\end{tabular}

[a] RMSF values are in $\AA$. 
Table S4: RMSF values of all 24 ribonucleotides in the apo cytosolic A-site and RMSF values in the presence of APR, G-418, and compounds 1, 3, and 5. [a]

\begin{tabular}{|c|c|c|c|c|c|c|c|}
\hline $\begin{array}{c}\text { Ribo- } \\
\text { nucleotide }\end{array}$ & $\begin{array}{c}\text { apo } \\
\text { (PDB: } \\
\text { 2G5K) }\end{array}$ & APR & 1 & 3 & $\begin{array}{c}\text { apo } \\
\text { (PDB: } \\
\text { 4U40) }\end{array}$ & G-418 & 5 \\
\hline C1402 & $2.97 \pm 0.42$ & $2.24 \pm 0.96$ & $3.58 \pm 0.72$ & $1.0 \pm 0.04$ & $1.2 \pm 0.05$ & $1.32 \pm 0.04$ & $0.98 \pm 0.03$ \\
\hline C1403 & $1.83 \pm 0.12$ & $1.16 \pm 0.08$ & $2.26 \pm 0.85$ & $0.75 \pm 0.08$ & $1.08 \pm 0.05$ & $1.14 \pm 0.04$ & $0.91 \pm 0.03$ \\
\hline C1404 & $1.22 \pm 0.02$ & $0.72 \pm 0.04$ & $1.3 \pm 0.55$ & $0.66 \pm 0.09$ & $0.93 \pm 0.06$ & $0.88 \pm 0.03$ & $0.78 \pm 0.01$ \\
\hline G1405 & $1.06 \pm 0.04$ & $0.64 \pm 0.06$ & $1.01 \pm 0.36$ & $0.64 \pm 0.08$ & $0.87 \pm 0.03$ & $0.87 \pm 0.06$ & $0.76 \pm 0.01$ \\
\hline U1406 & $1.14 \pm 0.1$ & $0.69 \pm 0.06$ & $1.02 \pm 0.33$ & $0.7 \pm 0.08$ & $1.12 \pm 0.05$ & $1.18 \pm 0.13$ & $0.96 \pm 0.04$ \\
\hline C1407 & $1.04 \pm 0.09$ & $0.73 \pm 0.04$ & $0.89 \pm 0.14$ & $0.71 \pm 0.06$ & $1.05 \pm 0.08$ & $1.15 \pm 0.21$ & $1.09 \pm 0.07$ \\
\hline G1408 & $0.92 \pm 0.02$ & $0.74 \pm 0.03$ & $0.86 \pm 0.1$ & $0.67 \pm 0.04$ & $1.11 \pm 0.08$ & $1.08 \pm 0.21$ & $1.24 \pm 0.1$ \\
\hline C1409 & $0.77 \pm 0.02$ & $0.69 \pm 0.02$ & $0.8 \pm 0.11$ & $0.6 \pm 0.02$ & $1.05 \pm 0.15$ & $0.94 \pm 0.1$ & $1.27 \pm 0.13$ \\
\hline U1410 & $0.74 \pm 0.02$ & $0.68 \pm 0.02$ & $0.83 \pm 0.06$ & $0.63 \pm 0.02$ & $0.94 \pm 0.07$ & $0.76 \pm 0.05$ & $0.87 \pm 0.08$ \\
\hline A1411 & $0.77 \pm 0.01$ & $0.7 \pm 0.02$ & $0.82 \pm 0.06$ & $0.69 \pm 0.02$ & $0.9 \pm 0.03$ & $0.78 \pm 0.04$ & $0.83 \pm 0.06$ \\
\hline C1412 & $0.91 \pm 0.03$ & $0.81 \pm 0.02$ & $0.97 \pm 0.08$ & $0.68 \pm 0.01$ & $0.91 \pm 0.01$ & $0.84 \pm 0.03$ & $0.82 \pm 0.02$ \\
\hline U1413 & $1.34 \pm 0.05$ & $1.16 \pm 0.05$ & $1.56 \pm 0.23$ & $0.87 \pm 0.03$ & $1.06 \pm 0.04$ & $1.04 \pm 0.02$ & $1.0 \pm 0.01$ \\
\hline A1487 & $1.05 \pm 0.04$ & $0.97 \pm 0.02$ & $1.02 \pm 0.1$ & $0.85 \pm 0.02$ & $1.01 \pm 0.02$ & $0.91 \pm 0.03$ & $0.91 \pm 0.03$ \\
\hline G1488 & $0.86 \pm 0.04$ & $0.78 \pm 0.01$ & $0.81 \pm 0.11$ & $0.72 \pm 0.01$ & $0.95 \pm 0.06$ & $0.81 \pm 0.02$ & $0.83 \pm 0.02$ \\
\hline U1489 & $0.89 \pm 0.03$ & $0.7 \pm 0.03$ & $0.87 \pm 0.15$ & $0.75 \pm 0.03$ & $1.1 \pm 0.15$ & $0.9 \pm 0.05$ & $0.87 \pm 0.02$ \\
\hline A1490 & $0.86 \pm 0.04$ & $0.63 \pm 0.06$ & $0.92 \pm 0.06$ & $0.7 \pm 0.08$ & $1.19 \pm 0.26$ & $0.87 \pm 0.06$ & $0.84 \pm 0.04$ \\
\hline A1491 & $1.72 \pm 0.09$ & $1.32 \pm 0.22$ & $1.73 \pm 0.17$ & $1.71 \pm 0.14$ & $1.41 \pm 0.37$ & $1.06 \pm 0.25$ & $0.99 \pm 0.03$ \\
\hline A1492 & $0.85 \pm 0.04$ & $0.64 \pm 0.06$ & $0.87 \pm 0.19$ & $0.6 \pm 0.07$ & $2.9 \pm 0.65$ & $1.52 \pm 0.2$ & $2.46 \pm 0.68$ \\
\hline A1493 & $1.56 \pm 0.09$ & $1.73 \pm 0.12$ & $1.67 \pm 0.14$ & $0.72 \pm 0.07$ & $2.45 \pm 0.53$ & $1.59 \pm 0.21$ & $1.95 \pm 0.46$ \\
\hline G1494 & $0.93 \pm 0.03$ & $0.74 \pm 0.01$ & $1.04 \pm 0.15$ & $0.58 \pm 0.04$ & $1.11 \pm 0.13$ & $0.97 \pm 0.11$ & $1.0 \pm 0.07$ \\
\hline U1495 & $0.92 \pm 0.06$ & $0.65 \pm 0.01$ & $1.07 \pm 0.3$ & $0.7 \pm 0.03$ & $1.05 \pm 0.04$ & $0.94 \pm 0.09$ & $0.79 \pm 0.01$ \\
\hline C1496 & $0.89 \pm 0.06$ & $0.65 \pm 0.02$ & $1.06 \pm 0.39$ & $0.68 \pm 0.04$ & $0.85 \pm 0.03$ & $0.78 \pm 0.04$ & $0.8 \pm 0.04$ \\
\hline G1497 & $0.77 \pm 0.01$ & $0.64 \pm 0.02$ & $0.82 \pm 0.2$ & $0.61 \pm 0.03$ & $0.77 \pm 0.03$ & $0.76 \pm 0.01$ & $0.71 \pm 0.03$ \\
\hline U1498 & $0.96 \pm 0.01$ & $0.85 \pm 0.03$ & $1.01 \pm 0.18$ & $0.76 \pm 0.03$ & $0.92 \pm 0.03$ & $0.88 \pm 0.01$ & $0.89 \pm 0.03$ \\
\hline
\end{tabular}

[a] RMSF values are in $\AA$. 
Table S5: RMSF values of all 24 ribonucleotides in the apo mitochondrial A-site and RMSF values in the presence of APR, G-418, and compounds 1, 3, and 5. ${ }^{[a]}$

\begin{tabular}{llllllc}
\hline Ribonucleotide & \multicolumn{1}{c}{ apo } & APR & \multicolumn{1}{c}{$\mathbf{1}$} & $\mathbf{3}$ & $\mathbf{G}-\mathbf{4 1 8}$ & $\mathbf{5}$ \\
\hline C1402 & $1.54 \pm 0.19$ & $1.21 \pm 0.05$ & $1.34 \pm 0.1$ & $1.27 \pm 0.07$ & $1.39 \pm 0.05$ & $1.09 \pm 0.07$ \\
$\mathbf{C} 1403$ & $1.29 \pm 0.21$ & $1.0 \pm 0.04$ & $1.07 \pm 0.07$ & $1.07 \pm 0.04$ & $1.07 \pm 0.03$ & $0.88 \pm 0.03$ \\
C1404 & $1.11 \pm 0.32$ & $0.76 \pm 0.02$ & $0.8 \pm 0.06$ & $0.79 \pm 0.02$ & $0.74 \pm 0.03$ & $0.78 \pm 0.08$ \\
G1405 & $1.05 \pm 0.21$ & $0.76 \pm 0.06$ & $0.78 \pm 0.07$ & $0.78 \pm 0.01$ & $0.77 \pm 0.03$ & $0.84 \pm 0.11$ \\
U1406 & $1.23 \pm 0.22$ & $1.03 \pm 0.08$ & $1.13 \pm 0.23$ & $1.0 \pm 0.08$ & $0.86 \pm 0.05$ & $0.94 \pm 0.07$ \\
C1407 & $1.28 \pm 0.13$ & $1.02 \pm 0.16$ & $1.21 \pm 0.29$ & $0.93 \pm 0.07$ & $0.86 \pm 0.04$ & $0.81 \pm 0.05$ \\
A1408 & $1.55 \pm 0.08$ & $0.93 \pm 0.17$ & $1.45 \pm 0.33$ & $0.95 \pm 0.18$ & $0.88 \pm 0.04$ & $0.72 \pm 0.03$ \\
C1409 & $1.64 \pm 0.3$ & $0.92 \pm 0.1$ & $1.15 \pm 0.09$ & $0.95 \pm 0.05$ & $0.92 \pm 0.02$ & $0.74 \pm 0.03$ \\
C1410 & $1.61 \pm 0.1$ & $1.26 \pm 0.02$ & $1.03 \pm 0.11$ & $0.95 \pm 0.06$ & $1.13 \pm 0.09$ & $0.88 \pm 0.03$ \\
C1411 & $1.17 \pm 0.06$ & $0.83 \pm 0.02$ & $0.85 \pm 0.16$ & $0.8 \pm 0.01$ & $0.95 \pm 0.05$ & $0.75 \pm 0.03$ \\
U1412 & $1.0 \pm 0.03$ & $0.84 \pm 0.03$ & $0.9 \pm 0.17$ & $0.81 \pm 0.01$ & $0.89 \pm 0.01$ & $0.8 \pm 0.03$ \\
C1413 & $1.11 \pm 0.05$ & $1.0 \pm 0.03$ & $1.04 \pm 0.15$ & $0.88 \pm 0.01$ & $1.01 \pm 0.02$ & $0.93 \pm 0.04$ \\
G1487 & $1.4 \pm 0.07$ & $1.1 \pm 0.05$ & $1.22 \pm 0.15$ & $1.0 \pm 0.03$ & $1.13 \pm 0.05$ & $1.06 \pm 0.03$ \\
A1488 & $1.19 \pm 0.09$ & $0.98 \pm 0.04$ & $1.06 \pm 0.13$ & $0.9 \pm 0.05$ & $0.97 \pm 0.03$ & $0.91 \pm 0.03$ \\
G1489 & $1.06 \pm 0.1$ & $0.96 \pm 0.09$ & $1 \pm 0.15$ & $0.89 \pm 0.11$ & $0.9 \pm 0.03$ & $0.81 \pm 0.06$ \\
A1490 & $1.33 \pm 0.18$ & $1.29 \pm 0.08$ & $1.31 \pm 0.23$ & $1.16 \pm 0.34$ & $1.12 \pm 0.03$ & $0.83 \pm 0.09$ \\
C1491 & $1.69 \pm 0.38$ & $1.5 \pm 0.17$ & $1.26 \pm 0.25$ & $0.96 \pm 0.02$ & $1.48 \pm 0.1$ & $0.9 \pm 0.11$ \\
A1492 & $3.02 \pm 0.61$ & $2.02 \pm 0.05$ & $2.03 \pm 0.23$ & $1.89 \pm 0.23$ & $2.55 \pm 0.21$ & $2.17 \pm 0.11$ \\
A1493 & $2.66 \pm 0.68$ & $1.71 \pm 0.24$ & $2.13 \pm 0.7$ & $1.67 \pm 0.13$ & $1.97 \pm 0.24$ & $1.96 \pm 0.15$ \\
G1494 & $1.35 \pm 0.1$ & $0.83 \pm 0.05$ & $1.29 \pm 0.55$ & $1.19 \pm 0.11$ & $1.07 \pm 0.31$ & $0.91 \pm 0.07$ \\
U1495 & $1.21 \pm 0.14$ & $0.88 \pm 0.02$ & $1.01 \pm 0.18$ & $1.0 \pm 0.03$ & $0.85 \pm 0.06$ & $0.78 \pm 0.02$ \\
C1496 & $1.14 \pm 0.31$ & $0.82 \pm 0.06$ & $0.84 \pm 0.04$ & $0.83 \pm 0.04$ & $0.81 \pm 0.04$ & $0.9 \pm 0.04$ \\
G1497 & $1.07 \pm 0.22$ & $0.85 \pm 0.04$ & $0.86 \pm 0.08$ & $0.81 \pm 0.11$ & $0.82 \pm 0.02$ & $0.93 \pm 0.04$ \\
U1498 & $1.43 \pm 0.21$ & $1.18 \pm 0.04$ & $1.14 \pm 0.03$ & $0.95 \pm 0.05$ & $1.14 \pm 0.05$ & $1.23 \pm 0.08$ \\
\hline & & & & & & \\
& & & & &
\end{tabular}

[a] RMSF values are in $\AA$. 


\section{HEI-OC1 cells viability assay}

HEI-OC1 cells were grown in Dulbecco's modified eagle's medium (DMEM) supplemented with 2\% Fetal calf serum (FCS) in a humidified chamber of $90 \%$ air, $10 \% \mathrm{CO}_{2}$ at $33{ }^{\circ} \mathrm{C}$. For analyses, 3200 cells in $50 \mu \mathrm{L}$ of medium were seeded into each well of a 96 -well microtiter plate and allowed to adhere for $24 \mathrm{~h}$. Thereafter, solutions containing the tested compounds ( $50 \mu \mathrm{L}$ per well) were added to the cells at final concentrations ranging from 0.1 to $5000 \mu \mathrm{g} / \mathrm{mL}$, and cultures were incubated for an additional $72 \mathrm{~h}$. Cell viability was determined by the MTT assay as follows: MTT was added to the medium at a final concentration of $0.25 \mathrm{mg} / \mathrm{mL}$, followed by a 2-h incubation. The medium was then removed by aspiration, and dimethyl sulfoxide (DMSO, $100 \mu \mathrm{L}$ per well) was added. Absorbance at $570 \mathrm{~nm}$ in each well was determined using a Tecan Spectra Fluor microplate reader with a reference wavelength of $630 \mathrm{~nm}$. Each compound was tested in duplicate, and cell viability was determined relative to untreated control cells. The $I_{50}$ values were obtained from concentration-response curves fitted to the data of at least two independent experiments using Grafit 7 software.

\section{HEI-OC1 Cells permeabilization assay}

HEI-OC1 cells were grown in DMEM supplemented with $10 \% \mathrm{FCS}$ and $10 \mu \mathrm{g} / \mathrm{ml}$ ciprofloxacin in a humidified chamber of $90 \%$ air, $10 \% \mathrm{CO}_{2}$ at $33^{\circ} \mathrm{C}$. For permeabilization assay, $10^{5}$ cells in $2 \mathrm{~mL}$ of medium were seeded into each well of a 6 -well plates and allowed to adhere for $24 \mathrm{~h}$. Thereafter, solutions containing the tested compounds were added to the cells at final concentrations of 50 , 300 and $600 \mu \mathrm{g} / \mathrm{mL}$. CAM was used as a negative control at concentration of $250 \mu \mathrm{g} / \mathrm{mL}$ and S-14 was used as a positive control at concentration of $40 \mu \mathrm{g} / \mathrm{mL}$. After $3 \mathrm{~h}$ of incubation $\left(10 \% \mathrm{CO}_{2}, 33\right.$ ${ }^{\circ} \mathrm{C}$ ) cells were harvested and pelleted at $500 \times \mathrm{g}$ for $5 \mathrm{~min}$. The supernatant was removed by aspiration, and cells were resuspended in $200 \mu \mathrm{l}$ Phosphate buffered saline (PBS). Subsequently, $20 \mu \mathrm{l}$ of 4',6-diamidino-2-phenylindole (DAPI, $0.5 \mu \mathrm{g} / \mathrm{mL}$ stock solution in PBS, Sigma) were added to each sample, and cells were immediately analyzed using a Gallios Flow Cytometer (Beckman Coulter). For each sample, $5 \times 10^{3}$ cells were plotted on a histogram of fluorescence intensity. Each experiment was repeated twice. Data were analyzed using Kaluza software. 
A positive control sample (cells treated with S-14) was used to calibrate the fluorescence intensity and was gated as the population of "dead cells". A sample of untreated cells was gated as the population of "healthy cells". Cells population with fluorescence intensity between these two gates was defined as "permeabilized cells". The results are presented as $\%$ of cells in each gate relative to the untreated sample.

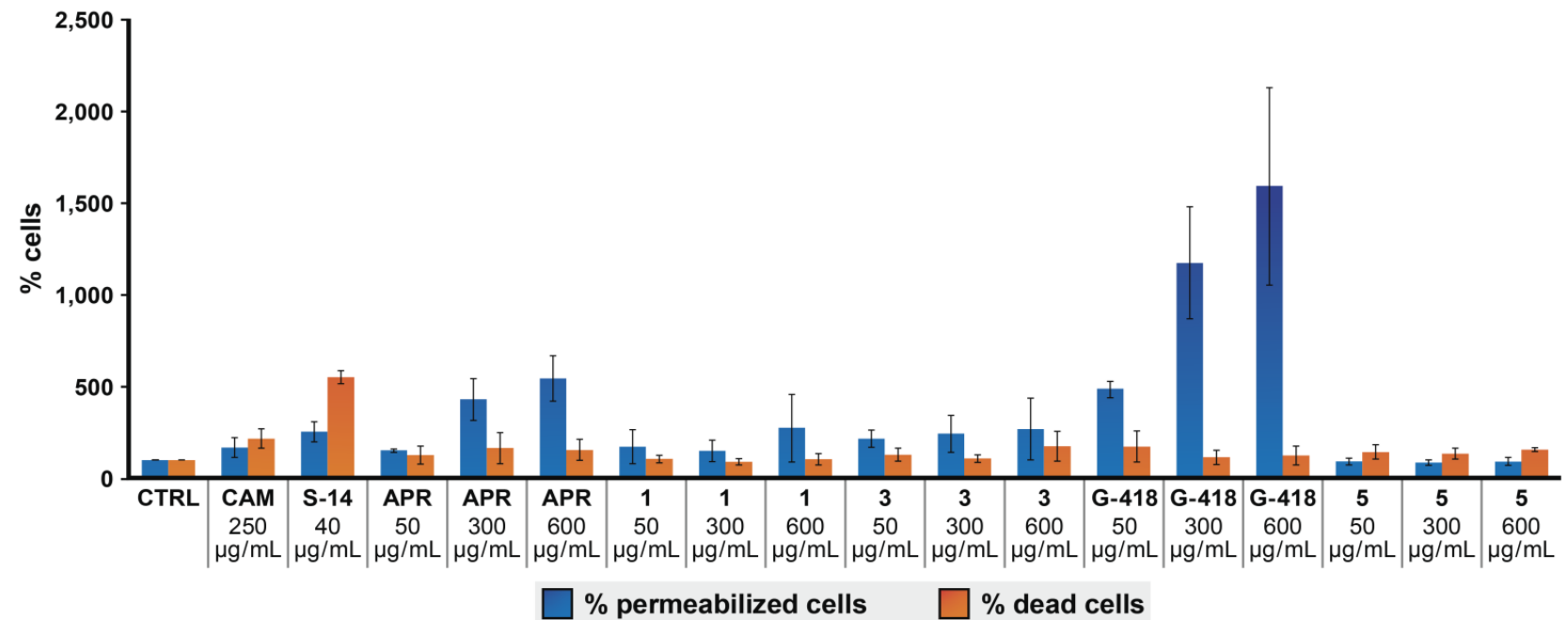

Figure S3. Effects of APR, G-418, and compounds 1, 3 and 5 on the permeabilization of HEIOC1 cells. Cells were treated with different concentrations of each compound for 3 hours, and permeability was evaluated by flow cytometry analysis of DAPI staining. The percentages of permeabilized and dead cells were determined relative to untreated cells. CAM was used as negative control and S-14 was used as a positive control. Results are expressed as means \pm SD from two independent experiments.

\section{Mitochondrial and cytosolic protein translation evaluation in HEl-OC1 Cells assay}

Mitochondrial and cytosolic protein translation was evaluated using MitoBiogenesis ${ }^{\mathrm{TM}}$ Flow Cytometry Kit (ab168540, Abcam) according to the manufacturer's protocol. Briefly, HEI-OC1 cells were grown in DMEM supplemented with $10 \%$ FCS and $10 \mu \mathrm{g} / \mathrm{ml}$ ciprofloxacin in a humidified chamber of $90 \%$ air, $10 \% \mathrm{CO}_{2}$ at $33{ }^{\circ} \mathrm{C}$. For analyses, $5 \times 104$ cells in $2 \mathrm{~mL}$ of medium were seeded into each well of 6 -well plates and allowed to adhere for $24 \mathrm{~h}$. Thereafter, solutions containing the tested compounds were added to the cells at final concentrations of $10,50,100$ and $300 \mu \mathrm{g} / \mathrm{mL}$. CAM was used at concentration of $25 \mu \mathrm{g} / \mathrm{mL}$ as a positive control for mitochondrial translation inhibition. After 6 days of incubation $\left(10 \% \mathrm{CO}_{2}, 33^{\circ} \mathrm{C}\right)$ cells were harvested and fixed by incubation with paraformaldehyde at final concentration of $4 \%$ for $15 \mathrm{~min}$ at room temperature. Cells were 
then pelleted at $500 \times \mathrm{g}$ for $5 \mathrm{~min}$, the supernatant was removed by aspiration, and cells were resuspended in $100 \mu \mathrm{l}$ of cold PBS, to which $900 \mu \mathrm{l}$ of cold methanol was added. Cells were stored at $-20{ }^{\circ} \mathrm{C}$ until analysis by flow cytometry. Before flow cytometry analysis, cells were pelleted (500 $\mathrm{x} \mathrm{g}, 5 \mathrm{~min}$ ) and washed twice with $1 \mathrm{~mL}$ of PBS. Thereafter, the supernatant was removed by aspiration, and $50 \mu \mathrm{l}$ of $1 \mathrm{X}$ Blocking Buffer was added to each sample followed by incubation at room temperature for $15 \mathrm{~min}$. Then, $50 \mu \mathrm{l}$ of $2 \mathrm{X}$ Primary Antibody Cocktail Solution in $1 \mathrm{X}$ Blocking Buffer was added to each sample for a final concentration of 1X Antibody Cocktail Solution. Samples were incubated at room temperature for $90 \mathrm{~min}$ at dark and washed twice with $1 \mathrm{~mL}$ of PBS. The supernatant was removed by aspiration, and cells were resuspended in $200 \mu$ PBS and analyzed immediately by Gallios Flow Cytometer (Beckman Coulter) For each sample, $5 \times 10^{3}$ cells were plotted on a histogram of MTCO1 AlexaFluor ${ }^{\circledR} 488$ fluorescence intensity (representing mitochondrial translation) and on a histogram of SDHA AlexaFluor ${ }^{\circledR} 647$ fluorescence intensity (representing cytosolic translation). Data were analyzed using Kaluza software. A sample of untreated cells was used to calibrate the fluorescence intensity. The results are presented as percentage of florescence intensity relative to the untreated sample.

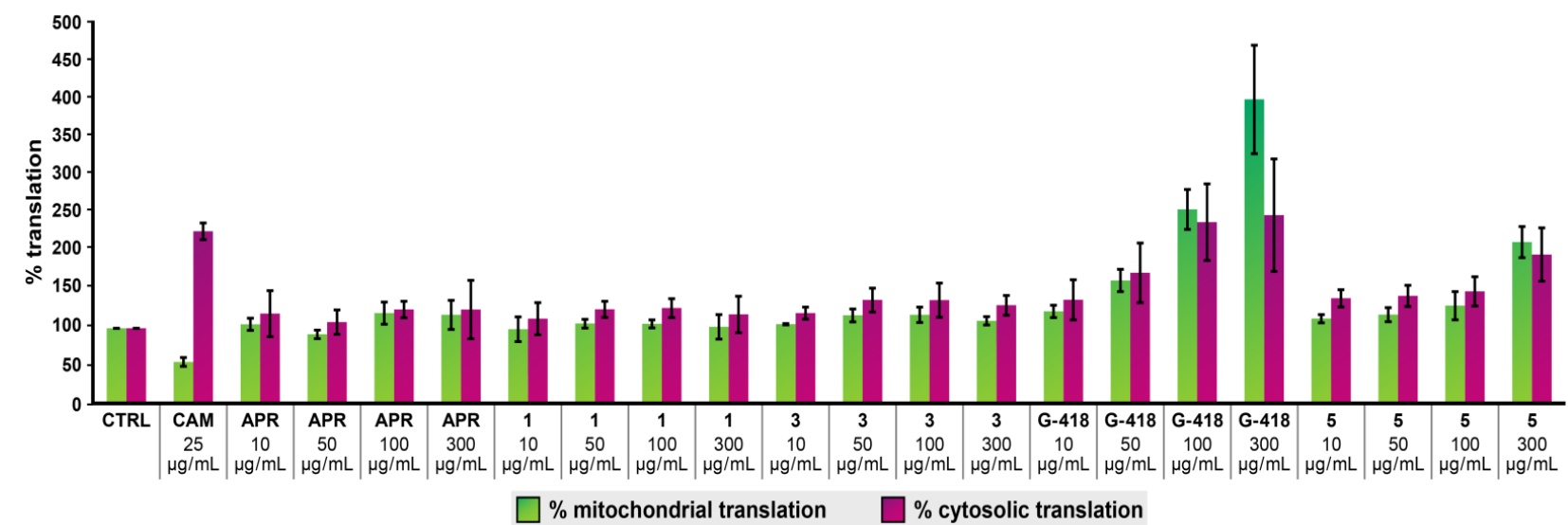

Figure 4S. Effects of APR, G-418, and compounds 1, 3, and 5 on levels of proteins translated in the cytoplasm and the mitochondria of HEI-OC1 cells. Cells were treated with different concentrations of each compound for 6 days, and levels of COX-1 (translated in the mitochondria, in green) and SDHA (translated in the cytoplasm, in magenta) were determined by flow cytometry. The percentages of protein levels relative to untreated cells are plotted. CAM was used as a positive control for mitochondrial translation inhibition. The results are expressed as means \pm SD from two independent experiments. 
8. ${ }^{1} \mathrm{H}$ NMR and ${ }^{13} \mathrm{C}$ NMR spectra
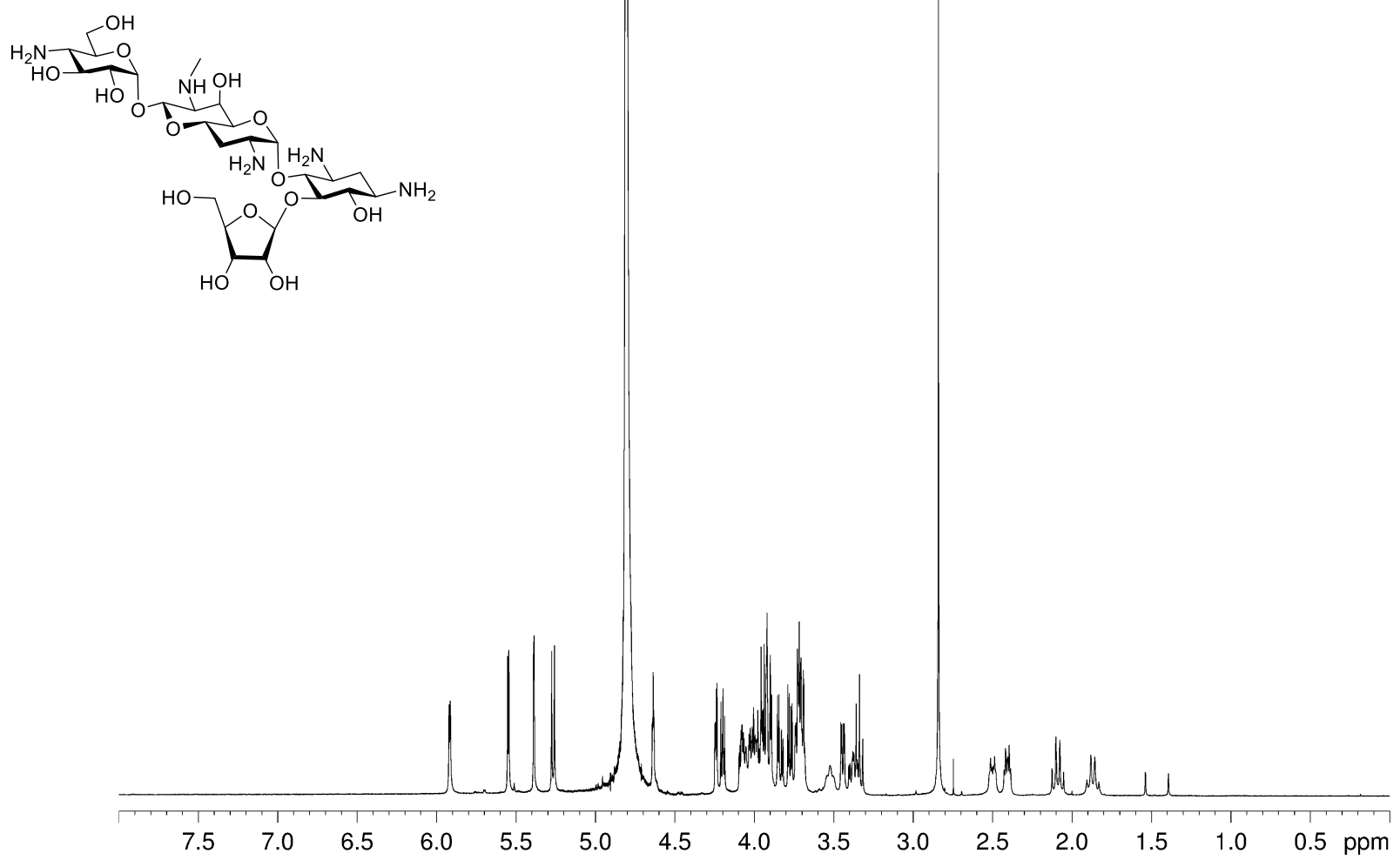

Figure $55.500 \mathrm{MHz}{ }^{1} \mathrm{H}-\mathrm{NMR}$ in $\mathrm{D}_{2} \mathrm{O}$ of compound 1 (TFA salt).

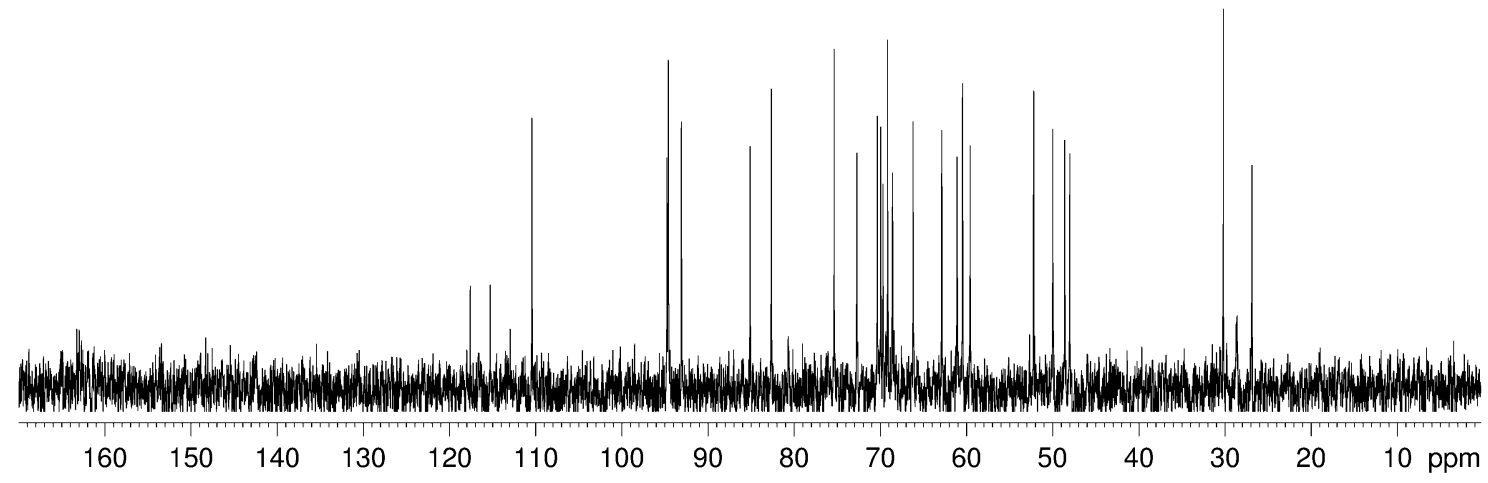

Figure S6. $100 \mathrm{MHz}{ }^{13} \mathrm{C}-\mathrm{NMR}$ in $\mathrm{D}_{2} \mathrm{O}$ of compound 1 (TFA salt). 


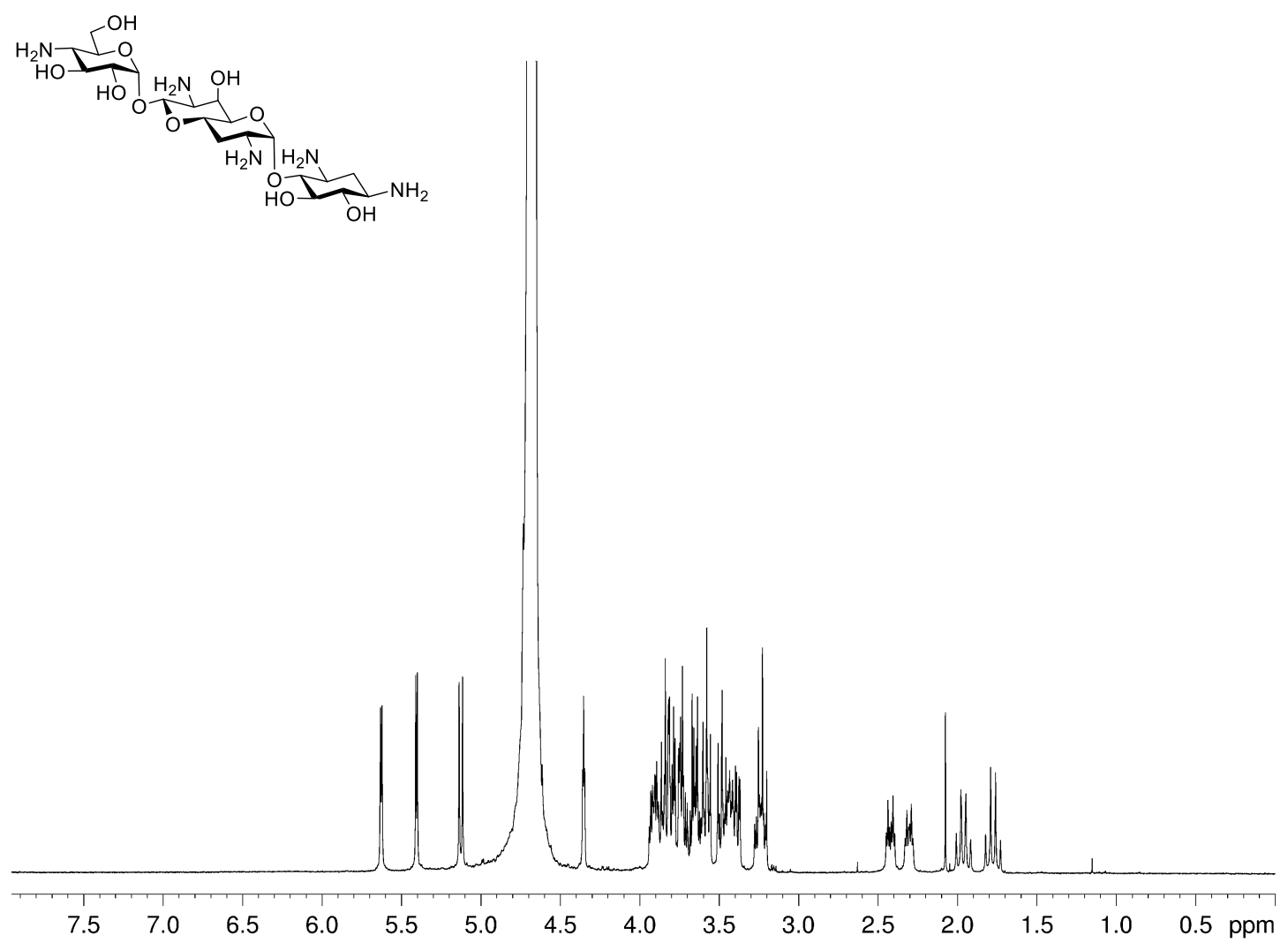

Figure S7. $400 \mathrm{MHz}{ }^{1} \mathrm{H}-\mathrm{NMR}$ in $\mathrm{D}_{2} \mathrm{O}$ of compound 2 (TFA salt).

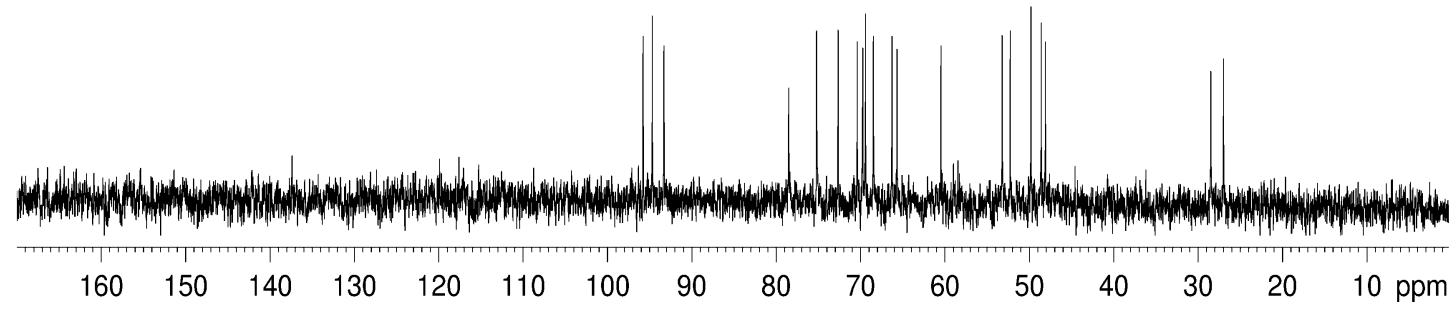

Figure S8. $125 \mathrm{MHz}{ }^{13} \mathrm{C}-\mathrm{NMR}$ in $\mathrm{D}_{2} \mathrm{O}$ of compound 2 (TFA salt). 


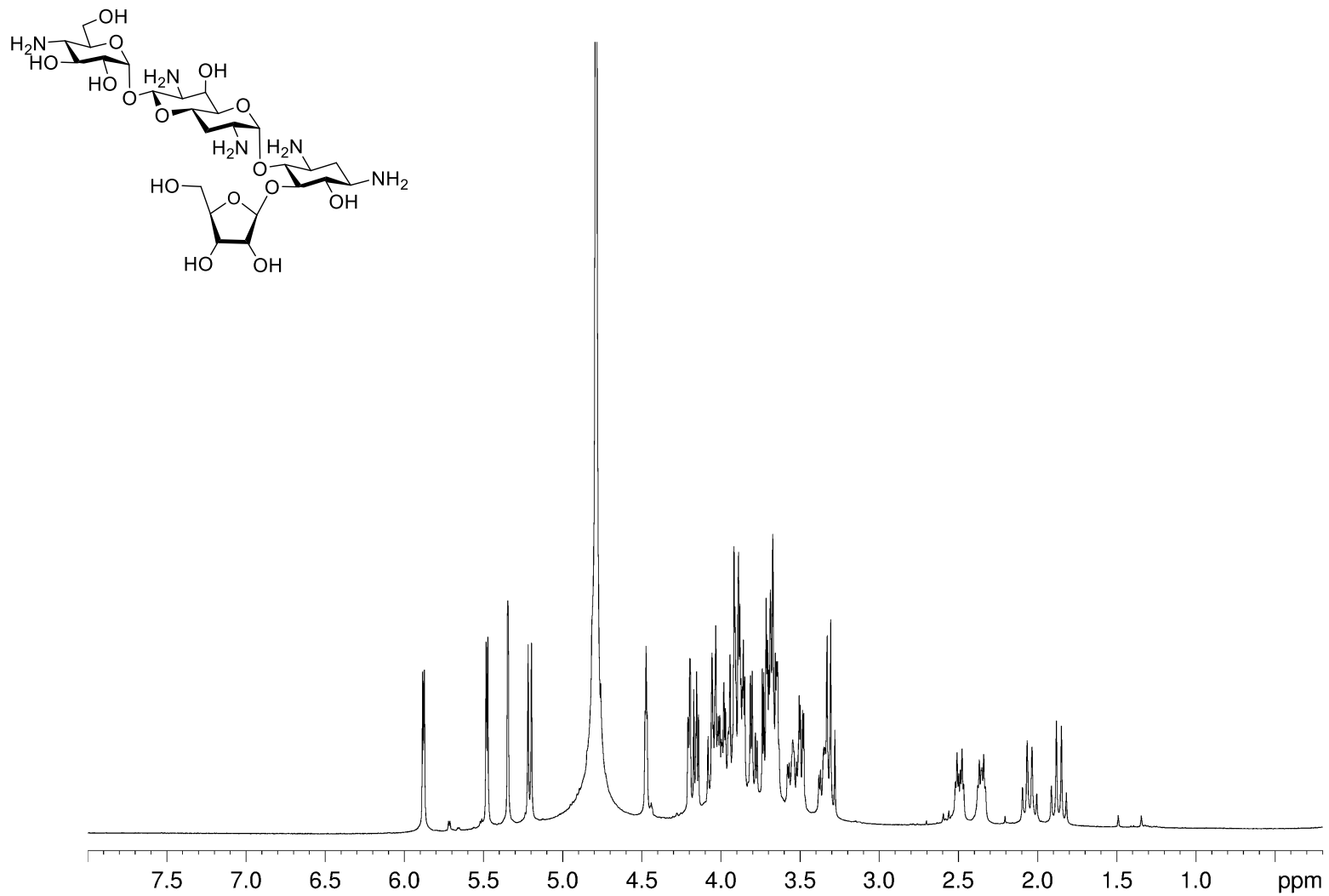

Figure S9. $400 \mathrm{MHz}{ }^{1} \mathrm{H}-\mathrm{NMR}$ in $\mathrm{D}_{2} \mathrm{O}$ of compound 3 (TFA salt).

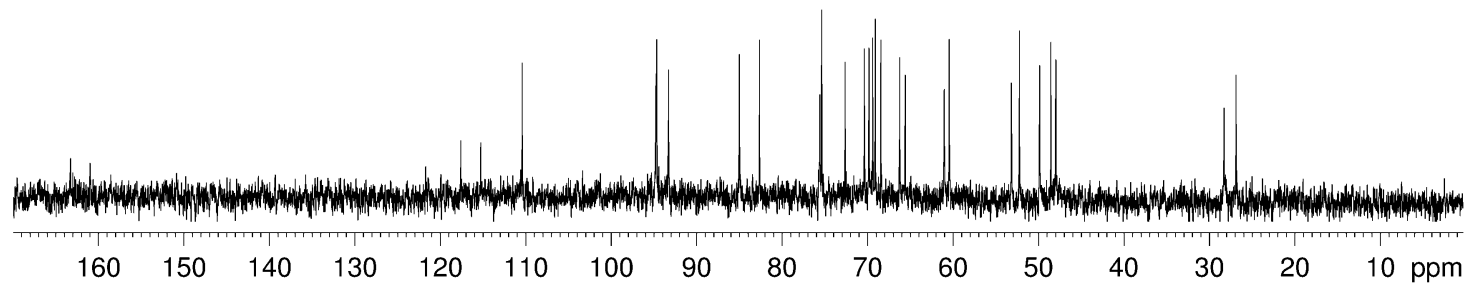

Figure S10. $125 \mathrm{MHz}{ }^{13} \mathrm{C}-\mathrm{NMR}$ in $\mathrm{D}_{2} \mathrm{O}$ of compound 3 (TFA salt). 


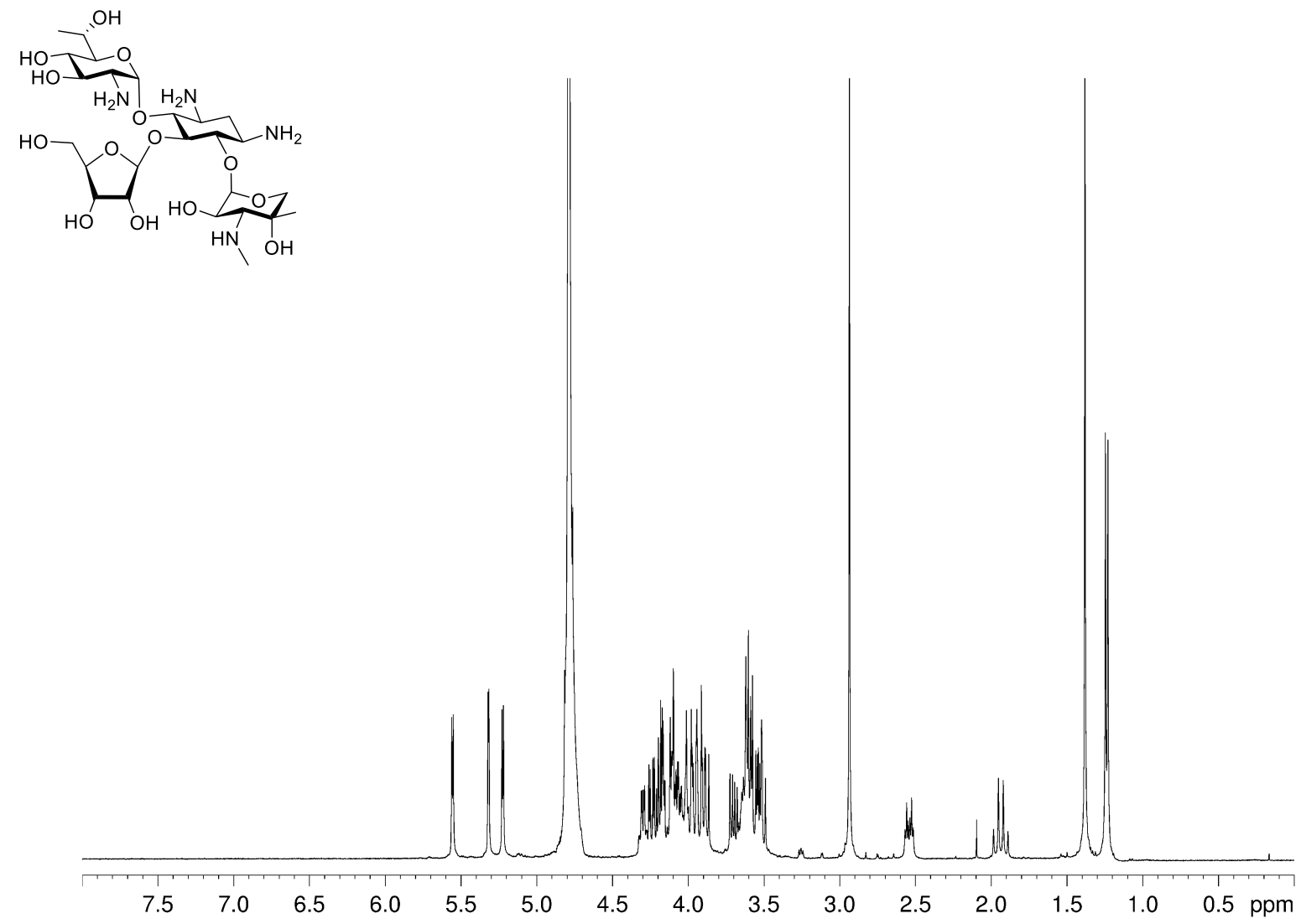

Figure $\mathrm{S} 11.400 \mathrm{MHz}{ }^{1} \mathrm{H}-\mathrm{NMR}$ in $\mathrm{D}_{2} \mathrm{O}$ of compound 4 (TFA salt).

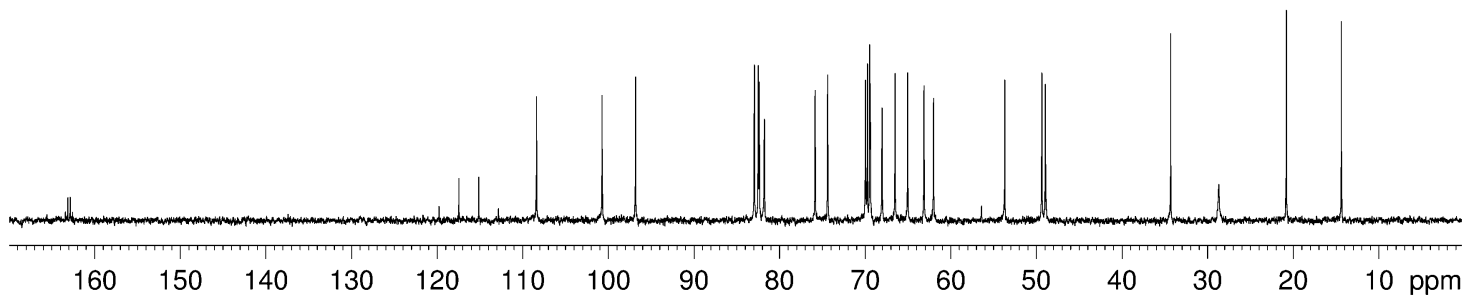

Figure $\mathrm{S} 12.125 \mathrm{MHz}{ }^{13} \mathrm{C}-\mathrm{NMR}$ in $\mathrm{D}_{2} \mathrm{O}$ of compound 4 (TFA salt). 


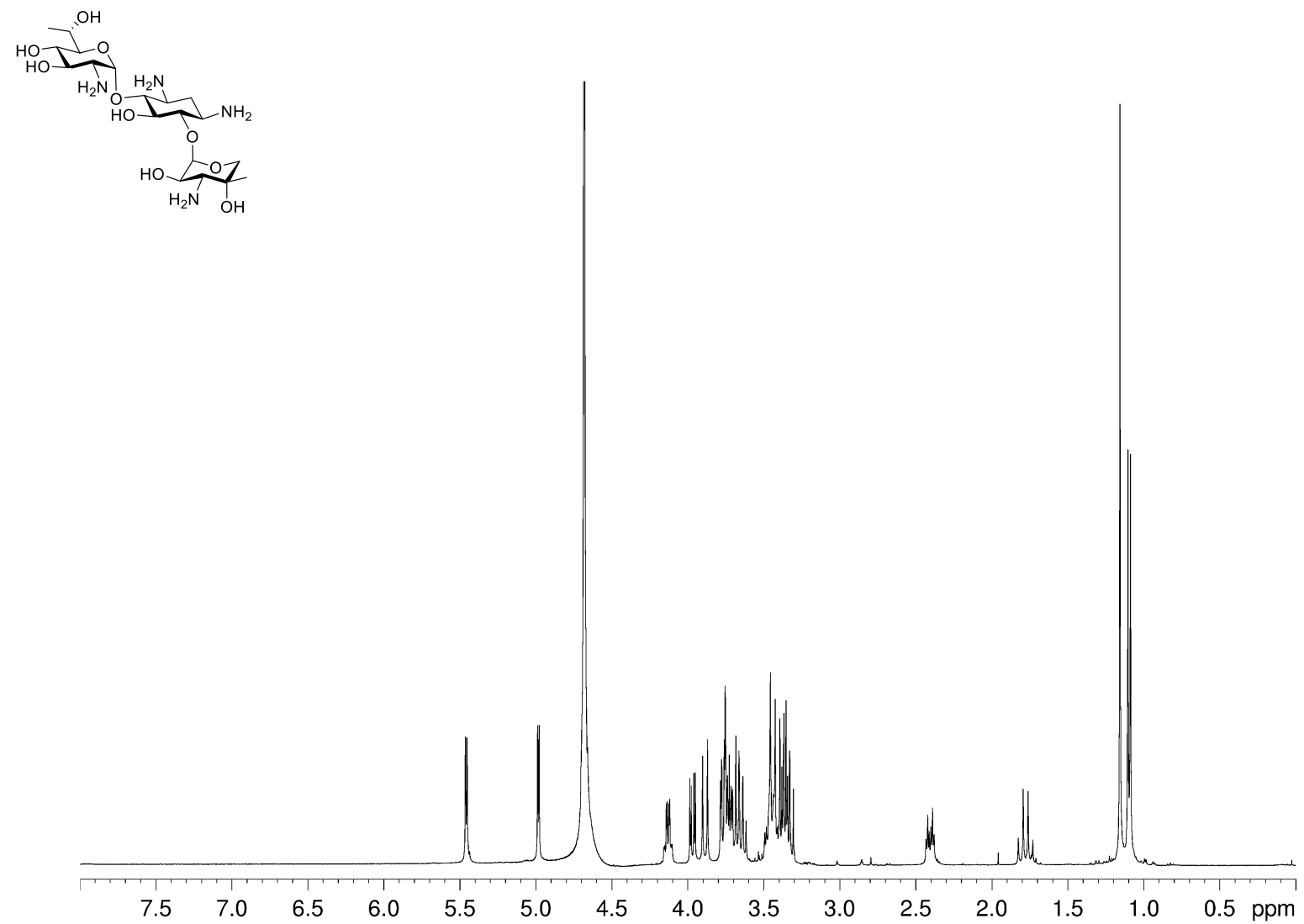

Figure S13. $400 \mathrm{MHz}{ }^{1} \mathrm{H}-\mathrm{NMR}$ in $\mathrm{D}_{2} \mathrm{O}$ of compound 5 (TFA salt).

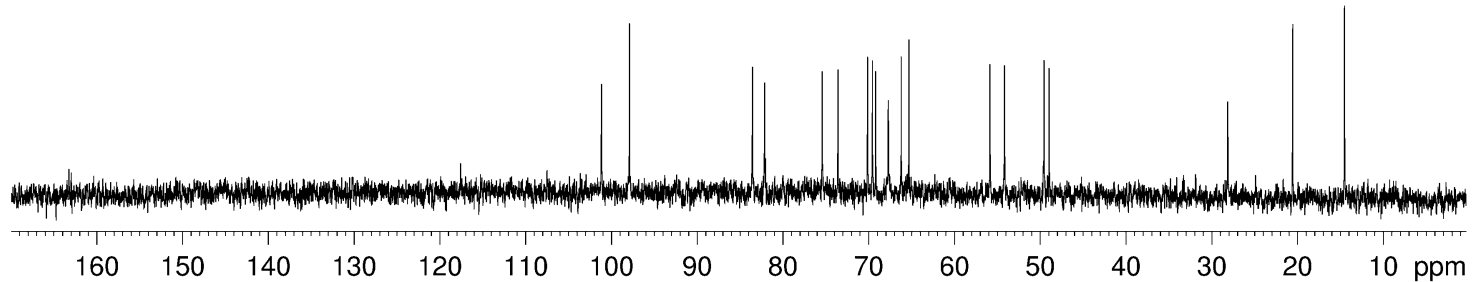

Figure S14. $125 \mathrm{MHz}{ }^{13} \mathrm{C}-\mathrm{NMR}$ in $\mathrm{D}_{2} \mathrm{O}$ of compound 5 (TFA salt). 


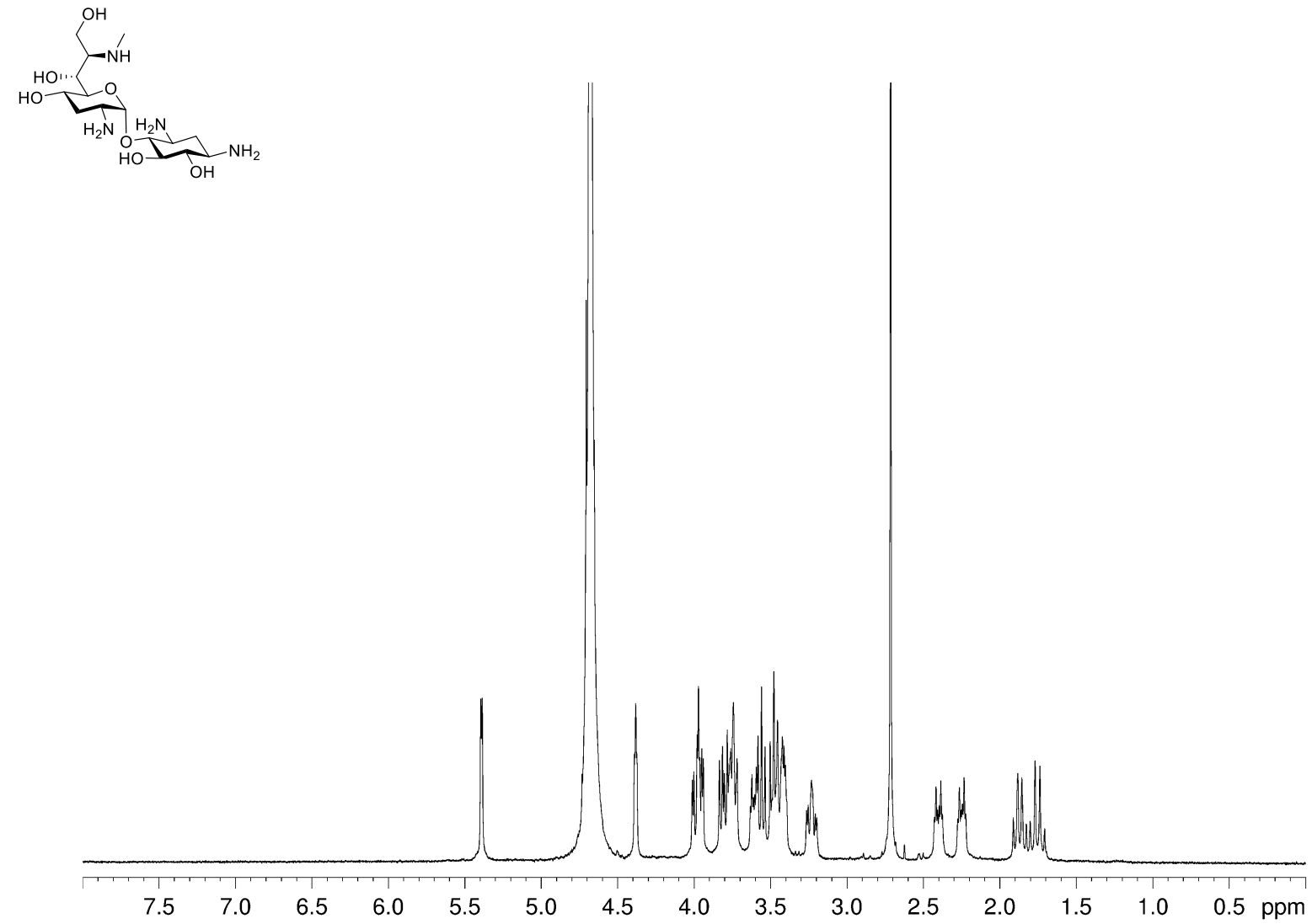

Figure $\mathrm{S} 15.400 \mathrm{MHz}{ }^{1} \mathrm{H}-\mathrm{NMR}$ in $\mathrm{D}_{2} \mathrm{O}$ of compound 6 (TFA salt).

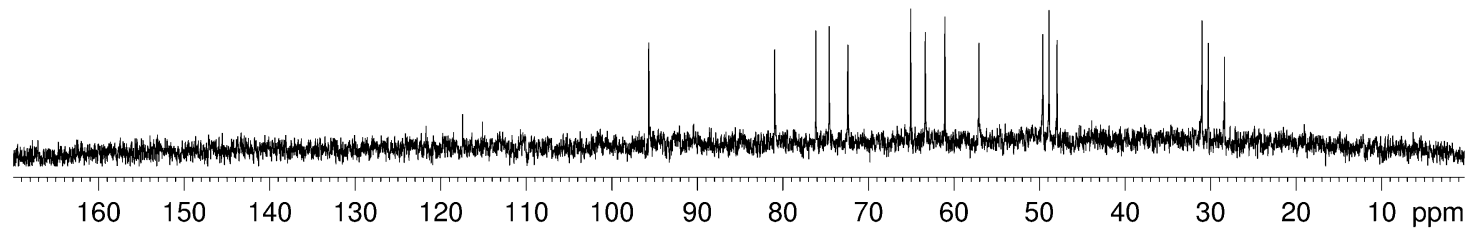

Figure S16. $125 \mathrm{MHz}{ }^{13} \mathrm{C}-\mathrm{NMR}$ in $\mathrm{D}_{2} \mathrm{O}$ of compound 6 (TFA salt). 


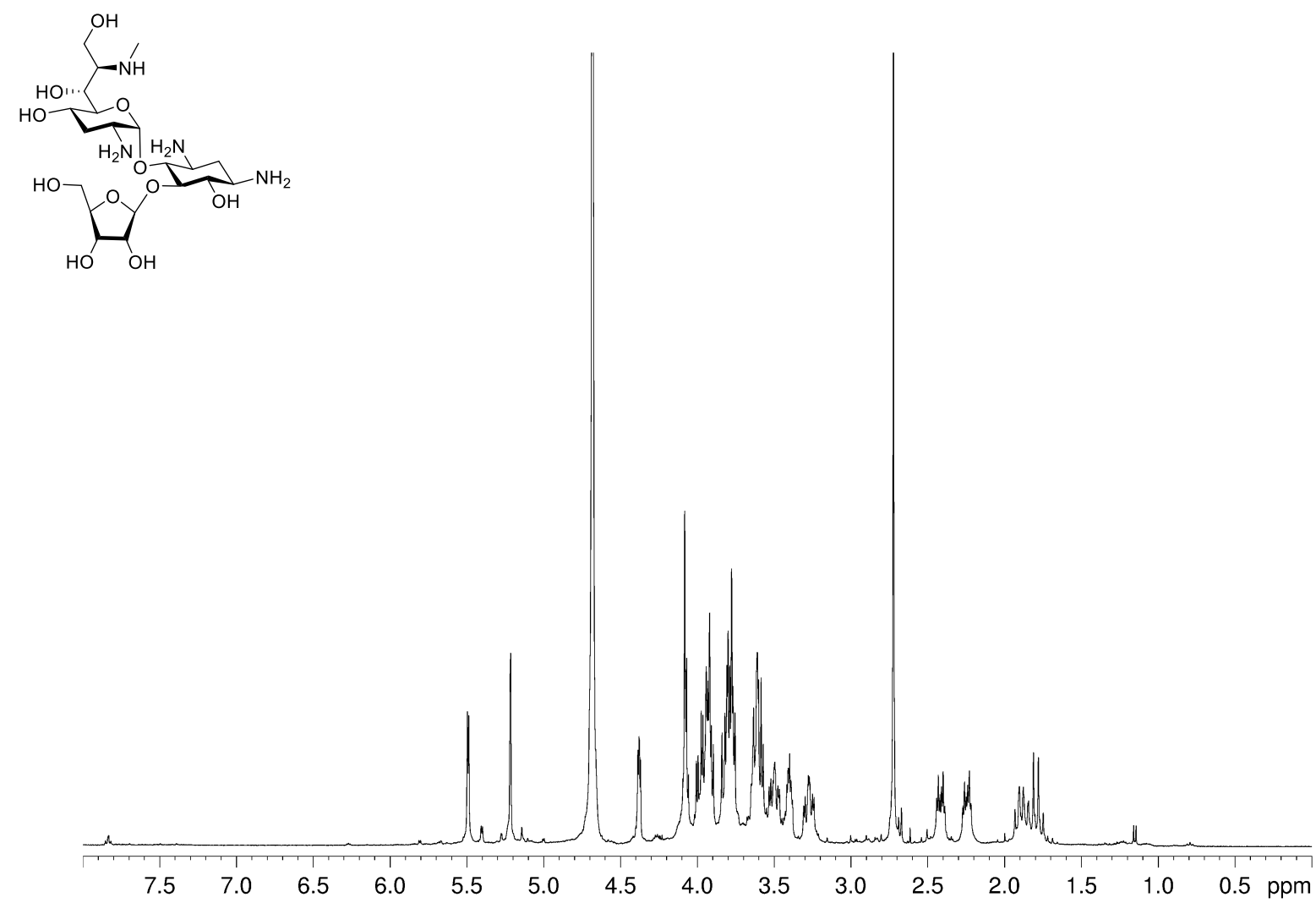

Figure $\mathrm{S} 17.400 \mathrm{MHz}{ }^{1} \mathrm{H}-\mathrm{NMR}$ in $\mathrm{D}_{2} \mathrm{O}$ of compound 7 (TFA salt).

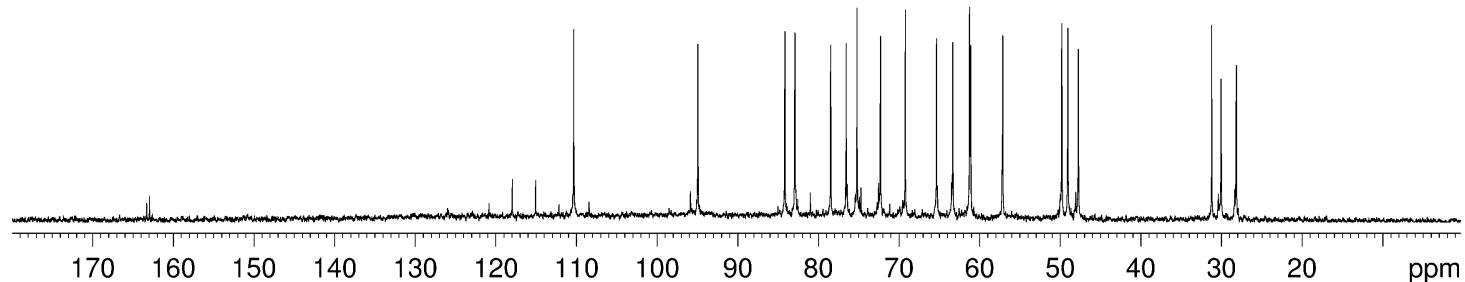

Figure S18. $100 \mathrm{MHz}{ }^{13} \mathrm{C}-\mathrm{NMR}$ in $\mathrm{D}_{2} \mathrm{O}$ of compound 7 (TFA salt). 

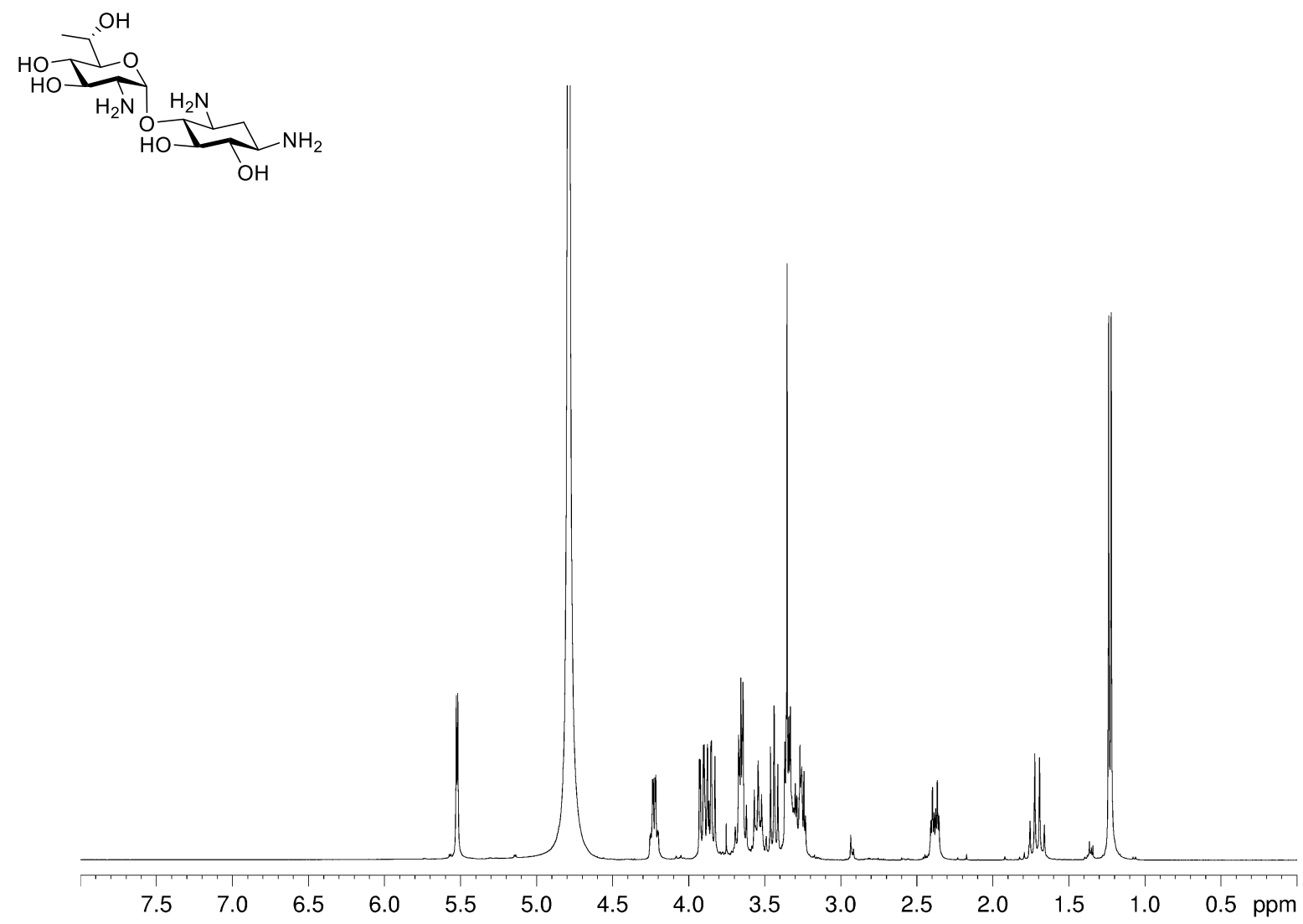

Figure S19. $400 \mathrm{MHz}{ }^{1} \mathrm{H}-\mathrm{NMR}$ in $\mathrm{D}_{2} \mathrm{O}$ of compound 8 (TFA salt).

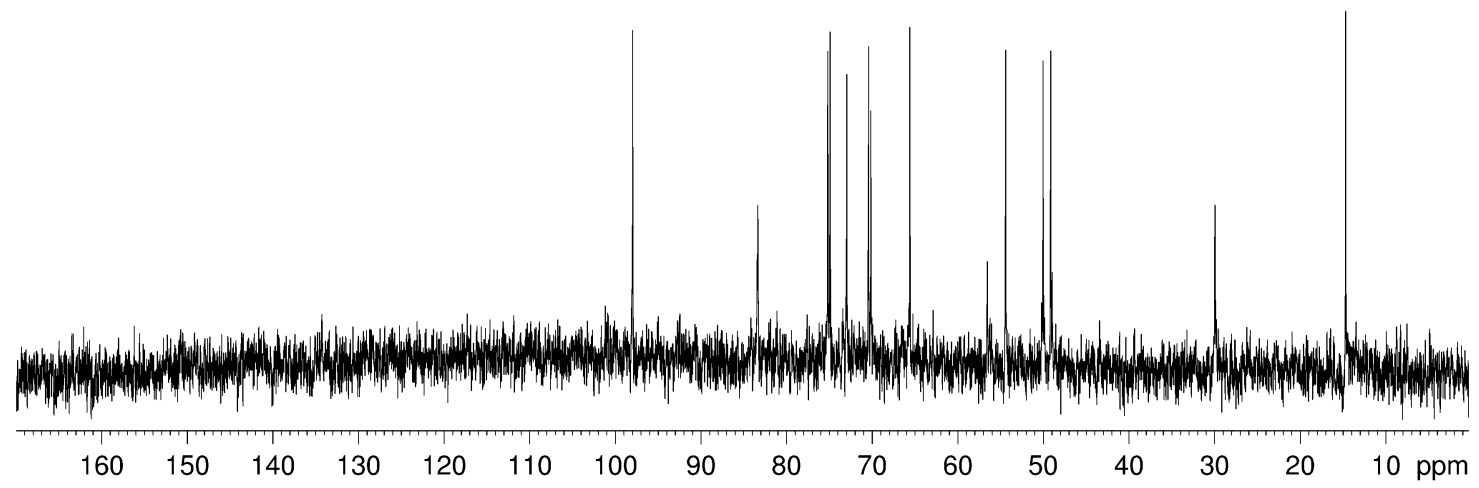

Figure $\mathrm{S} 20.125 \mathrm{MHz}{ }^{13} \mathrm{C}-\mathrm{NMR}$ in $\mathrm{D}_{2} \mathrm{O}$ of compound 8 (TFA salt). 


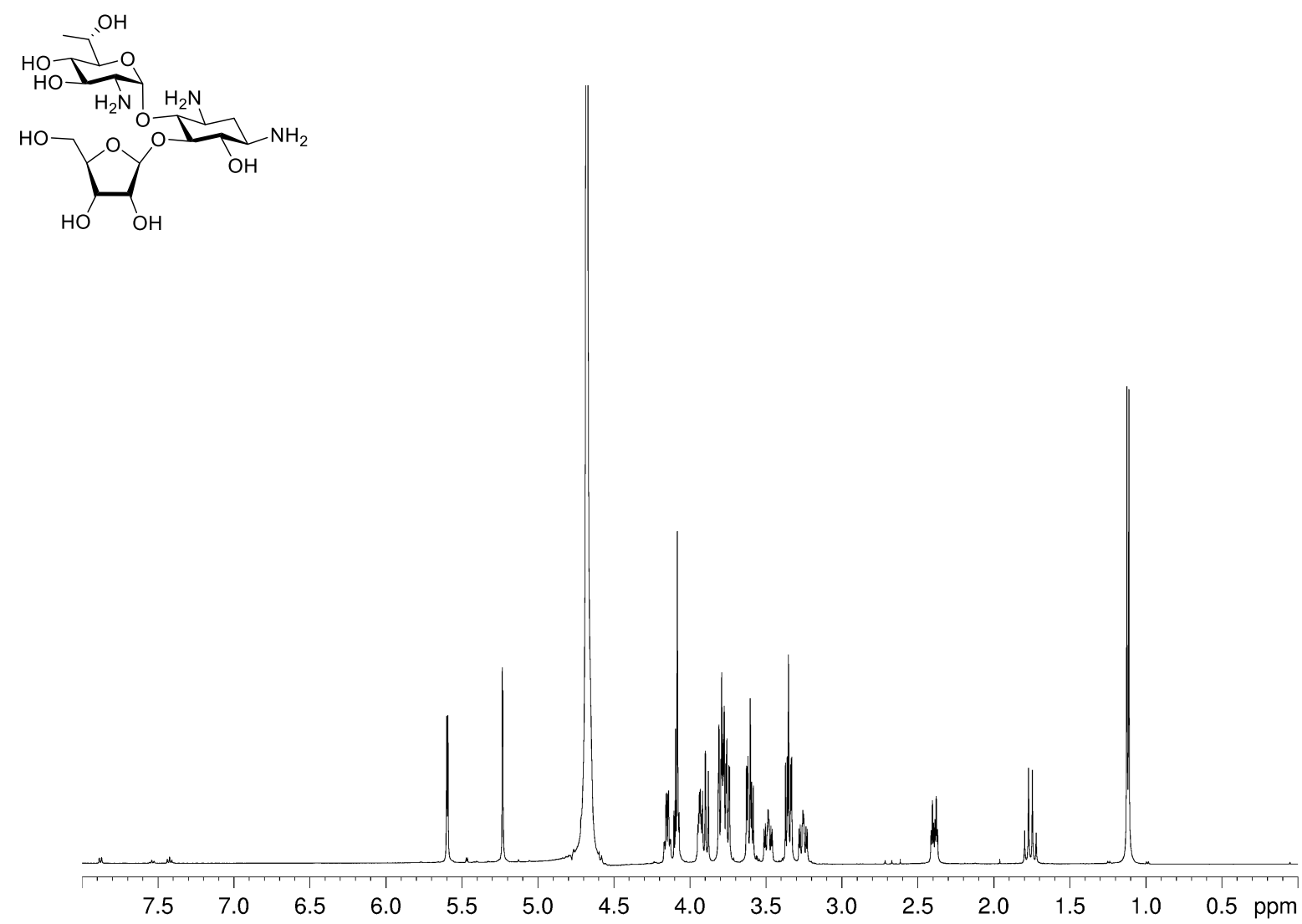

Figure $\mathrm{S} 21.500 \mathrm{MHz}{ }^{1} \mathrm{H}-\mathrm{NMR}$ in $\mathrm{D}_{2} \mathrm{O}$ of compound 9 (TFA salt).

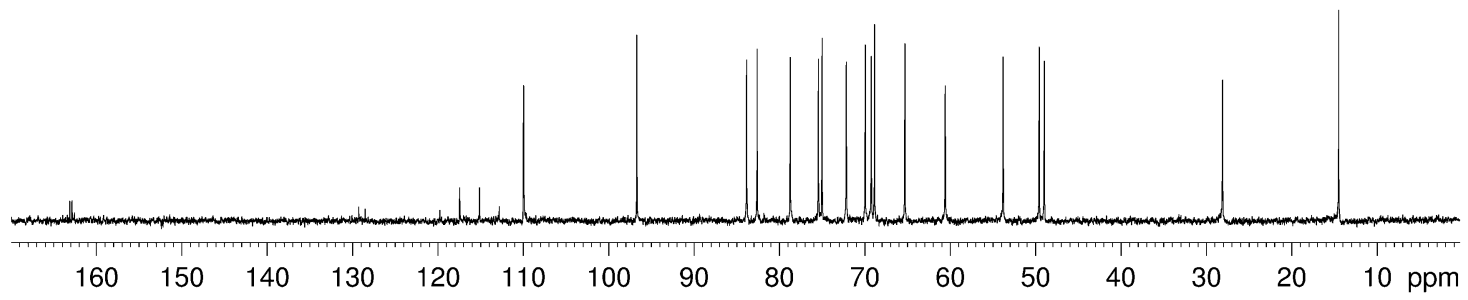

Figure S22. $125 \mathrm{MHz}{ }^{13} \mathrm{C}-\mathrm{NMR}$ in $\mathrm{D}_{2} \mathrm{O}$ of compound 9 (TFA salt). 


\section{References}

(1) Mandhapati, A. R.; Shcherbakov, D.; Duscha, S.; Vasella, A.; Böttger, E. C.; Crich, D. Importance of the 6'-Hydroxy Group and Its Configuration for Apramycin Activity. ChemMedChem 2014, 9 (9), 2074-2083. https://doi.org/10.1002/cmdc.201402146.

(2) Quirke, J. C. K.; Rajasekaran, P.; Sarpe, V. A.; Sonousi, A.; Osinnii, I.; Gysin, M.; Haldimann, K.; Fang, Q. J.; Shcherbakov, D.; Hobbie, S. N.; Sha, S. H.; Vasella, A.; Böttger, E. C.; Crich. D. Apralogs: Apramycin 5-O-Glycosides and Ethers with Improved Antibacterial Activity and Ribosomal Selectivity and Reduced Susceptibility to the Aminoacyltranserferase (3)-IV Resistance Determinant. J. Am. Chem. Soc. 2019, 142(1), 530-544. jacs.9b11601. https://doi.org/10.1021/jacs.9b11601.

(3) Herzog, I. M.; Louzoun Zada, S.; Fridman, M. Effects of 5-O-Ribosylation of Aminoglycosides on Antimicrobial Activity and Selective Perturbation of Bacterial Translation. J. Med. Chem. 2016, 59 (17), 8008-8018. https://doi.org/10.1021/acs.jmedchem.6b00793.

(4) O'Connor, S.; Lam, L. K. T.; Jones, N. D.; Chaney, M. O. Apramycin, a Unique Aminocyclitol Antibiotic. J. Org. Chem. 1976, 41 (12), 2087-2092. https://doi.org/10.1021/jo00874a003.

(5) Nudelman, I.; Glikin, D.; Smolkin, B.; Hainrichson, M.; Belakhov, V.; Baasov, T. Repairing Faulty Genes by Aminoglycosides: Development of New Derivatives of Geneticin (G418) with Enhanced Suppression of Diseases-Causing Nonsense Mutations. Bioorganic Med. Chem. 2010, 18 (11), 3735-3746. https://doi.org/10.1016/j.bmc.2010.03.060.

(6) Matt, T.; Ng, C. L.; Lang, K.; Sha, S. H.; Akbergenov, R.; Shcherbakov, D.; Meyer, M.; Duscha, S.; Xie, J.; Dubbaka, S. R.;. Perez-Fernandez D.; Vasella A.; Ramakrishnan V.; Schacht J.; Böttger E. C. PNAS. 2012, 109 (27), 10984-10989. https://doi.org/10.1073/pnas.1204073109.

(7) Kondo, J.; François, B.; Urzhumtsev, A.; Westhof, E. Crystal Structure of the Homo Sapiens Cytoplasmic Ribosomal Decoding Site Complexed with Apramycin. Angew. Chemie - Int. Ed. 2006, 45 (20), 3310-3314. https://doi.org/10.1002/anie.200600354. 
(8) Garreau De Loubresse, N.; Prokhorova, I.; Holtkamp, W.; Rodnina, M. V.; Yusupova, G.; Yusupov, M. Structural Basis for the Inhibition of the Eukaryotic Ribosome. Nature 2014, 513 (7519), 517-522. https://doi.org/10.1038/nature13737.

(9) Greber, B. J.; Bieri, P.; Leibundgut, M.; Leitner, A.; Aebersold, R.; Boehringer, D.; Ban, N. The Complete Structure of the 55S Mammalian Mitochondrial Ribosome. Science 2015, 348 (6232), 303-308. https://doi.org/10.1126/science.aaa3872.

(10) Madhavi Sastry, G.; Adzhigirey, M.; Day, T.; Annabhimoju, R.; Sherman, W. Protein and Ligand Preparation: Parameters, Protocols, and Influence on Virtual Screening Enrichments. J. Comput. Aided. Mol. Des. 2013, 27 (3), 221-234. https://doi.org/10.1007/s10822-013-9644-8.

(11) Schrödinger Release 2017-2: Schrödinger Suite 2019-2 Protein Preparation Wizard; Schrödinger, LLC, New York, NY, 2016;

(12) Ruiz-Carmona, S.; Alvarez-Garcia, D.; Foloppe, N.; Garmendia-Doval, A. B.; Juhos, S.; Schmidtke, P.; Barril, X.; Hubbard, R. E.; Morley, S. D. RDock: A Fast, Versatile and Open Source Program for Docking Ligands to Proteins and Nucleic Acids. PLoS Comput. Biol. 2014, 10 (4), e1003571. https://doi.org/10.1371/journal.pcbi.1003571.

(13) Schrödinger Release 2017-2: LigPrep, Schrödinger, LLC, New York, NY, 2017.

(14) Wang, J.; Wolf, R. M.; Caldwell, J. W.; Kollman, P. A.; Case, D. A. Development and Testing of a General Amber Force Field. J. Comput. Chem. 2004, 25 (9), 1157-1174. https://doi.org/10.1002/jcc.20035.

(15) Wang, J.; Wang, W.; Kollman, P. A.; Case, D. A. Automatic Atom Type and Bond Type Perception in Molecular Mechanical Calculations. J. Mol. Graph. Model. 2006, 25 (2), 247260. https://doi.org/10.1016/j.jmgm.2005.12.005.

(16) Bochevarov, A. D.; Harder, E.; Hughes, T. F.; Greenwood, J. R.; Braden, D. A.; Philipp, D. M.; Rinaldo, D.; Halls, M. D.; Zhang, J.; Friesner, R. A. Jaguar: A High-Performance Quantum Chemistry Software Program with Strengths in Life and Materials Sciences. Int. J. Quantum Chem. 2013, 113 (18), 2110-2142. https://doi.org/10.1002/qua.24481.

(17) Van Der Spoel, D.; Lindahl, E.; Hess, B.; Groenhof, G.; Mark, A. E.; Berendsen, H. J. C. 
GROMACS: Fast, Flexible, and Free. Journal of Computational Chemistry 2005, 26 (16), 1701-1718. https://doi.org/10.1002/jcc.20291.

(18) Pérez, A.; Marchán, I.; Svozil, D.; Sponer, J.; Cheatham, T. E.; Laughton, C. A.; Orozco, M. Refinement of the AMBER Force Field for Nucleic Acids: Improving the Description of a/y Conformers. Biophys. J. 2007, 92 (11), 3817-3829.

https://doi.org/10.1529/biophysj.106.097782.

(19) Banáš, P.; Hollas, D.; Zgarbová, M.; Jurečka, P.; Orozco, M.; Cheatham, T. E.; Šponer, J.; Otyepka, M. Performance of Molecular Mechanics Force Fields for RNA Simulations: Stability of UUCG and GNRA Hairpins. J. Chem. Theory Comput. 2010, 6 (12), 38363849. https://doi.org/10.1021/ct100481h.

(20) Smith, D. E.; Dang, L. X. Computer Simulations of $\mathrm{NaCl}$ Association in Polarizable Water. J. Chem. Phys. 1994, 100 (5), 3757-3766. https://doi.org/10.1063/1.466363.

(21) Dang, L. X.; Kollman, P. A. Free Energy of Association of the K+. 18-Crown-6 Complex in Water. A New Molecular Dynamics Study. J. Phys. Chem. 1995, 99 (1), 55-58. https://doi.org/10.1021/j100001a011.

(22) Darden, T.; York, D.; Pedersen, L. Particle Mesh Ewald: An N.log(N) Method for Ewald Sums in Large Systems. J. Chem. Phys. 1993, 98 (12), 10089-10092. https://doi.org/10.1063/1.464397.

(23) Hashem, Y.; Auffinger, P. A Short Guide for Molecular Dynamics Simulations of RNA Systems. Methods 2009, 47 (3), 187-197. https://doi.org/10.1016/j.ymeth.2008.09.020.

(24) Hess, B.; Bekker, H.; Berendsen, H. J. C.; Fraaije, J. G. E. M. LINCS: A Linear Constraint Solver for Molecular Simulations. J. Comput. Chem. 1997, 18 (12), 1463-1472. https://doi.org/10.1002/(SICI)1096-987X(199709)18:12<1463::AID-JCC4>3.0.CO;2-H.

(25) Humphrey, W.; Dalke, A.; Schulten, K. VMD: Visual Molecular Dynamics. J. Mol. Graph. 1996, 14 (1), 33-38. https://doi.org/10.1016/0263-7855(96)00018-5. 